\title{
ALTERNATIVAS ESTRATÉGICAS PARA LA COMPETITIVIDAD SOSTENIBLE DE PORCELANATOS Y PISOS DE COLOMBIA S.A.S.
}

\author{
CLAUDIA JOHANA ACOSTA \\ MIGUEL ÁNGEL GARCÍA MORA
}

UNIVERSIDAD SANTO TOMAS

FACULTAD DE ADMINISTRACIÓN

MAGÍSTER EN ADMINISTRACIÓN

BOGOTÁ 


\title{
ALTERNATIVAS ESTRATÉGICAS PARA LA COMPETITIVIDAD SOSTENIBLE DE PORCELANATOS Y PISOS DE COLOMBIA S.A.S.
}

\author{
CLAUDIA JOHANA ACOSTA \\ MIGUEL ÁNGEL GARCÍA MORA
}

\begin{abstract}
Trabajo presentado como requisito parcial para obtener el título de Magíster en Administración
\end{abstract}

Director

MILLER RIVERA LOZANO M. Sc.

UNIVERSIDAD SANTO TOMAS

FACULTAD DE ADMINISTRACIÓN

MAGÍSTER EN ADMINISTRACIÓN

BOGOTÁ 
Nota de Aceptación

Firma del presidente del jurado

Firma del jurado

Firma del jurado

Bogotá D. C., agosto de 2019. 


\section{Contenido}

pág.

Introducción $\quad 1$

1. Planteamiento del Problema

2. Planteamiento de la Pregunta Problema $\quad 8$

$\begin{array}{lr}\text { 3. Objetivos } & 9\end{array}$

$\begin{array}{lr}3.1 \text { Objetivo general } & 9\end{array}$

3.2 Objetivos específicos 9

4. Justificación $\quad 10$

5. Marco de Referencia 12

5.1 Marco Teórico 12

5.2 Marco Conceptual 17

$\begin{array}{ll}\text { 5.3 Marco Legal } & 20\end{array}$

$\begin{array}{ll}5.4 \text { Hipótesis } & 21\end{array}$

5.5 Marco Metodológico 23

5.5.1 Tipo de investigación 23

$\begin{array}{ll}\text { 5.5.2 Metodología } & 23\end{array}$

5.5.3 Tratamiento de la información 23

6. Objetivo 1

6.1 ¿Ofrece la industria oportunidades atractivas para el crecimiento? 24 
6.2 ¿Qué clase de fuerzas competitivas enfrentan los miembros de la industria y qué intensidad tiene cada una?

6.2.1 Barreras de entrada

6.2.2 Poder de los consumidores

6.2.3 Rivalidad de los productores

6.2.4 Productos sustitutos

6.2.5 Poder de los proveedores

6.3 ¿Qué factores promueven el cambio en la industria, y qué efectos tendrán?

6.3.1 Vigilancia tecnológica

6.3.1 El internet de las cosas y su impacto cultural

6.3.2 Telefonía celular

6.4 ¿Cuáles son las posiciones que ocupan en el mercado los rivales de la industria?: ¿quién tiene una posición sólida y quién no?

6.5 ¿Qué movimientos estratégicos es probable que realicen los rivales?

6.6 ¿Cuáles son los factores clave para el éxito futuro competitivo?

7. Objetivo 2

8. Objetivo 3

8.1 Plan de Comunicación

8.1.1 Presencia en la web

8.1.2 Otros medios BTL

8.1.3 Medios ATL

8.1.4 Otros elementos de la campaña 
8.4 Diversidad de Portafolios $\quad 89$

8.5 Sistema de indicadores que definen la medición del cumplimiento de las metas 90

9. Conclusiones y Recomendaciones 93

9.1 Conclusiones 93

9.2 Recomendaciones 93

$\begin{array}{ll}\text { Referencias Bibliográficas } & 95\end{array}$ 


\section{Lista de Figuras}

pág.

Figura 1. Impresora de casas en 3D 2

Figura 2. Inflación 1993 - 1997 con relación al PIB y el desempleo 26

Figura 3. Tasas de interés efectivo anual y tasa de cambio \$/dólar 26

Figura 4. Desarrollo presentado en el área de licencias de construcción (millones de $\mathrm{m}^{2}$ ) 27

Figura 5. Cartera como porcentaje del Producto Interno Bruto 28

Figura 6. Evolución anual de la tasa de desempleo en Colombia 29

Figura 7. Proyección del PIB 2012 a 2030

Figura 8. Número de viviendas población colombiana 33

Figura 9. Propensiones de oferta y demanda - Total mercado 2011-2017 36

Figura 10. Propensiones de oferta y demanda de VIS- 2014-2017 37

Figura 11. Importaciones de Pisos Laminados 2017-2018 39

Figura 12. Ejemplo vivienda domótica 50

Figura 13. Servicios del hogar digitalizado $\quad 51$

Figura 14. Impresora 3D $\quad 52$

Figura 15. Rotor de turbina de avión desarrollado en impresora 3D 52

Figura 16. Evolución de la telefonía celular $\quad 57$

Figura 17. Pirámide de la Responsabilidad Social Empresarial por Archie Carroll 59 
Figura 18. Perspectivas sociales a tener en cuenta en la empresa 59

Figura 19. Mapa por grupos estratégicos competidores de Porcelanatos y Pisos 64

Figura 20. Matriz Interna y Externa MIME $\quad 69$

Figura 21. Matriz de Posición Estratégica y Evaluación de Acción - PEYEA 70

Figura 22. Comparación de perfiles competitivos 72

Figura 23. Estrategia de Diferenciación dirigida Porcelanatos y Pisos de Colombia S.A.S 82 


\section{Lista de Tablas}

pág.

Tabla 1. Proyección de la población por grupos de edad

Tabla 2. Evolución del PIB con respecto a 1998 (100\%)

Tabla 3. Proyección del PIB 2015 a 2030 (\$millones pesos 2005)

Tabla 4. Posición de las empresas de la competencia en el mercado

Tabla 5. Continuum del intercambio en dos modelos de marketing.

Tabla 6. Posición de las empresas de la competencia en el mercado

Tabla 7. Matriz FODA Porcelanatos y Pisos de Colombia S.A.S.

Tabla 8. Matriz de Evaluación de Factores Externos MEFE

Tabla 9. Matriz de Evaluación de Factores Internos MEFI

Tabla 10. Matriz de Perfil Competitivo MCP

Tabla 11. Matriz Cuantitativa de la Planificación Estratégica MCPE

Tabla 12. Puntuación de las estrategias, de acuerdo con la Matriz Cuantitativa de la Planificación

Tabla 13. Prioridad de las estrategias según la matriz MCPE

Tabla 14. Objetivos a cumplir por cada indicador

Tabla 15. Formato de socialización para los directivos Porcelanatos y Pisos de Colombia S.A.S. 


\section{Resumen}

En este trabajo se formulan alternativas estratégicas para la competitividad sostenible de la organización empresarial Porcelanatos y Pisos de Colombia S.A.S., lo que incluye la evaluación del contexto competitivo de la empresa, la caracterización de sus recursos, capacidades y competitividad y la definición de alternativas estratégicas para la construcción de planes de acción que propicien el desarrollo competitivo sostenible. La metodología empleada se basa en las propuestas realizadas por Thompson, Gamble, Peteraf, y Strickland (2012) en su obra Administración estratégica. Teoría y casos

El trabajo consta de nueve capítulos: en los cuatro primeros se plantea el problema que da origen a la investigación, se formula dicho problema, se formulan los objetivos a desarrollar y se exponen las razones que llevaron a su desarrollo. El marco de referencia es el propósito del quinto capítulo, que incluye los aspectos teóricos, conceptuales y legales, así como la formulación de la hipótesis y el marco metodológico. A continución se desarrolla un capítulo por cada uno de los objetivos definidos, y de acuerdo con los interrogantes que plantea el trabajo de Thompson et al (2012). Por último, en el capítulo noveno se presentan las conclusiones centrales y las recomendaciones que se desprenden de las diferentes fases desarrolladas en los capítulos precedentes.

Como conclusión central se puede señalar que la empresa cuenta con los recursos necesarios para asegurar su sostenibilidad, aunque para poder lograrlo debe acoger las recomendaciones que se formulan en el capítulo final de acuerdo con los hallazgos identificados a lo largo del proceso 
de diagnóstico y análisis estratégico empleado.

Palabras claves: administración estratégica, competencia, construcción, recursos, capacidades, sostenibilidad. 


\begin{abstract}
In this work, strategic alternatives are formulated for the sustainable competitiveness of the business organization Porcelanatos de Colombia S.A.S., which includes the evaluation of the competitive context of the company, the characterization of its resources, capabilities and competitiveness and the definition of strategic alternatives for the construction of action plans that promote sustainable competitive development. The methodology used is based on the proposals made by Thompson, Gamble, Peteraf, and Strickland in their book Strategic Management. Theory and cases (2012)
\end{abstract}

The work consists of nine chapters and in the first four the problem that gives rise to the research is raised, the problem is formulated, the objectives to be developed are formulated and the reasons that led to its development are presented. The framework is the purpose of the fifth chapter, which includes the theoretical, conceptual and legal aspects, as well as the formulation of the hypothesis and the methodological framework. One chapter is then developed for each of the defined objectives, and according to the questions posed by the book of Thompson, Gamble, Peteraf, and Strickland (2012). Finally, the ninth chapter presents the central conclusions and recommendations that emerge from the different phases developed in the preceding chapters.

As a central conclusion, it can be pointed out that the company has the necessary resources to ensure its sustainability, although in order to achieve this it must accept the recommendations made in the final chapter, in accordance with the findings identified throughout the diagnostic and analysis process strategic employee. 
Keywords: strategic administration, competition, building, resources, capabilities, sustainability. 


\section{Introducción}

La industria de la construcción en general y la industria de porcelanatos y pisos en particular, se enfrenta a condiciones cambiantes en diferentes aspectos. Por ejemplo, las proyecciones de la población colombiana efectuadas por el DANE (2005) señalan que ésta tendrá entre 1985 y 2020 el comportamiento que se observa en la tabla 1.

Tabla 1. Proyección de la población por grupos de edad

\begin{tabular}{ccc}
\hline Edades & 1985 & 2020 \\
\hline $0-4$ & $13 \%$ & $9 \%$ \\
$5-9$ & $12 \%$ & $8 \%$ \\
$10-14$ & $11 \%$ & $8 \%$ \\
$15-19$ & $11 \%$ & $8 \%$ \\
$20-24$ & $10 \%$ & $8 \%$ \\
$25-29$ & $8 \%$ & $8 \%$ \\
$30-34$ & $7 \%$ & $8 \%$ \\
$35-39$ & $5 \%$ & $7 \%$ \\
$40-44$ & $4 \%$ & $6 \%$ \\
$45-49$ & $4 \%$ & $6 \%$ \\
$50-54$ & $3 \%$ & $6 \%$ \\
$55-59$ & $3 \%$ & $5 \%$ \\
$60-64$ & $3 \%$ & $4 \%$ \\
$65-69$ & $2 \%$ & $3 \%$ \\
$70-74$ & $1 \%$ & $2 \%$ \\
$75-79$ & $1 \%$ & $1 \%$ \\
80 y más & $1 \%$ & $2 \%$ \\
\hline Nota & $70 \%$ & $\mathrm{DANE}$
\end{tabular}

Nota: Elaboración propia a partir de datos obtenidos de las Cifras DANE (2005) 
Esas cifras indican que la población colombiana está envejeciendo, es decir, habrá mayor porcentaje de personas de los grupos de edades adultas, lo cual incidirá necesariamente en el tipo de productos y en el precio que ese mercado está dispuesto a pagar por ellos.

Otro aspecto que ha tenido ya una gran incidencia en otros mercados es el desarrollo de nuevas tecnologías. En este sentido, los medios de comunicación fueron uno de los sectores que primero se vio afectado por la sustitución que los medios electrónicos han hecho de los medios impresos. Sin embargo, también en la construcción se esperan novedades; de hecho, ya se han anunciado desarrollos capaces de imprimir casas completas en tiempos muy cortos (Enter, 2015), lo que conceptualmente puede asemejarse a lo que se muestra en la figura 1

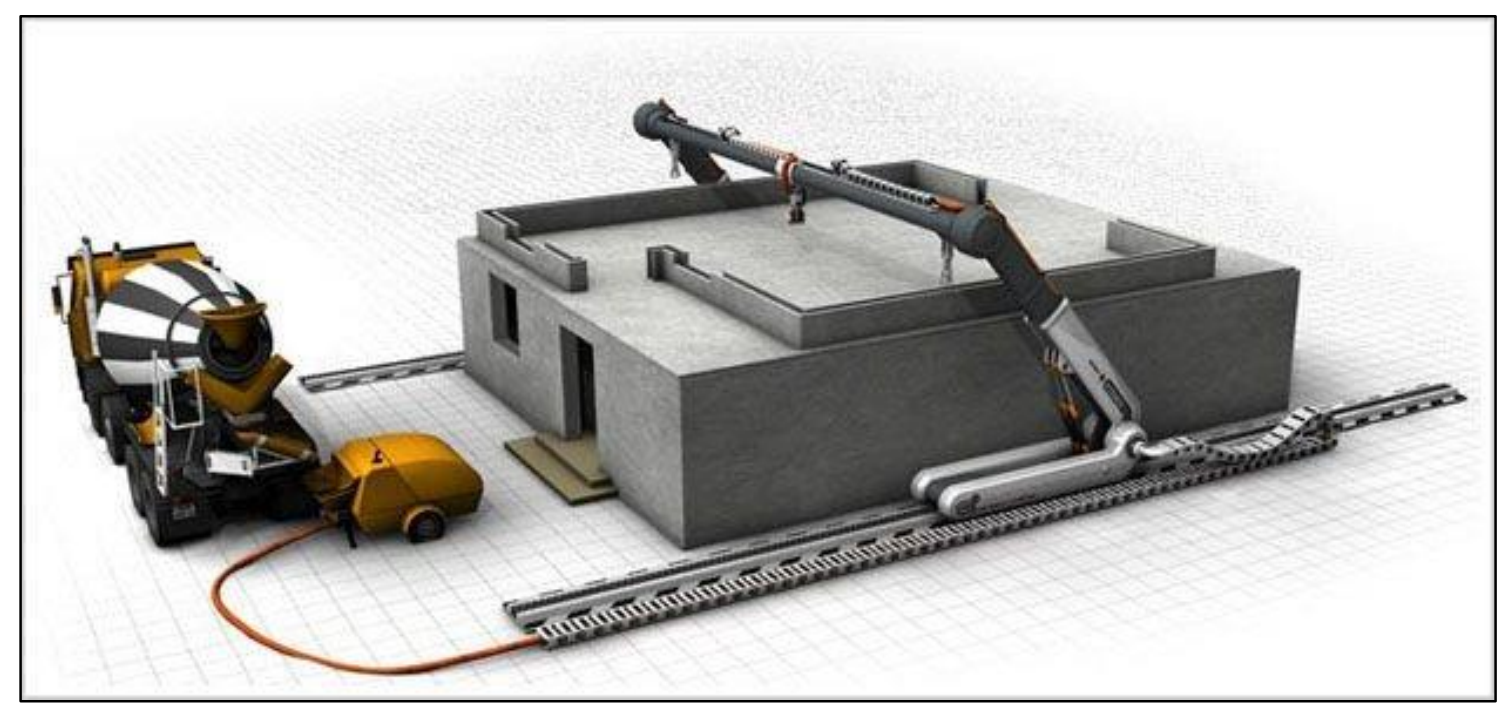

Figura 1. Impresora de casas en 3D. Obtenido de Enter $(2015$, p.2)

Esas condiciones ya no son hipótesis de largo plazo, sino amenazas u oportunidades de mediano y algunas de corto plazo. Dadas esas condiciones, el presente trabajo busca construir el modelo de administración estratégica de la empresa Porcelanatos y Pisos de Colombia S.A.S.

Ahora bien, a causa de la tecnificación en los procesos productivos en porcelanatos, la innovación de la formulación de los productos y los nuevos equipos de planta han generado ahorros en los costos de producción, pero se han incrementado los costos logísticos que de cierta forma 
restringen las expectativas de rentabilidad de la empresa, por lo tanto, se requiere de forma urgente por parte de la empresa, la evolución hacia nuevas alternativas por medio de un planteamiento estratégico que permita lograr el desarrollo efectivo y el cumplimiento de los imperativos estratégicos de este plan de negocio ofrecido por Porcelanatos y Pisos de Colombia S.A.S.

Actualmente las empresas se encuentran enfrentadas a un mercado con enormes exigencias como lo son los precios, la calidad, la variedad, el crédito, la localización, la injerencia de aspectos externos como las transformaciones políticas y gubernamentales, la economía mundial, el avance de tecnologías novedosas; aspectos que han posibilitado que el área comercial comprenda uno de los fundamentales sectores económicos donde la planeación estratégica es esencial para comprender y percatarse de los requerimientos de los consumidores, y por tanto, poder tomar las determinaciones más adecuadas con el fin de poder cumplir con los objetivos planteados, buscando siempre estar apoyados por todos aquellos quienes componen la empresa.

Puesto que la empresa conforma una organización integrada por diversos individuos que buscan un bien común, ésta efectúa varias actividades utilizando recursos humanos, materiales tecnológicos y financieros, buscando lograr su meta, que en la mayoría de las ocasiones es la consecución de utilidades.

A partir de lo anterior y con el desarrollo del presente documento, se busca que la empresa Porcelanatos y Pisos de Colombia S.A.S., adopte planes estratégicos que abarcan desde conocer su misión, visión, recursos, políticas y valores, a través de un estudio concienzudo de varias matrices que permitirán determinar las dificultades que la empresa enfrenta, como por ejemplo la matriz FODA. Adicional a ello, la aplicación de estas matrices conforman los mecanismos básicos para poder llevar a cabo un plan de acción óptimo para la entidad.

Porcelanatos y Pisos de Colombia S.A.S. es una entidad que labora con capital propio, y que 
ha mostrado un incremento en el mercado, lo cual hace necesario desarrollar este planteamiento estratégico que le permitirá a la empresa conocer mejor su potencial y demandar sus productos hacia un mercado cada vez más exigente.

El presente trabajo de grado está compuesto por nueve capítulos principales: del primero al cuarto se realiza el planteamiento del problema, el establecimiento de los objetivos e igualmente la justificación.

Bajo el capítulo quinto se desarrolla el marco teórico que trata sobre la etapa filosófica que corresponde a un plan estratégico. Bajo el marco conceptual se efectúa la descripción de los términos utilizados en el desarrollo del trabajo. En el marco legal, se detallan las normas reglamentarias que rigen el sector de la construcción. En el marco metodológico, se realiza el análisis y diagnóstico situacional de la empresa para determinar la clase de estudio que se va a efectuar.

Del capítulo sexto al capítulo octavo, se plantean los objetivos que se esperan alcanzar con el desarrollo de este trabajo, realizando ya de manera práctica la aplicabilidad de las diversas matrices consideradas trascendentales como las cinco fuerzas competitivas del mercado según Porter, la matriz FODA, y demás matrices que van a permitir diagnosticar la situación real que tiene la empresa.

En el capítulo noveno se procede a generar las conclusiones y recomendaciones que surgen del estudio, buscando establecer las líneas estratégicas para el fortalecimiento de la empresa en el corto, mediano y largo plazo, sobresaliendo el enfoque sistémico de la capacitación que necesitan las personas que conforman la entidad, bajo los conceptos de formación básica, ética y técnica, las cuales sirven de gran aporte para ponerlas en práctica al interior de la organización. 


\section{Planteamiento del Problema}

El sector de la construcción es considerado como una de las industrias que posee mejores probabilidades de negocio a futuro, y sobre todo para países con menor desarrollo como lo es Colombia. Lo anterior se suma al déficit de vivienda que existe tanto a nivel de cantidad y calidad, al igual que los costos reducidos que se necesitan por concepto de mano de obra en esta industria.

En este sector intervienen distintas clases de empresas que plantan sus deseos y aspiraciones para la consecución de los mejores resultados operativos tanto en la etapa constructiva, como cuando se van a efectuar mejoras a las viviendas, y son quienes les implantan todos sus anhelos a estas obras. De igual manera, interviene el sector financiero, así como el asegurador. En este sentido, el sector de la construcción simboliza no solo la satisfacción de vivienda para sus propios habitantes, sino que también conforma la ocasión para las personas de poder invertir con riesgos mínimos, cautivando el interés constante de individuos que poseen excedentes monetarios que se requieren para realizar la inversión.

Así como este sector es de mucho movimiento económico, también lo es en cuestión de competencia, por lo tanto, está expuesto de manera constante a etapas de demanda y oferta que sobrevienen de la fusión entre las condiciones macroecómicas tanto a nivel interno como externo dentro del ramo, las cuales provocan influencia a nivel de precios y accesibilidad de los recursos. De igual manera, este sector tiene una importante injerencia en la producción de empleo, ya que le da acceso de trabajo a la mano de obra no calificada.

Por lo anterior, el desarrollo de esta tesis se centra en analizar las perspectivas señaladas 
anteriormente, al igual que muchas otras de forma más específica, pudiendo constatar que conforma un sector dificultoso donde se concentran diversidad de participantes, y donde cada cual busca sus propios ideales.

En este contexto, quienes deseen ingresar a formar parte de este negocio, deben tener en cuenta múltiples variables, desde analizar las diversas normas estatales que la reglamentan, hasta el punto de analizar y tener en cuenta la misma competencia, bien sea a nivel nacional como internacional. Toda esta serie de complicaciones que surgen dentro de este sector, generan no solo definir el presupuesto de aquella empresa que interviene en él, sino de planificar a futuro la manera en que la empresa se encuentra trabajando, y la manera como estarán procediendo los competidores, así como también, aquello que pueden esperar los clientes, y como se desempeñarán los otros intervinientes que la conforman, o tienen injerencia en el desenvolvimiento del sector de la construcción.

Actualmente la empresa Porcelanatos y Pisos de Colombia S.A.S. carece de una herramienta que le permita planear sus acciones con una visión estratégica, lo que la lleva a definir sus prioridades con base más en la presión y en las coyunturas de corto plazo, que en una visión amplia de su propia realidad y de que la rodea en el entorno en el que compite.

En estas condiciones, la administración de la empresa se basa frecuentemente en percepciones que carecen de validación, con base en la experiencia empírica y en los esfuerzos constantes de sus directivos y colaboradores. Si bien la empresa ha logrado subsistir, es consciente de que la metodología científica aplicada a la administración con una visión estratégica puede cimentar decisiones más juiciosas que pueden conducirle a un éxito más sostenible en el tiempo.

La ausencia de un proceso de planeación desarrollado de manera metódica se manifiesta en situaciones tales como inventarios excesivos con referencias de muy baja rotación, fallas en el 
cumplimiento con la entrega de los pedidos a sus clientes, pérdida en oportunidades de negocio, exceso de recursos económicos que generan rendimientos poco atractivos, altos niveles de presión tanto a nivel directivo como operativo, insatisfacción de los clientes y demás situaciones propias de una serie casi ininterrumpida de crisis en las diferentes áreas que conforman la estructura de la organización.

Si bien el riesgo es inherente a toda actividad empresarial, también es cierto que la planeación es la mejor opción para enfrentarlo y minimizar su impacto, por lo que el presente trabajo se propone realizar un proceso de análisis estratégico de la empresa, que permita contar con un mapa de ruta apropiado a la realidad actual de la industria, de la economía nacional y de la empresa Porcelanatos y Pisos de Colombia S.A.S. 


\section{Planteamiento de la Pregunta Problema}

¿Cómo propiciar el desarrollo competitivo sostenible de Porcelanatos y Pisos de Colombia S.A.S.? 


\section{Objetivos}

Con el planteamiento de los objetivos señalados a continuación y dentro de un modelo de administración estratégica, se busca solucionar la falta de indicadores de gestión en la empresa. Estos objetivos buscan mejorar la gestión administrativa y productiva de la empresa, a través de estrategias e indicadores de gestión para que opere acorde a los requerimientos del mercado.

\subsection{Objetivo general}

Formular alternativas estratégicas para la competitividad sostenible de la organización empresarial Porcelanatos y Pisos de Colombia S.A.S.

\subsection{Objetivos específicos}

- Evaluar el contexto competitivo de Porcelanatos y Pisos de Colombia S.A.S.

- Caracterizar los recursos, capacidades y competitividad de Porcelanatos y Pisos de Colombia S.A.S.

- Definir alternativas estratégicas para la construcción de planes de acción que propicien el desarrollo competitivo sostenible de Porcelanatos y Pisos de Colombia S.A.S. 


\section{Justificación}

La importancia de desarrollar este trabajo se puede considerar tanto desde el punto de vista teórico, como metodológico y temático. Desde el punto de vista teórico, este ejercicio permite poner al servicio de la empresa objeto de estudio una serie de conceptos de administración estratégica que, de no ser aplicados en la práctica, se quedarían en un documento escrito sin efectos útiles.

Adicional a lo anterior es importante resaltar que el conocimiento bien utilizado puede hacer la diferencia entre las organizaciones que permanecen en un determinado mercado y las que se ven obligadas a despedir empleados, cerrar plantas de producción y almacenes, e incumplir a sus clientes y acreedores; en este sentido la información de la empresa objeto del presente análisis está a disposición, lo que representa una valiosa oportunidad no solo para los investigadores sino para los directivos de la empresa a fin de identificar, analizar y proponer alternativas que mejoren el posicionamiento de la entidad en el mercado

Sin embargo, la sola intención de hacer el ejercicio no es suficiente, dado que se requiere seguir una metodología que ya está probada y documentada; esta metodología debe empezar por cuestionarse por el atractivo que ofrece esta industria de la construcción para los accionistas de la empresa en términos de utilidades. Una vez se haya verificado este aspecto básico, se debe proceder a analizar la forma como funciona la empresa en la actualidad frente a las condiciones que impone el mercado, con lo cual se podrán identificar las acciones que se deben emprender para acoplarse mejor al entorno. Por último, se requiere plasmar los hallazgos de esas dos primeras 
fases, en un modelo de planeación que sirva de herramienta de gestión para los directivos de la empresa, y que oriente sus decisiones estratégicas y operativas.

En cuanto a la justificación temática del trabajo, debe tenerse en cuenta que Colombia atraviesa unas condiciones macroeconómicas y sociales que no se habían dado en el pasado, especialmente debido a la fase de transición que se presenta como consecuencia del acuerdo de paz suscrito por el gobierno de Juan Manual Santos con la guerrilla de las FARC. El período de transición actual tiene efectos en todos los sectores de la economía y particularmente en la industria de construcción, por lo que la situación actual de esta industria no es la misma que hace solo unos años. La empresa Porcelanatos y Pisos De Colombia S.A.S. requiere entonces de una visión actualizada de esa realidad como insumo que, junto con su diagnóstico interno, permitan construir un instrumento que le permita a la administración tener una visión actualizada y completa de lo que debe hacer para mantenerse en el mercado de manera exitosa. 


\section{Marco de Referencia}

\subsection{Marco Teórico}

El desarrollo que ha presentado el mercado a nivel mundial y la tendencia a la globalización, ha generado que aquellas empresas que buscan mantener su competitividad planteen la forma de utilizar filosofías de administración que les otorgue esa sostenibilidad y que puedan superarse permanentemente.

Por lo tanto, estas empresas deben acudir a una planificación estratégica que es la que proporciona el encausamiento que dirigirá la misión, visión, objetivos y estrategias de la entidad, pues posibilita el desarrollo de planes para cada una de sus áreas funcionales. Con base en una buena planificación estratégica se puede observar la sucesión de consecuencias, causas y efectos en la empresa durante determinado tiempo, vinculada con una determinación real o intencionada que adoptará el director de la misma.

La esencia de la planeación estratégica está basada en la planificación sistemática de los aspectos fuertes, débiles y las restricciones, tanto a nivel de la empresa como de su entorno, primordialmente, se deben analizar las fuerzas de los competidores y los proyectos acerca de acciones a futuro, al igual que aquellas oportunidades y amenazas que surgen de la situación que enfrenta la empresa con relación al ambiente donde se desenvuelve.

Con el fin de efectuar dichos cambios, la empresa debe estimular a los directivos a pensar de manera estratégica, para que se anticipen a las transformaciones y puedan mejorar las estrategias 
cuando éstas lo necesiten.

De acuerdo con lo anterior, en primera instancia se debe determinar el fundamento del término estrategia, cuyo origen es militar y surge del término griego strategos que se utiliza para escoger la manera como se va a dirigir a la armada en presencia del enemigo. Poniéndolo en práctica dentro del entorno empresarial, y según Drucker (1996), la estrategia está conformada por el estudio de la situación actual y de su transformación si se requiriese, abarcando dentro de ella, el estudio y descripción sobre los recursos con que se cuenta, y de aquellos que debería poseer. De igual forma, se debe analizar la competencia con relación a las estrategias que posee la empresa para direccionarlas hacia un mejor desarrollo de las mismas, conforme lo señala Treacy \& Wieserma (1995) a continuación.

La naturaleza de la competencia está cambiando dramáticamente en muchas industrias en el contexto global actual y en ocasiones se hace inclusive difícil identificar y definir el campo de acción y las fronteras de las operaciones de los negocios. "Hoy en día no es posible seguir dirigiendo las empresas como hasta hace unas décadas" (Treacy \& Wiersema, 1995,p.28).

Adicional a lo anterior, también existen procedimientos y metodologías que orientan a los directivos a fin de que puedan comprender la manera cómo evoluciona la empresa, al igual que los orienta en la toma de determinaciones en relación a la estrategia más acorde que les permita obtener ventaja competitiva en sus etapas de desarrollo empresarial. Estas metodologías usualmente están encaminadas a un crecimiento de mediano y largo plazo y se han desarrollado en diferentes escuelas del pensamiento, destacándose especialmente la denominada Escuela de Harvard, la Escuela de la Planeación Estratégica, la de Estrategia y Estructura, la de Estrategia Competitiva y la de la Empresa Japonesa, basada en el manejo eficiente de los recursos (Japón, importa muchos de los insumos que requiere para sus procesos industriales), especialmente los intangibles como el 
factor humano, la experiencia, el conocimiento y el Good Will. (Barrios, 2009)

Para efectos del presente trabajo, se puede definir la estrategia empresarial, según lo señalan Munuera \& Rodríguez (2007) a continuación.

Un conjunto de acciones encaminadas a la consecución de una ventaja competitiva sostenible en el tiempo y defendible frente a la competencia, mediante la adecuación y flexibilidad de todos los recursos y capacidades de la firma y el entorno en que se desempeña a fin de satisfacer los objetivos de los participantes en ella (p.34).

De igual forma, y según Ogliastri (1996), señala que por medio de la puesta en marcha de técnicas de planeación estratégica como, por ejemplo, la implementación de matrices de valoración de desempeño de productos y mercados en una industria concreta, se pueden generar ventajas competitivas sostenibles, es decir, aquel tipo de ventajas que le permite a la empresa diferenciarse de su competencia. Una de las técnicas que plantea Ogliastri es la denominada BCG (formulada por la Boston Consulting Group) que evalúa el desempeño de un producto en términos de participación en el mercado versus el crecimiento de la demanda y la matriz de la General Electric (Mckinsey), que además de contemplar el crecimiento de una empresa, indica que el atractivo está realmente en el crecimiento y las oportunidades de la industria como tal.

También señala Ogliastri (1996), que dentro de los encausamientos estratégicos que debe atravesar una entidad durante toda su etapa evolutiva, como por ejemplo, la fase de creación o surgimiento, que es aquella etapa donde no hay una guía estratégica, ni existen procedimientos de proyección o planeación, sino que se cuenta básicamente con la visión que posee el empresario, y donde sus métodos administrativos son muy reducidos, y donde, además prevalece la improvisación, dirigidos básicamente por el apasionamiento y la entrega, particularidades que se 
denotan especialmente en empresas de tipo familiar.

A medida que la empresa está en la fase de crecimiento, se presentan problemáticas generadas por la desorganización de tipo administrativo, donde el mando directivo está centrado en una sola persona, o porque surgen desconfianzas en el manejo, o porque se presentan derroches en recursos, etc. A causa de todas estas problemáticas, se requiere redireccionar la empresa, inyectar capital, al igual, que nueva tecnología, generándose de esta forma, la necesidad de que exista la posibilidad de permitir el ingreso a nuevos socios, y con ello, se puede dar comienzo a una nueva fase de desarrollo, cimentada en normas de la empresa.

En este sentido, la planeación estratégica se fundamenta en normas precisas que surgen a través de un grupo de profesionales de área, por lo que se crea un método organizacional desarrollado por funciones. De esta manera, la entidad continúa con su desarrollo y progreso hasta que surge la segunda crisis generada por el crecimiento en la región, y la aparición de productos y/o servicios nuevos, al igual, que el surgimiento de nuevos requerimientos de alianzas estratégicas que cimienten el surgimiento del nuevo desarrollo empresarial. (Ogliastri, 1996)

La burocratización es normalmente la causa de esta segunda crisis (Ogliastri,1996), por ello es necesaria la creación de centros independientes y con autonomía de planeación estratégica por regiones o por líneas de productos o servicios; es así que se entra en una etapa que busca la consolidación de una cultura organizacional basada en la dirección por objetivos comunes mediante un sistema de planeación en todos los niveles de la firma de acuerdo a los lineamientos de la Alta Dirección (Junta Directiva, Gerencia General).

A partir de lo anterior, puede presentarse una nueva crisis a causa de la falta de vigilancia, organización y explotación de economías de escala, para lo cual se hace necesario realizar la reestructuración de la empresa, con el fin de obtener oportunidades estratégicas a nivel general, 
por lo tanto, se requiere concentrar ciertas funciones y hacer una reestructuración en ciertos productos, o de alguna manera buscar eliminar alguno de ellos. En esta fase, se busca realizar diferenciación basada en la estructura que tiene la empresa. A través del uso de portafolios, surge la planeación estratégica (Kotler \& Murray, 1975), generando dentro de la empresa áreas de finanzas, mercadeo y ventas, producción, conformando un excelente apoyo a la estrategia empresarial.

Por otra parte, y de acuerdo a Pulido (2011) también existe la definición de estrategia generada por la escuela de Harvard, que señala que ésta se determina por el análisis de la situación actual del ámbito general, bien sea a nivel económico, sociocultural o demográfico.

Adicional a lo anterior, también se encuentra la escuela de estrategia competitiva generada por Michael Porter, que se cimienta en el fundamento de la habilidad que posee la empresa para realizar competencia a largo plazo. Según Porter (2004), las cualidades de una industria se basan en la competencia. Para realizar ese análisis, Porter desarrolló diversos mecanismos, como el análisis de las cinco fuerzas, buscando con ello reconocer aquellos factores del ambiente que poseen injerencia sobre la capacidad que tiene la empresa para subsistir en un determinado sector, y bajo un entorno competitivo. Trató también acerca de la cadena de valor que conforman los procedimientos básicos con las tareas de soporte, para enfocarse en efectuar de manera eficaz las labores que producen valor dentro de la empresa.

Ahora bien, en el ejercicio de las labores diarias de una empresa, ésta debe contar con la facultad de adaptarse a los medios donde se desenvuelve, con el fin de que pueda respaldar de esta forma su mantenimiento y desarrollo dentro del mercado. Si una empresa no consigue alcanzar una adaptación en el mercado, va a estar inmersa en una rigidez organizativa o inmovilidad estructural, lo cual va a imposibilitar el poder acomodar su conducta organizativa a los nuevos 
entornos, minimizando las probabilidades de acomodación a los que puede llegar a adherirse, e igualmente, complicando y dilatando la implementación de otras alternativas que sí podría alcanzar, por lo cual, se va generando un círculo vicioso que puede desencadenar en la desaparición de aquellas empresas que no cuentan con las particularidades que demandan los contextos actuales.

Así mismo, y de acuerdo con Lamiere (2017), toda empresa debe comprometerse de forma estratégica a los cambios que surgen en los entornos político, normativo, socio-económico y tecnológico, sugiriendo para ello tener en cuenta temas tan fundamentales como la producción, el mercadeo, las ventas, los recursos financieros y el recurso humano (Rodríguez, C \& Garzón, C, 2009)

\subsection{Marco Conceptual}

- Administración: la administración es una ciencia social que, partiendo del conocimiento de la naturaleza humana, busca de la manera más eficiente y hábil de prever o planear, organizar, dirigir, coordinar, integrar y controlar cualquier organismo central en busca de sus objetivos. (Galindo \& García, 2017)

- Austeridad: severidad y rigidez en la forma de obrar o vivir. (Bonal \& Verger, 2017)

- Competitividad: es la capacidad que tiene una empresa o país de obtener rentabilidad en el mercado en relación a sus competidores. La competitividad depende de la relación entre el valor y la cantidad del producto ofrecido y los insumos necesarios para obtenerlo. (Mora, Vera, Melgarejo, \& Molina, 2015)

- Control: es la función del proceso administrativo, mediante la cual se evalúa, mide o supervisa la ejecución de los planes para detectar y regular desorientaciones con el fin de establecer 
las medidas correctivas necesarias conforme a los objetivos de la empresa en condiciones de eficiencia y eficacia. (Mora et al, 2015)

- Diagnóstico estratégico: conforma el estudio a nivel interno de una empresa de sus fortalezas y debilidades, al igual que el estudio de las amenazas y oportunidades que debe enfrentar. Este diagnóstico abarca, el reconocimiento del entorno, de la competencia, la cultura corporativa y las fortalezas y debilidades internas. (Pavón, 2015)

- Dirección: es la función del proceso administrativo que consiste en influir en las personas para que contribuyan a las metas de la organización y del grupo; se relaciona directamente con la manera como debe alcanzarse los objetivos mediante las actividades de las personas que conforman la organización. (Mora et al, 2015)

- Direccionamiento estratégico: es el proceso por el cual miembros guías de una organización prevén su futuro y desarrollan los procedimientos y operaciones necesarias para alcanzarlo. (Hernández, Cardona \& Del Rio, 2017)

- Matriz de evaluación de los factores internos y externos: es un instrumento que se utiliza para evaluar el factor interno y externo en aspectos tales como fortalezas, debilidades, oportunidades y amenazas. (Thompson et al, 2012)

- Matriz FODA: instrumento para el diagnóstico interno y externo de una organización, en la cual se registran sus fortalezas, oportunidades, debilidades y amenazas. Posteriormente se realiza un análisis cruzado para encontrar estrategias que permitan aprovechar las fortalezas y oportunidades, para enfrentar las amenazas y debilidades. (Thompson et al, 2012)

- Matriz MCP: la Matriz del Perfil Competitivo de una empresa (MCP) permite la identificación de los principales competidores de la empresa, así como sus fuerzas y debilidades particulares, a partir de los factores claves de éxito, su ponderación y su calificación. (Thompson 
et al, 2012)

- Matriz MCPE: la Matriz Cuantitativa para la Planeación Estratégica (MCPE) permite priorizar las estrategias que debe seguir una empresa a partir de la identificación de sus fortalezas, oportunidades, debilidades y amenazas, por medio de la calificación del atractivo de cada estrategia y de su ponderación. (Thompson et al, 2012)

- Matriz PEYEA: la matriz de posición estratégica y evaluación de la acción PEYEA, permite identificar el tipo de estrategias más adecuadas para una organización, a saber, agresiva, conservadora, defensiva y/o competitiva, a partir de un plano que incluye un eje de dimensión interna (fuerza financiera y ventaja competitiva) y otro de la dimensión externa (estabilidad del entorno y fuerza de la industria). (Thompson et al, 12)

- Planeación Sistémica: hace referencia a las relaciones del hombre con la sociedad y el entorno, las cuales pueden ser identificadas en términos de sistemas ya que contiene partes relacionadas entre sí, y en algún sentido constituye un todo completo. En este tipo de sistema se intenta definir el sistema identificando las partes o elementos, por un lado, y por otro las conexiones o interacciones. (Nikulin \& Becker, 2015)

- Prospectiva: se define como una alternativa de visualización del futuro, incide fundamentalmente en lo que a lo lejos puede suceder, es decir, conocer cómo será el mañana, cuáles son las condiciones que abarca el entorno. Permite la posibilidad de elegir y tomar un direccionamiento para lograr lo que se quiere, analizando las diferentes alternativas que el futuro abarca y determinando las ventajas que más favorezcan a la organización. (Astigarraga, 2016)

- Visionario: alguien con la capacidad de tener un concepto claro del futuro. (Chasdi \& Ronis, 2017) 


\subsection{Marco Legal}

Dentro de las normas legales relacionadas con el sector de la construcción se pueden mencionar las siguientes:

- Artículo 51 de la Constitución Política de Colombia: garantiza la vivienda digna a todos los colombianos y ordena fijar condiciones necesarias para hacer efectivo este derecho y promover planes de vivienda de interés social, sistemas adecuados de financiación a largo plazo y formas asociativas de ejecución de estos programas de vivienda.

- Ley 9 de 1989, Artículo 44 (modificado por el Artículo 91 de la Ley 388 de 1997): Definición de la vivienda de interés social.

- Decreto 1789 de 2004. Artículo 5: El valor límite de la Vivienda de interés social.

- Decreto 2060 de 2004: Por el cual se establecen normas mínimas para VIS urbana.

- Decreto 2083 de 2004: Por el cual se modifica el decreto 2060 de 2004 en cuanto a las áreas mínimas de lotes VIS.

- El Decreto 554 de 2003, recomendó la liquidación del Inurbe y la creación del Fondo Nacional de Vivienda, Fonvivienda.

- Ley 3 de 1992 y Decreto 2620 de 2000: El subsidio familiar de vivienda.

- Ley 400 de 1997 Establece criterios y requisitos mínimos para el diseño, construcción y supervisión técnica de edificaciones nuevas, así como de aquellas indispensables para la recuperación de la comunidad con posterioridad a la ocurrencia de un sismo, que puedan verse sometidas a fuerzas sísmicas y otras fuerzas impuestas por la naturaleza

- Ley 1480 de 2011 por medio de la cual se expide el Estatuto del Consumidor.

- Decreto 410 de 1971 por el cual se expide el Código de Comercio. 


\subsection{Hipótesis}

Teniendo como base la problemática que experimenta la empresa Porcelanatos y Pisos de Colombia S.A.S en lo relacionado con el manejo administrativo interno y la competencia, con este trabajo se busca brindar soluciones de nivel estratégico, basadas inicialmente en la información disponible sobre la empresa, con el fin de presentar un planteamiento que le permita, como primera medida, tener una visión amplia de su desenvolvimiento actual tanto interno como externo, con miras a desarrollar las estrategias que conduzcan a un mejor desempeño.

Con ese plan estratégico se busca asegurar una mayor solidez financiera, mejorar su eficiencia operativa y direccionar su actuar hacia el cliente, mayor capacitación, mayor sentido de pertenencia con la entidad. Para construir el planteamiento estratégico, se estudiarán las cinco fuerzas competitivas de Porter, con el fin de definir el nivel de atracción que tiene el sector de la construcción, al igual poder encausar mejor el tratamiento que se le debe dar no solamente al manejo administrativo, sino también el comportamiento que se debe adoptar frente a la competencia.

Con relación al manejo de la parte administrativa el plan estratégico debe abarcar el mejoramiento de la cultura interna y de su clima laboral, utilizando políticas de valorización de los trabajadores para mejorar el desempeño laboral de éstos, lo cual se logra a través de que se aplique la mejor política de responsabilidad social al personal involucrado en cuanto a capacitación, salud y entorno ambiental.

Siendo una de las herramientas más colaborativas para el desarrollo de una empresa el hecho de poseer y mantener bien desarrollada el área correspondiente a la tecnología, que en el mundo de hoy en el cual se vive una etapa donde todo gira en torno a la globalización, se requiere por 
parte de las directivas de la empresa Porcelanatos y Pisos de Colombia S.A.S. prestar absoluta importancia a la evolución tecnológica al interior de ella, para lo cual se requiere estar siempre adelante en cuanto al conocimiento de las opciones y tendencias que se presentan en este sector empresarial, para lo cual la empresa debe acondicionar de la mejor forma la herramienta de la vigilancia tecnológica, ya que el sector de la construcción experimenta permanentemente transformaciones trascendentales que surgen de la dinámica de las inversiones tanto a nivel privado como público, los permanentes cambios que se dan a nivel político, el mismo comportamiento de la economía, el cambio en el poder adquisitivo de las familias, la disponibilidad con la que se cuenta para la adquisición de nuevas tecnologías y materiales y métodos que se encuentran en cuanto a construcción, son asuntos de gran trascendencia que se debe tener en cuenta al interior de la empresa, para poder analizar de manera prospectiva y de estrategias para que exista un equilibrio y crecimiento de la misma en este mercado.

El escenario donde se desenvuelve la empresa Porcelanatos y Pisos de Colombia S.A.S. deja ver que es un factor clave para iniciar a cimentar bases sólidas y rentables para la misma, para lo cual se pretende buscar posicionar a la empresa en una zona de competitividad y calidad con relación a su competencia. Aunque el futuro del medio es exigente para las diferentes variables que se analizan al interior del trabajo, ya que las empresas que conforman el mercado de la construcción y sobre todo en el área relacionada al porcelanato y los pisos, poseen capacidades tanto técnicas y financieras, para lo cual Porcelanatos y Pisos de Colombia S.A.S., debe trabajar fuerte para el robustecimiento de sus capacidades técnicas y tecnológicas. Poder lograr estas metas, requiere de un buen encausamiento con relación a los recursos tanto tecnológicos, económicos, humanos y estratégicos. Por lo tanto, debe existir una permanente continuidad en los procesos y los trabajadores que encausan los factores clave, para que, a través de ellos, y el trabajo en grupo, 
se puedan ver materializadas las acciones estratégicas para alcanzar los objetivos propuestos.

\subsection{Marco Metodológico}

5.5.1 Tipo de investigación. La investigación es de tipo exploratorio y acude a técnicas exploratorias, correlacionales y explicativas (Hernández et al, 2010). En efecto, es exploratoria dado que se basa en la exploración de las cifras que dan cuenta de la situación de la empresa y del entorno. Es correlacional porque esas variables son procesadas de acuerdo con técnicas propias de la administración estratégica, con el propósito de identificar criterios para su priorización, y es explicativa porque el proceso de análisis se basa en la comprensión de las variables estudiadas a la luz de los conceptos teóricos que sustentan el proceso investigativo.

5.5.2 Metodología. La metodología empleada es cuantitativa, dado que se basa en el empleo de instrumentos que permiten medir o cuantificar una serie de variables, con el propósito de reducir la subjetividad del proceso de planeación estratégica de la empresa. (Hernández et al, 2010)

5.5.3 Tratamiento de la información. La información obtenida dentro de la empresa, en el mercado y en el entorno, será procesada por medio de diferentes matrices, de acuerdo con los conceptos y métodos explicados por Thompson et al (2012). 


\section{Objetivo 1}

De acuerdo con Thompson et al (2012), lo primero que se debe considerar en la evaluación estratégica de una empresa es su ambiente industrial y competitivo, lo cual supone dar respuesta al siguiente interrogante: ¿Ofrece la industria la perspectiva de utilidades atractivas? Para dar respuesta a esa pregunta, los autores plantean otras seis más que se estudian a continuación:

\section{1 ¿Ofrece la industria oportunidades atractivas para el crecimiento?}

Con base en su objeto social, para la empresa Porcelanatos y Pisos de Colombia es concluyente el comportamiento que tiene el sector de la construcción. Cuando se estudia todo lo que ha tenido que atravesar esta industria en los últimos años, se debe señalar que en los inicios de la última década del siglo XX las licencias de construcción otorgadas en metros cuadrados ascendieron a 106.5 millones para el año 1994, simbolizando un crecimiento por encima del $50 \%$ únicamente en tres años, según lo muestran las cifras de Camacol (2010), aunque los precios se incrementaron por encima del 60\% durante el mismo lapso de tiempo (Banco de la República, 2000), bajo la presencia de estos dos fenómenos se puede constatar la poca oferta de vivienda con relación a su demanda. Aunque, para este estudio se debe considerar el crecimiento del índice de precios al consumidor, lo que permite denotar que la inflación se presentó entre un 25 y 32\% durante la etapa comprendida entre 1990 y 1992, significando esto, que el costo de la vivienda aumentó en niveles por encima de la inflación. 
La tendencia inflacionaria mostró un punto de quiebre terminando el año 1994 en el momento en que se generó la caída en el costo de los inmuebles a causa del enorme incremento anterior, que posibilitó que diversos inversionistas fueran seducidos a la compra y se generaran enormes proyectos que permitieron balancear y sobrepasar la demanda. El descenso en cuanto a adquisición de vivienda se aceleró, primordialmente para quienes tenían préstamos con las entidades bancarias y las corporaciones de ahorro y vivienda, pudiendo en muchos casos equipararse el valor de la deuda con el valor comercial del inmueble, generando que ciertos deudores no continuaran con sus obligaciones y plantearan una renegociación de su deuda, o en última instancia tener que hacer entrega del inmueble.

Bajo la problemática expuesta anteriormente, se generó una afectación a las empresas de la industria, de modo que tuvo que soportar desaceleración, lo cual generó que pocas personas desearan adquirir vivienda nueva o realizar reformas en las viviendas, puesto que, en la práctica, esta inversión se podría transformar en un gasto. Al respecto el Banco de la República (2000), manifiesta:

Como en todas las crisis de finca raíz, la cartera hipotecaria siguió creciendo aún después de que comenzaran a bajar los precios de la misma. La descolgada en los precios se produjo a mediados de 1994. Los metros cuadrados de licencias de construcción aprobadas cayeron en 1995, y muy dramáticamente en 1996 (p.86)

Así mismo, se puede ver que para ese periodo las tasas de inflación en el país fueron exageradamente altas, entre tanto, el PIB se estaba desacelerando y con relación al desempleo, este se estaba incrementando, tal como se puede observar en la figura 2 


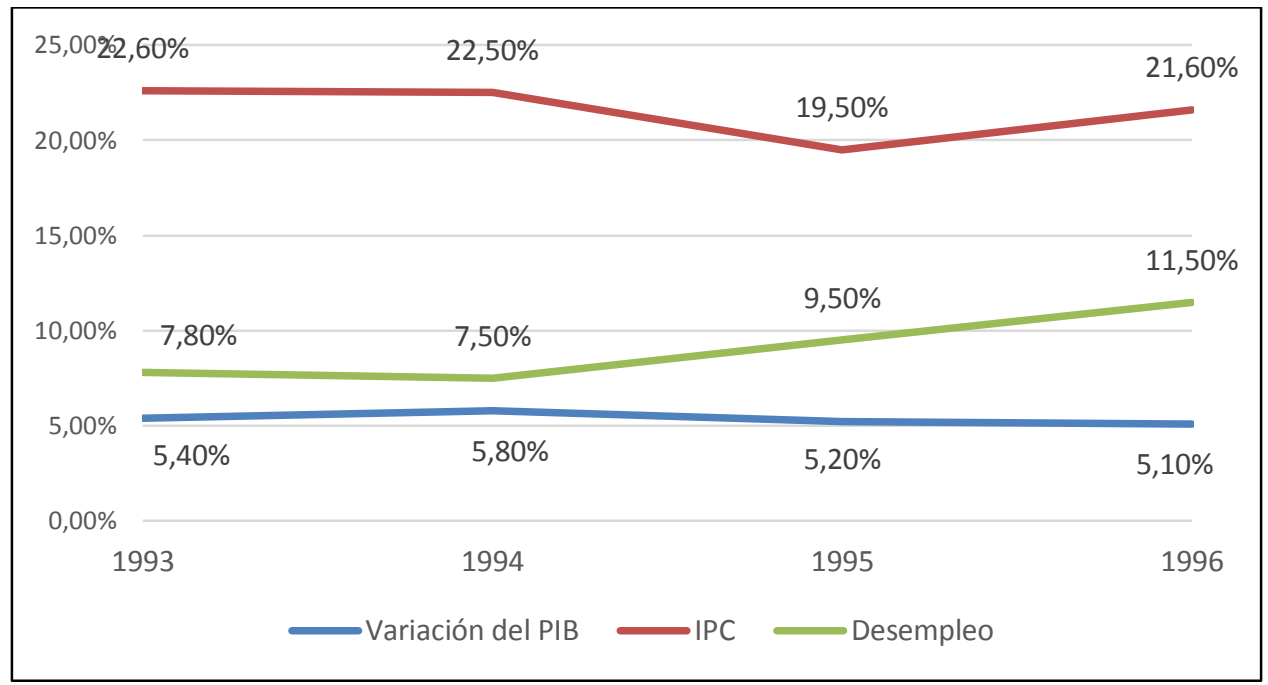

Figura 2. Inflación 1993 - 1997 con relación al PIB y el desempleo. Obtenido de Banco de la República (2005,p.12)

De igual manera, las tasas de interés efectivo anual sobrepasaban el 30\%, mientras que la tasa de cambio creció en cerca del 60\%, ya que para 1993 pasó de \$804/dólar a \$1294/dólar, según se puede observar en la figura 3

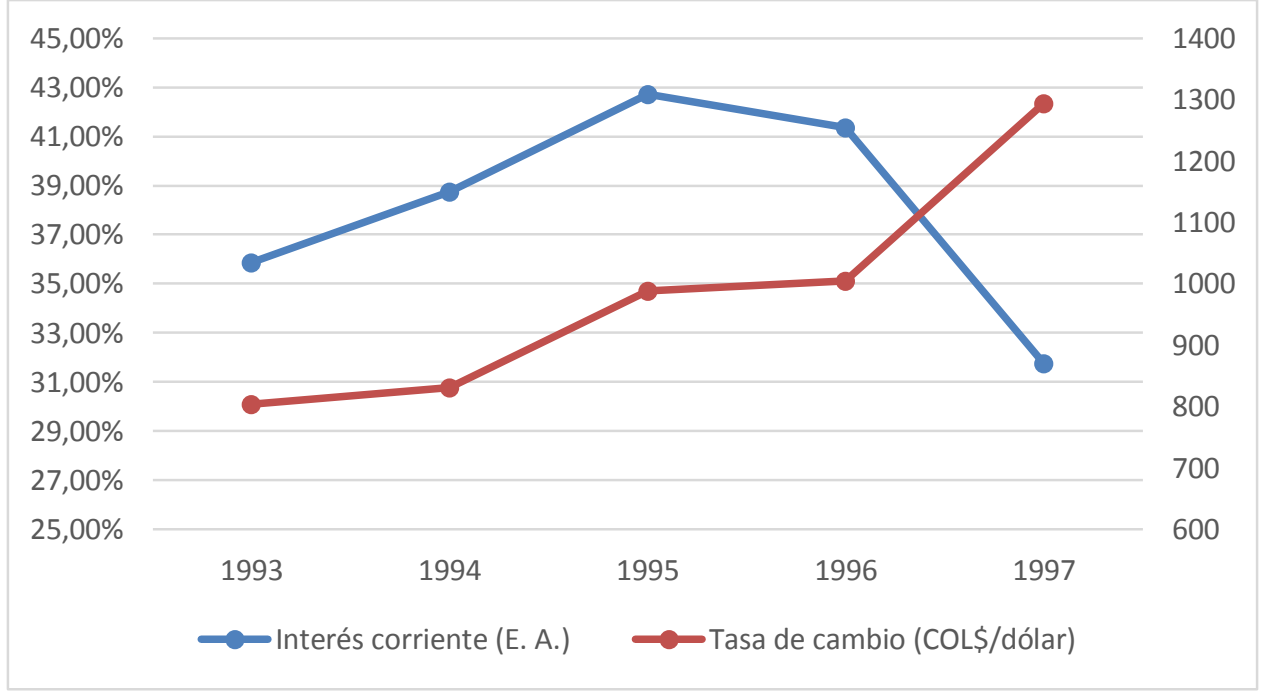

Figura 3. Tasas de interés efectivo anual y tasa de cambio \$/dólar. Obtenido de Banco de la República (2005,p.21)

Debido a la fluctuación en estas tasas de interés se produjo un incremento acelerado de la deuda, e igualmente, generaron que la financiación de proyectos de inversión industrial tuviese 
costos más elevados, y de la misma manera se presentaran costos elevados en todas las líneas de crédito. También por estas elevadas tasas de interés, las importaciones de bienes de capital también presentaron altos costos, perjudicando tanto a la industria como a la economía en los hogares.

Para el año de 1998 la tasa de cambio del dólar sobrepasó los \$1600/dólar, aunque el Banco de la República trabajó en la intervención del mercado. A causa de todas estas problemáticas, el Producto Interno Bruto (PIB) continuó su descenso, y además se presentaron dificultades políticas en el país, puesto que se generó una problemática donde resultaron comprometidos dineros del narcotráfico con campañas políticas de la época, siendo esta línea política la que terminó escogida como ganadora en las elecciones a la presidencia.

Todas estas muestras perjudiciales en cuanto a los diversos indicadores económicos y de deterioro dentro del entorno político, generaron repercusiones a partir del año 2001, aunque el impacto generado por estos motivos dentro de la industria de la construcción, se denota con el número de metros cuadrados otorgados bajo las licencias de construcción, que dejó ver la

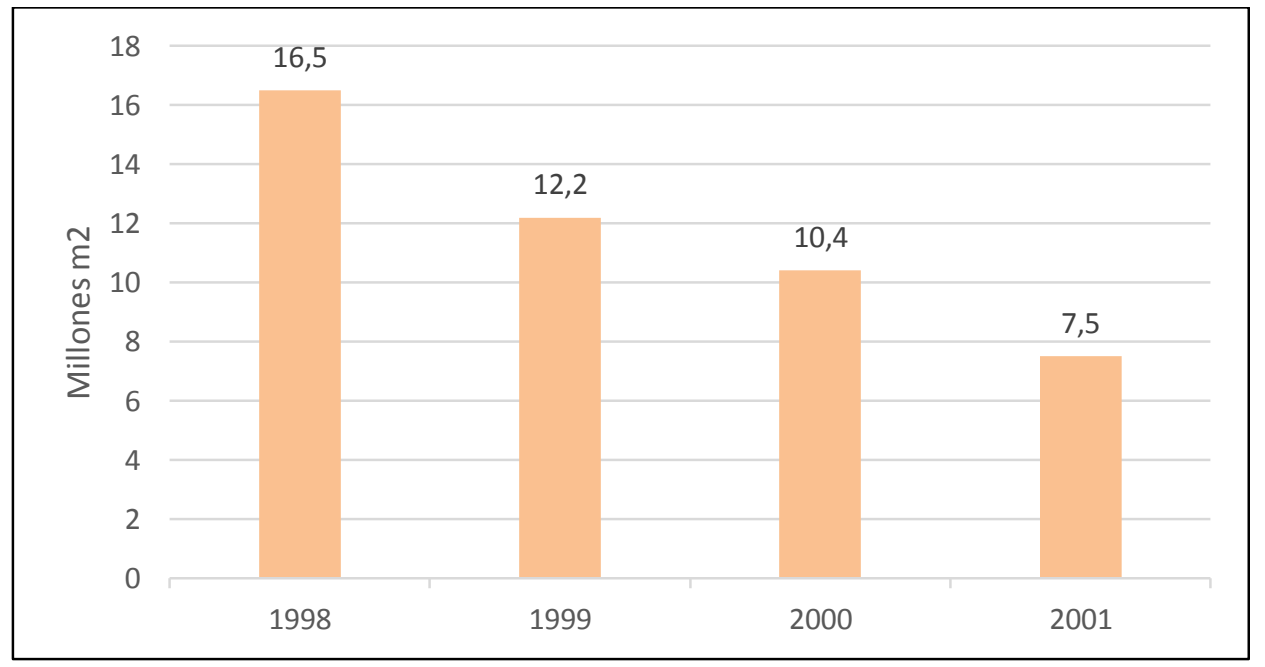

Figura 4. Desarrollo presentado en el área de licencias de construcción (millones de $\mathbf{~ m}^{2}$ ). Obtenido de Camacol (2010,p.13).

Teniendo en cuenta el comportamiento presentado anteriormente, este formó parte en el hecho de que se incrementara el desempleo, puesto que este sector puede producir empleo de mano de 
obra no calificada en lapsos cortos de tiempo. De manera posterior, se pudo observar una restauración económica que deja ver el desarrollo de la cartera en los bancos, con relación al PIB en Colombia, para los años 2000 al 2010. A continuación, en la figura 5 se puede observar, que a partir del 2004 básicamente se presenta un incremento permanente en el indicador de profundización financiera, ya que pasa de $20,53 \%$ a $32,16 \%$

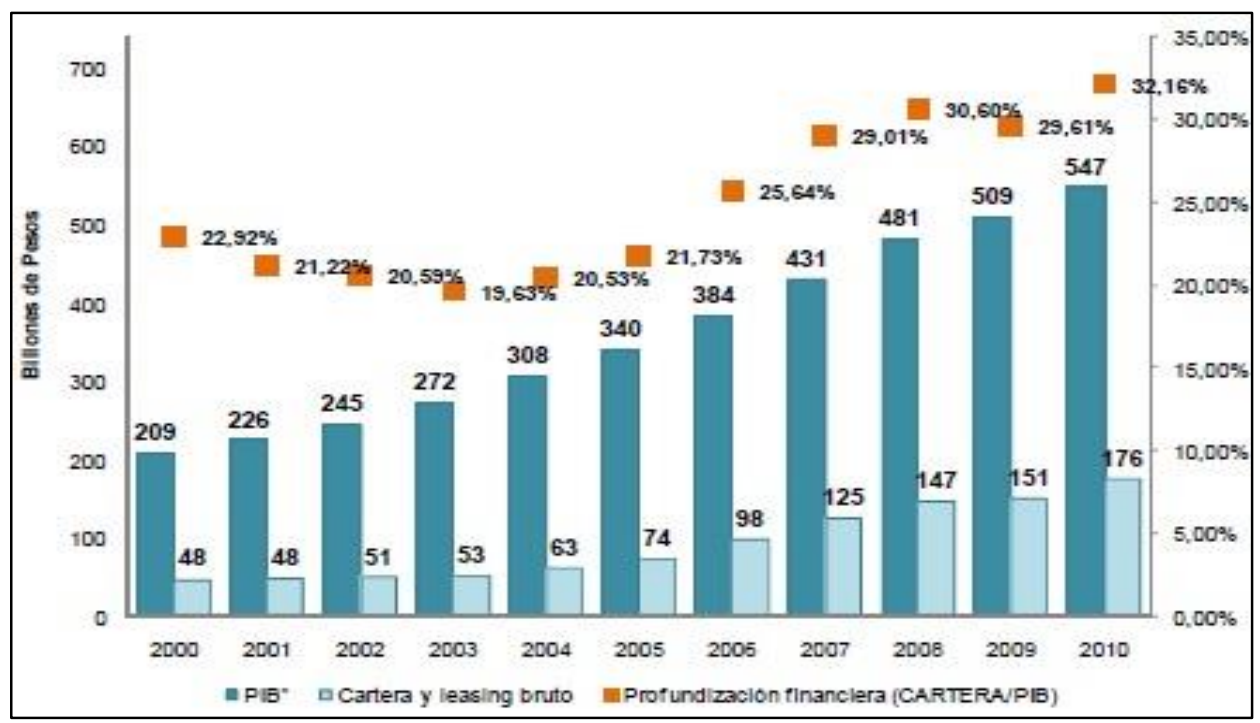

Figura 5. Cartera como porcentaje del Producto Interno Bruto. Datos obtenidos de Superintendencia Financiera. (2013,p.12)

Así mismo, se pudo advertir una aceleración de la economía nacional desde el año 2002 y hasta el año 2006, época que también abarca el primer periodo de la Presidencia de Álvaro Uribe Vélez, e igualmente, se puede observar después, un descenso entre los años 2006 al 2009. La tasa de incremento del PIB para los años 2009 y 2010 fue de 4,3\%

Aun así, la disparidad evaluada por el Coeficiente de Gini ${ }^{1}$ ha presentado un aumento bastante alarmante desde la década de los 90. De acuerdo con la valoración de la concentración del ingreso por parte del Programa de las Naciones Unidas para el Desarrollo (PNUD), el valor del Coeficiente de Gini para Colombia es de 59,2 (Gómez, 2010), esto genera que sea catalogado como el país de

\footnotetext{
${ }^{1}$ Coeficiente de Gini: estadística que mide la desigualdad, entre 0 y 100 , el 0 significa la igualdad absoluta todos los habitantes del país tienen una riqueza similar-, y el 100 la desigualdad absoluta.
} 
mayor inequidad en el continente americano. Cabe mencionar el valor que alcanza este índice para otros países del hemisferio: Estados Unidos 40,8, México 46,1, Venezuela 48,2, Costa Rica 49,8 y Guatemala 55,1.

En cuanto al desempleo, en la ¡Error! No se encuentra el origen de la referencia. se observa la evolución anual de la tasa de desempleo en Colombia. Como se observa en esa Figura, la tasa de desempleo en Colombia presentó una tendencia de descenso entre 2002 y 2011, al pasar de 15.52\% a 10.83\%; esa tendencia solo se reversó entre 2005 y 2006 y entre 2008 y 2009.

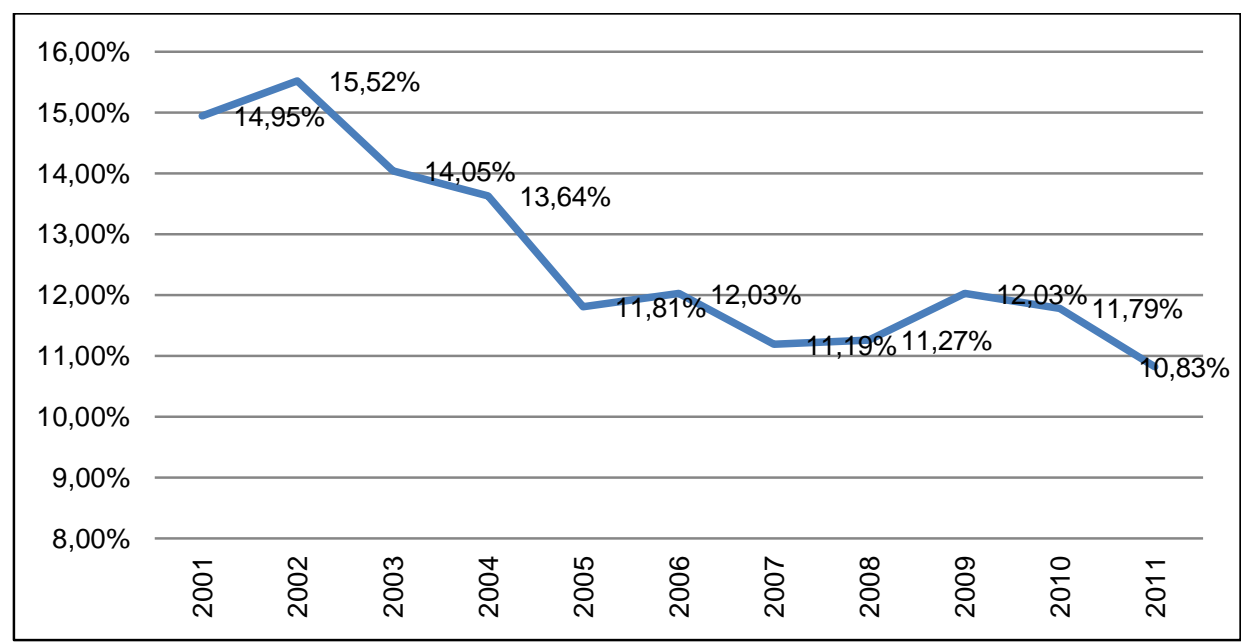

Figura 6. Evolución anual de la tasa de desempleo en Colombia. Obtenido de Banco de la República (2014,p.33)

Al observar este comportamiento de la economía en Colombia, se podía evidenciar la esperanza que poseían tanto empresarios como consumidores, proceso que generó un incremento en la demanda de vivienda, mostrando una mejor perspectiva para el sector de la construcción.

De otra parte, y referente al aspecto educativo con relación a la cobertura total, la tasa nacional en preescolar, básica y media es del 90\%, aunque para cada departamento la situación es diferente. Sin embrago, uno de cada dos estudiantes que entra a realizar un programa de educación superior, no finaliza sus estudios, y el porcentaje de deserción en educación superior asciende a un 45,4\%, con una tasa neta de cobertura en este nivel educativo únicamente del 37\%. Pero, para el 2002 esa 
tasa ascendía a un 24\%. El grado de analfabetismo para personas mayores de 15 años asciende a un 5,8\% (MEN, 2010)

Así mismo, existen otra clase de indicadores en cuanto a la situación económica del país como son: El 97,4\% de los hogares cuenta con acceso a la energía eléctrica, el 87,3\% puede acceder a acueducto, el 72,3\% cuenta con acceso a alcantarillado -para las cabeceras municipales el acceso es de $89,1 \%$-, el $90,2 \%$ de los hogares cuenta con telefonía celular $-92,4 \%$ para las cabeceras municipales-, el $71,5 \%$ posee servicio sanitario $-88,3 \%$ para cabeceras municipales, el $90,1 \%$ posee afiliación al Sistema General de Seguridad Social en Salud, del cual el 49,7\% bajo el régimen subsidiado y el 50,1\% bajo el régimen contributivo (DANE, 2012). Si se compara el tamaño del PIB de los últimos años frente al de 1998, se puede construir la Tabla 2, de acuerdo con las cifras del DANE (2012).

Tabla 2. Evolución del PIB con respecto a 1998 (100\%)

\begin{tabular}{lc}
\hline Año & PIB \\
\hline 1998 & $100 \%$ \\
1999 & $108 \%$ \\
2000 & $148 \%$ \\
2001 & $160 \%$ \\
2002 & $174 \%$ \\
2003 & $193 \%$ \\
2004 & $218 \%$ \\
2005 & $240 \%$ \\
2006 & $271 \%$ \\
2007 & $304 \%$ \\
2008 & $339 \%$ \\
2009 & $359 \%$ \\
2010 & $387 \%$
\end{tabular}

Nota: Elaboración propia con base en datos de DANE (2012)

Analizando todo este entorno descrito anteriormente, el desarrollo que posee la industria de 
acabados para la construcción, mostró un periodo de demanda decreciente durante los últimos diez años del Siglo XX y después mostró un restablecimiento, primordialmente a partir del año 2002. Durante la etapa de descenso, se presentaron reducidos niveles de inversión y de generación de productos nuevos, y ya en los últimos años la constante demanda ha generado que se impulsen nuevos proyectos con relación a los acabados para las obras. Para el período 2008-2012 esta industria mostró incremento por encima del 10\% en el mercado de Colombia, pero para los dos últimos años ha mostrado alzas inferiores

Por otra parte, en cuanto al escenario futuro de la industria, de acuerdo con Montenegro y Rivas (2018), en términos de ingreso per cápita, un colombiano es más rico que un chino promedio; sin embargo, el ingreso per cápita de USA es de US\$47,400, casi cinco veces más alto que el colombiano. En el país el crecimiento económico ha estado acompañado de estabilidad macroeconómica, si se considera que Colombia nunca declaró moratoria de su deuda y evitó los episodios hiperinflacionarios de otros países; en los años recientes tuvo una tasa de crecimiento promedio anual de $4.12 \%$, por lo que el desafío del país es crecer a tasas superiores para salir rápidamente de la pobreza. La tasa de crecimiento económico desde la década de los 70 fue similar a la de Brasil y Chile, mientras que Perú y Argentina tuvieron un crecimiento superior.

En el aspecto social, en 110 años el ingreso per cápita aumentó 16 veces, mientras que la expectativa de vida aumentó 38 años, debido en parte a que la mortalidad infantil se redujo 12.7 veces; la tasa de analfabetismo disminuyó a 7\% y la pobreza cayó en 55\%. La deuda internacional es relativamente baja (34.1\% del PIB) y el país cuenta con un alto nivel de reservas, mientras que el tema de la sostenibilidad del sistema pensional no ha sido resuelto y el déficit fiscal es relativamente alto. Durante el 2018 las calificadoras de riesgo, Standard \& Poor's y Fitch aumentaron la calificación de la deuda externa de Colombia a grado de inversión (BBB-) con 
perspectiva estable. (Montenegro \& Rivas, 2018)

En los años recientes se ha experimentado un boom en minería y petróleo y se firmaron tratados de libre comercio con USA, Canadá, México, Chile, la Unión Europea y Corea; no obstante, existe una gran dependencia económica del petróleo, lo que constituye una amenaza en un entorno internacional de baja de precios. La inflación ha sido de un solo dígito en los últimos diez años, la tasa de cambio real está más fuerte que su nivel promedio de los últimos 20 años. De acuerdo con el DANE, el PIB tuvo en los últimos 35 años crecimiento anual promedio de $3.76 \%$. Si esa misma tasa se mantuviera al menos hasta 2030, la evolución del PIB sería la que se proyecta en la figura 7 y en la tabla 3

Tabla 3. Proyección del PIB 2015 a 2030 (\$millones pesos 2005)

\begin{tabular}{lrrrrrr}
\hline \multicolumn{1}{r}{ Año } & 2019 & 2020 & 2021 & 2022 & 2023 & 2024 \\
\hline PIB & 602,129 & 624,749 & 648,219 & 672,571 & 697,838 & 724,054 \\
Año & 2025 & 2026 & 2027 & 2028 & 2029 & 2030 \\
PIB & 751,255 & 779,477 & 808,760 & 839,143 & 870,668 & 903,376 \\
\hline
\end{tabular}

Nota: elaboración propia

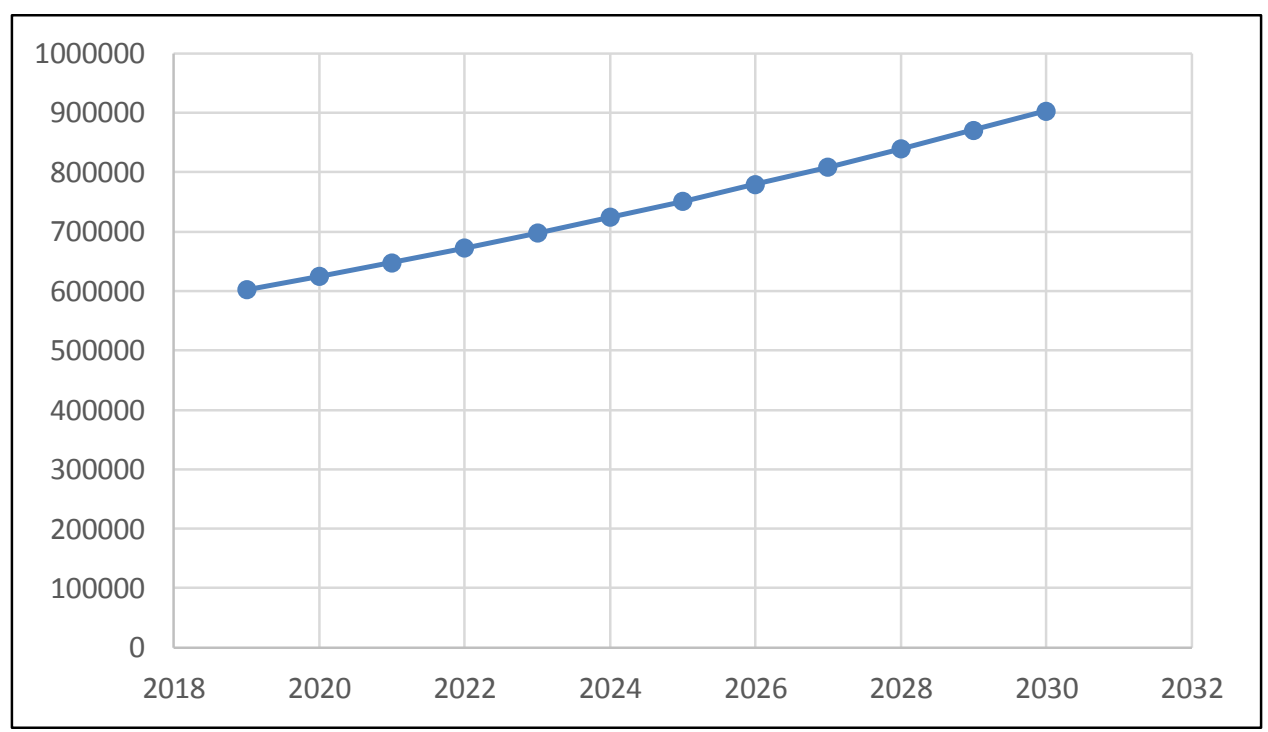

Figura 7. Proyección del PIB 2012 a 2030. Elaboración propia

Por otra parte, si se toman las proyecciones de población construidas por el DANE y se calcula el PIB per cápita, éste crece en más del 50\% a 2030 con respecto a la situación de 2005 y en 16\% 
con respecto a 2014, tomando las cifras a pesos constantes. Esto quiere decir que la capacidad adquisitiva de la población sería creciente, siempre y cuando exista equidad en la distribución de los ingresos.

Otra cifra que interesa de manera especial para los objetivos del presente trabajo es la proyección del número de viviendas que habrá en el país en los próximos años. De acuerdo con las cifras del DANE (2014), mientras en 2005 tenían vivienda propia el 24,9\% de los habitantes, en 2030 ese porcentaje pasará al 29.1\%. Eso implica que entre 2014 y 2030 el número de viviendas tendrá un crecimiento del $13 \%$.

De otro lado, teniendo en cuenta la Encuesta de Calidad de Vida (ECV) que publicó el DANE en 2017, la población en Colombia está integrada por un total de 48,8 millones de personas, que abarcan un número aproximado a 15 millones de hogares y que habitan en 14,7 millones de viviendas, como se puede observar en la ¡Error! No se encuentra el origen de la referencia. con un promedio de 3,27 personas por hogar, mientras que para el año 2015, mostraba un total 13,7 millones de viviendas y con un promedio de 3,39 personas, lo que permite ver una disminución de número de habitantes por hogar de 3,5\% en un rango de 2 años.

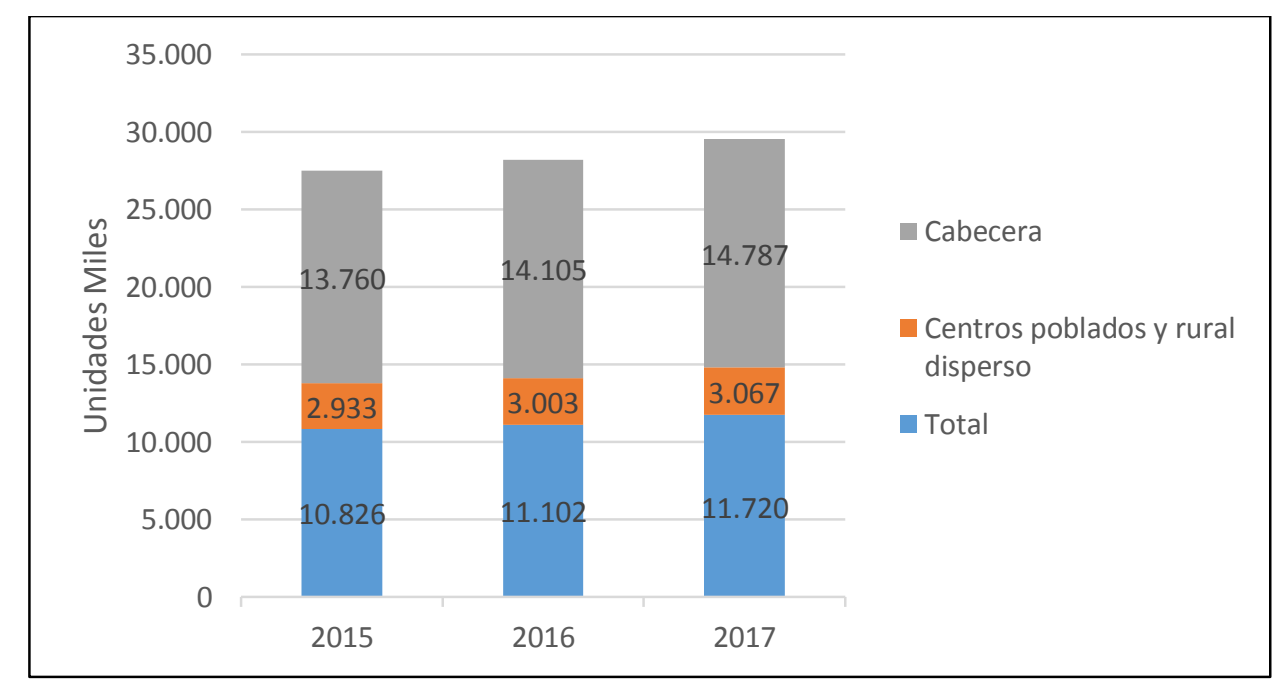

Figura 8. Número de viviendas población colombiana. Obtenido de Asobancaria (2018,p.12) 
Concretamente los hogares conformados por una sola persona se aumentaron en un $18,0 \%$, pues pasaron de 2 millones de hogares en el año 2015 a 2,4 millones de hogares en 2017. En iguales proporciones están los hogares de dos personas, que aumentaron en un 10,7\% al confrontar las encuestas de los dos años mencionados, logrando 3 millones de hogares para el 2017. Para familias donde viven 3,4 o más personas el crecimiento fue más lento, ya que existen variaciones anuales de 4,6\% para viviendas de 3 personas, variación de 0,7\% viviendas de 4 personas y de 1,7\% hogares de más de cinco personas. (Asobancaria, 2018)

Por lo tanto, el número de viviendas donde habitan familias de más de 3 personas redujo su participación entre los años 2015 y 2017, aspecto que permite notar una constante reducción en el tamaño promedio de quienes habitan las viviendas u hogares colombianos y su estructura. Este comportamiento genera una demanda de hogares más pequeños y un mayor déficit de vivienda, dado que la misma población se distribuye en hogares más pequeños.

De acuerdo con el Censo de Edificaciones publicado por el DANE en el 2017, se comenzaron un total de 157.951 unidades de vivienda, que ascendieron en metros cuadrados a un total de 13,4 millones, lo que mostró una variación anual de 1,1\% con relación a las viviendas que se iniciaron en años anteriores, y con relación al área construida mostró una reducción de 3,6\% con relación al año 2016.

Para el segmento de vivienda VIS, se comenzaron 71.447 unidades en 2017, que representa un área de 4,2 millones de $\mathrm{m}^{2}$; entre tanto, para vivienda no VIS se comenzaron 86.504 unidades de vivienda en 9,2 millones de $\mathrm{m}^{2}$. Esas cifras reflejan un crecimiento de $17.3 \%$ con relación al 2016 en número de viviendas VIS y de 19,1\% en área construida, mientras que en viviendas no VIS la variación fue de una reducción 9,2\% en unidades y de 10,5\% en área construida. (Asobancaria, 2018). 
En el escenario externo también resulta conveniente considerar los Objetivos del Milenio definidos por las Naciones Unidas (2013); debe recordarse que el objetivo uno es erradicar la pobreza extrema y el hambre; el segundo es lograr la enseñanza primaria universal; el tercero es promover la igualdad de género y el empoderamiento de la mujer; el cuarto es reducir la mortalidad de los niños menores de 5 años; el quinto es mejorar la salud materna; el sexto es Combatir el VIH/SIDA, el paludismo y otras enfermedades; el séptimo es garantizar la sostenibilidad del medio ambiente y el octavo, fomentar una alianza mundial para el desarrollo. Como se observa, existen varios objetivos que tienen una incidencia respecto de la empresa que puede considerarse favorable a su crecimiento, como son los objetivos uno, dos, cuatro, cinco y seis, dado que el logro de todos ellos implica o genera demanda directa de infraestructura. En cambio, el objetivo siete puede implicar restricciones en algunos procedimientos de extracción y fabricación, y los objetivos tres y ocho se pueden considerar de efecto neutro para la empresa.

Con relación a los nuevos lanzamientos de construcción y las ventas de vivienda nueva en Colombia, han reflejado una inclinación sostenida decreciente desde inicios del año 2017. El modesto cumplimiento de los indicadores que encabezan el sector, se encuentra vinculado fundamentalmente a la vivienda no VIS, con un precio superior a 135 SMMLV, y se encauza con la desaceleración actual de la economía del país y la descomposición en la desconfianza de los hogares.

Para los meses de octubre de 2016 y septiembre de 2017, se presentaron un total de 165.912 lanzamientos en el mercado de la construcción, que corresponde a una reducción de 14,0\%, equivalente a 27.111 unidades de oferta nueva durante el último año. Igualmente, las ventas fueron un total de 176.503 unidades durante el mismo periodo, que representa un $4,8 \%$ menos que durante el mismo periodo del año anterior. Los lanzamientos muestran una modificación negativa en seis 
sucesivos meses en los últimos doce meses, y entre tanto, las ventas se han disminuido por tres meses, como se puede observar en la figura 9

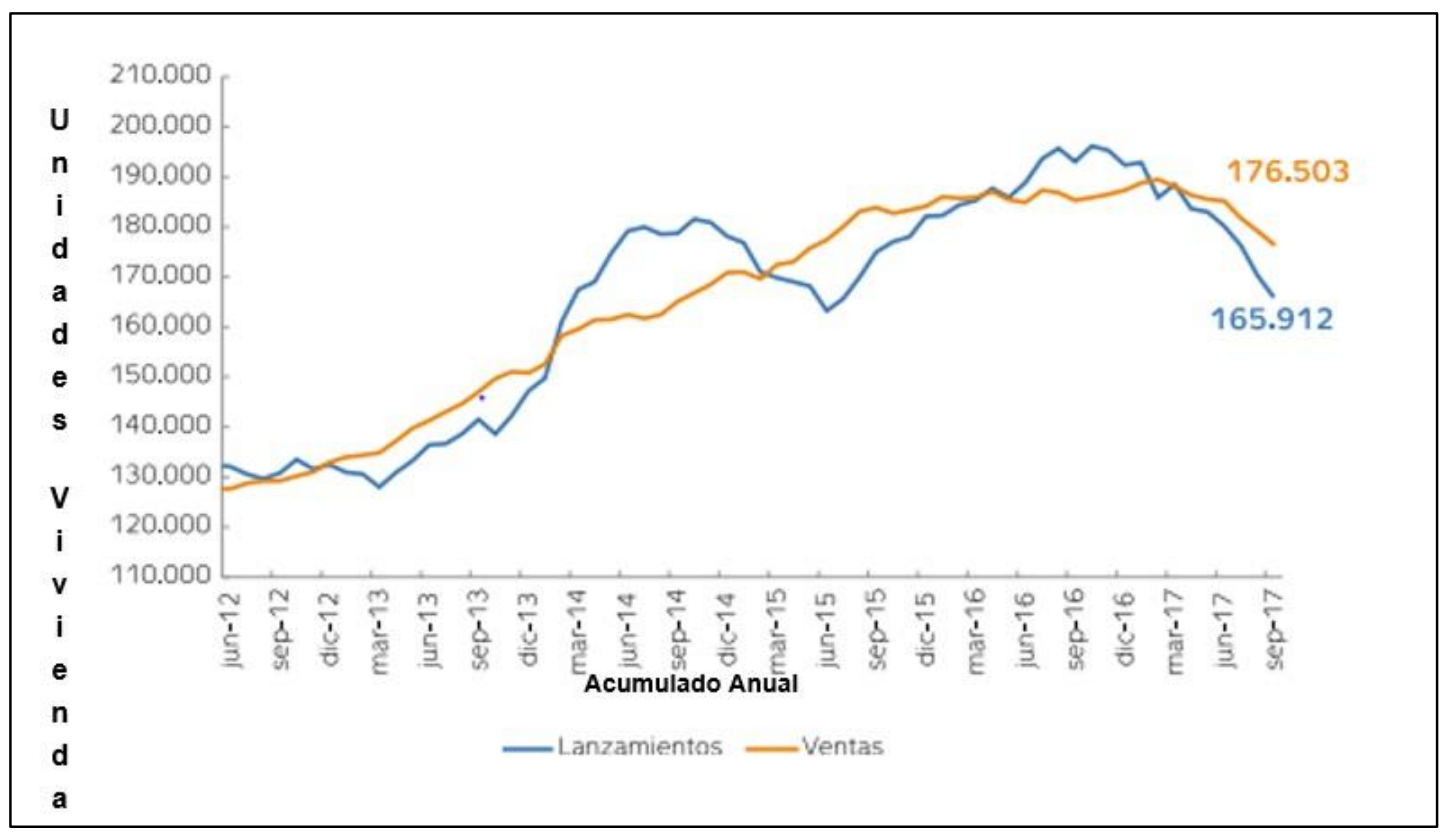

Figura 9. Propensiones de oferta y demanda - Total mercado 2011-2017. Obtenido de (Camacol, 2017,p.44)

Con relación a la participación de la vivienda de interés social, los lanzamientos aumentaron en $0,3 \%$ anual hasta llegar a posicionarse en 54.389. De igual forma, las cadencias de mercantilización señalaron 63.825 viviendas vendidas con un incremento del 2,8\%. Por lo tanto, en las ventas y los lanzamientos obtuvieron buenos resultados, que se generaron gracias al buen manejo de la industria de 70 a 135 SMMLV, que mostró un incremento del 17,3\% en el año; este comportamiento se produjo especialmente a través del proyecto "Mi casa ya", y el estímulo sobre la tasa de interés para la vivienda de interés social.

En la ¡Error! No se encuentra el origen de la referencia. que se presenta a continuación, se puede observar la evolución tanto de la oferta como la demanda de vivienda de interés social entre los años 2014 a 2017. 


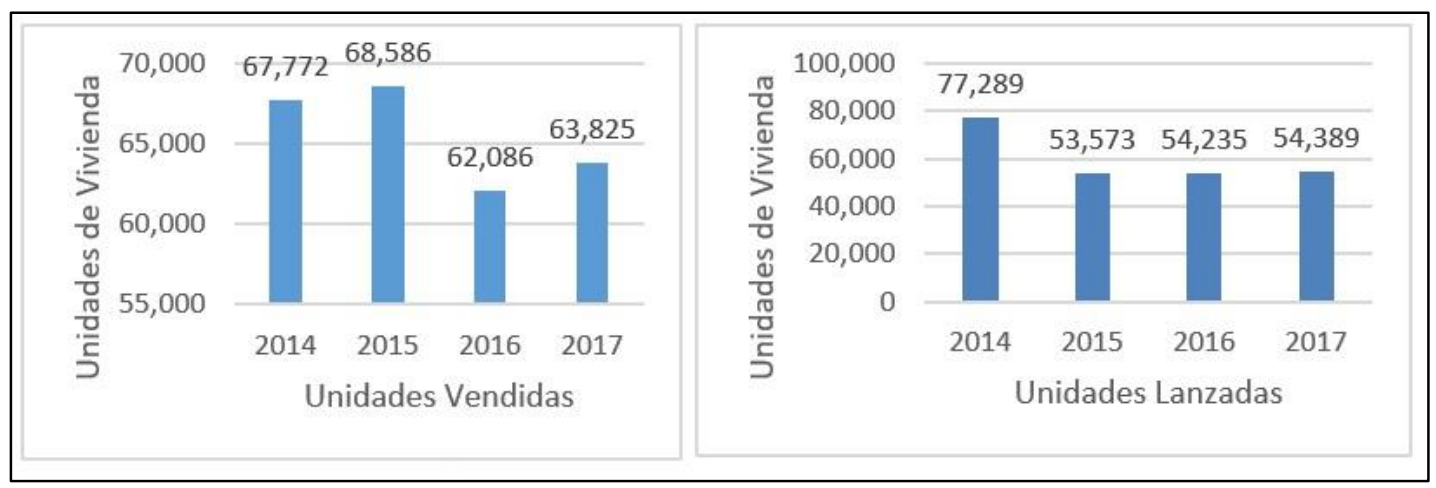

Figura 10. Propensiones de oferta y demanda de VIS- 2014-2017. Datos obtenidos de (Camacol, 2017,p.43)

Desde el 2012, la construcción de viviendas se ha incrementado, generando provecho a 5,3 millones de colombianos, edificando 1,51 millones de viviendas (VIS y no VIS, contando con subsidios, y sin ellos), esto, motivado principalmente por la puesta en marcha de distintos proyectos de vivienda que han sido desarrollados por la nación, y gracias a estos proyectos se produjo el robustecimiento de este sector como el propulsor del crecimiento económico y la generación de trabajo.

Las viviendas de interés social ascienden a la suma de 793.000 que representan el 51\%, y las que no están dentro del mercado de viviendas de interés social ascienden a la suma de 752.000 que representan el 49\%. Otorgándole beneficios a 5,3 millones de colombianos, con vivienda nueva. Dentro del primer semestre de 2017 se iniciaron obras en 119.626 unidades de vivienda urbana, de las cuales 59.688 corresponden al área de vivienda de interés social.

Se empezaron a construir con financiación o cofinanciación de la nación, un total de 859.024 viviendas (tanto VIS como no VIS) desde el año 2010. Dentro de las cuales 103.381 viviendas corresponden a viviendas gratis que ya se han acabado.

Teniendo en cuenta las evaluaciones efectuadas por el DANE, DNP y el Ministerio de Vivienda, Ciudad y Territorio, y de acuerdo con datos arrojados por la Gran Encuesta Integrada 
de Hogares del DANE, el déficit habitacional cuantitativo en los años 2005 y 2016 se redujo del $14,4 \%$ a $10,3 \%$ respectivamente, y de la misma manera el déficit cualitativo que en ese mismo periodo se redujo del $12,6 \%$ al $5,6 \%$.

Con relación a la financiación de vivienda, para los primeros nueve meses del año 2017 se entregaron créditos para vivienda por valor de 7,3 billones de pesos, lo que deja ver un crecimiento de 4,2\% con relación al mismo período del año anterior. Lo cual demuestra la confianza que tiene la población a las políticas que existen en el área de la vivienda, es así que, con el Índice de Confianza del Consumidor de Fedesarrollo, para octubre de 2017 arrojó un 1,3\% en su informe. Todos estos aspectos dejan ver un horizonte para el sector de la construcción bastante estimulante, en cierta forma, gracias a los proyectos apalancados por el Gobierno, que permiten producir efectos en múltiples variables del sector como por ejemplo generación de empleo, y además el valor agregado que le da a la labor de la construcción, al igual que a aquellas áreas que están vinculadas con el área de la construcción (Ministerio de Vivienda, Ciudad y Territorio, 2017).

Las cifras analizadas permiten pensar que la industria de la construcción en Colombia sí ofrece oportunidades atractivas para el crecimiento. Este crecimiento podría ser aún mayor si logra consolidarse el proceso de paz que suscribió el gobierno de Juan Manuel Santos con la guerrilla de las FARC. Como evidencia de esa situación, en la ¡Error! No se encuentra el origen de la referencia. se presenta la distribución de las importaciones de pisos laminados hacia Colombia entre 2017 y 2018. 


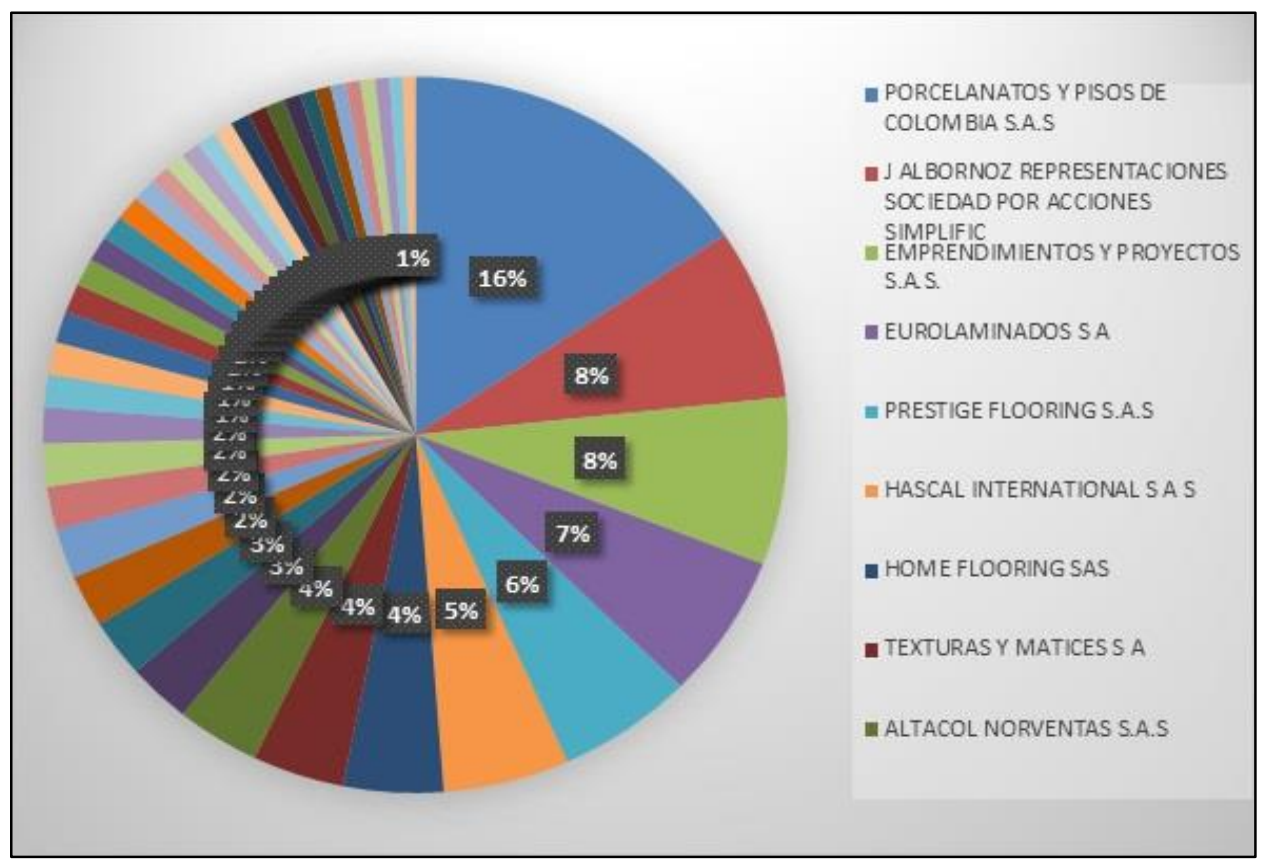

Figura 11. Importaciones de Pisos Laminados 2017-2018. Obtenido de (Legiscomex, 2019,p.11)

Se observa que Porcelanatos y Pisos de Colombia fue el importador con mayor participación y duplicó la participación del segundo actor del mercado.

\section{2 ¿Qué clase de fuerzas competitivas enfrentan los miembros de la industria y qué intensidad tiene cada una?}

6.2.1 Barreras de entrada. De acuerdo con la teoría de las cinco fuerzas desarrollada por Michael Porter (2004), existen siete posibles barreras de entrada que pueden usarse para limitar la participación de nuevos actores en un determinado mercado; esas barreras pueden ser las economías de escala, la diferenciación de producto, las inversiones de capital, la desventaja en costos independientemente de la escala, el acceso a canales de distribución, el know how y las políticas gubernamentales. Con el propósito de poder identificar las que aplican en este 
microentorno, se describen brevemente a continuación.

Las economías de escala: Se pueden generar cuando los altos volúmenes de negociación le permiten a una empresa reducir sus costos, dificultando a un nuevo competidor entrar con precios bajos (Porter, 2009). Este tipo de barreras se pueden crear especialmente en empresas industriales dedicadas a la transformación de materias primas, por lo que es representativa en el negocio de porcelanatos y pisos.

A su vez, en cuanto a la a diferenciación del producto, si una empresa logra diferenciar y posicionar fuertemente su producto, una nueva compañía que desee competir debe hacer cuantiosas inversiones para desplazar a su rival. Sin embargo, la velocidad con que en la actualidad se copian algunas ideas y con la que reaccionan los competidores logran reducir esta barrera. En el caso de los porcelanatos y pisos es relativamente fácil copiar ciertas ideas, especialmente diseños, aunque no toda la idea de negocio, los espacios, el ambiente, la atención, es decir los elementos menos tangibles, que permiten mantener la diferenciación en la medida en que la empresa sea reconocida por un servicio de mejor calidad que el que ofrezcan sus competidoras.

Por lo tanto, la empresa de Porcelanatos y Pisos de Colombia, debe tener una fuerza innovadora superior a la de sus competidores para evitar el que sean copiados sus trabajos. De igual manera, la empresa debe generar mayor nivel de capacitación para que sus empleados adquieran la suficiente experiencia, especialización y conocimiento, con el fin de que, en base a dicha experiencia, a sus competidores les sea mucho más difícil poder realizar copias de su labor. Pero uno de los aspectos que es más difícil de imitar, son los aspectos socialmente más completos que son aquellas facultades intangibles con las que cuenta la empresa, como su reputación, sus vínculos estables con compradores y su propia imagen, constituyendo un punto a favor frente a los competidores de la empresa Porcelanatos y Pisos de Colombia S.A.S, conformando para el 
comprador una ventaja sustentable (Thompson et al, 2012)

Las inversiones de capital pueden generarse cuando una empresa tiene sólidos recursos financieros que le permiten tener una mejor posición frente a competidores más pequeños, dado que esos recursos le permiten sobrevivir más tiempo que aquellos si se presentara una guerra de precios, además de invertir en la compra de algunos activos que otras compañías más pequeñas no pueden hacer, ampliar el mercado nacional, además de influir sobre el poder político de los países o regiones donde operan. Esta es una barrera cuya importancia puede ser determinante en la industria de pisos y porcelanatos, dado que en este tipo de industrias requiere inversiones significativas de capital para adquirir inventarios o maquinaria, por lo que la cantidad de capital que tenga la empresa puede crear una clara ventaja ante los clientes o ante los competidores.

Algo similar sucede cuando se analiza la barrera de la desventaja en costos independientemente de la escala; de acuerdo con Porter, esas ventajas podían ser las patentes, el control sobre fuentes de materias primas, la localización geográfica, los subsidios del gobierno, o su curva de experiencia (Porter, 2009). Esta barrera puede ser importante en el mercado de porcelanatos y acabados, teniendo en cuenta que la curva de experiencia puede ser un elemento de diferenciación que no es fácil de construir y que requiere tiempo. Una forma de enfrentar esta barrera es contratar empleados con experiencia previa, lo cual puede servir a la hora de entrar en contacto con los clientes que busquen precisamente esa experiencia como una garantía de la calidad de los productos que adquieren.

Respecto al acceso a los canales de distribución, tal como lo explica Nicholson (2014), si los canales que requiere un producto están bien atendidos por las firmas establecidas, los nuevos competidores deben convencer a esos distribuidores de que acepten sus productos mediante estrategias de reducción de precios, aumento de márgenes de utilidad para el canal, compartir 
costos de promoción del distribuidor, compromiso de mayores esfuerzos promocionales en el punto de venta, etc. Todas estas estrategias reducen las utilidades de la compañía entrante. Es claro que este tipo de barrera aplica a productos que requiere canales de distribución física, cosa que se descarta en el caso que se estudia en el presente trabajo.

Por su parte, el know-how o el saber hacer de toda empresa marcan una importante limitación a los posibles competidores que tienen que acudir a ese mercado concreto. El know-how se crea con base en conocimiento y no solamente con experiencia, pues es posible que personas muy jóvenes tengan determinada formación que les permite conocer técnicas o procedimientos que no se adquieren con el tiempo sino con la educación, por ejemplo. Por lo tanto, el saber producir porcelanatos y pisos es una barrera que no se compra fácilmente con grandes inversiones de capital, y que en cambio sí puede crearse con adecuados procesos de selección de quienes serán los empleados que se vinculen a la empresa.

Por último, las políticas del gobierno pueden limitar o impedir la entrada de nuevos competidores mediante leyes, normas y requisitos que pueden incluir, por ejemplo, normas sobre el control del medio ambiente o sobre los requisitos de calidad y seguridad de los productos; estas normas pueden exigir grandes inversiones de capital o sofisticación tecnológica. Dado el tipo de actividades de las empresas que ofrecen productos para pisos y porcelanatos, esta puede ser una barrera de entrada para el sector.

6.2.2 Poder de los consumidores. En el caso de los productos objeto de estudio, los consumidores no tienen un poder importante que pueda generarles un poder a la hora de adquirir estos productos. Se trata de un mercado compuesto por compradores que, si bien pueden estar afiliadas a organizaciones o agremiaciones de constructores o consumidores, esa afiliación no es usada para ejercer presión o influencia al momento de negociar con sus proveedores de este tipo 
de productos. Sin embargo, se debe mantener una buena relación con estas agremiaciones, que pueden influir en la expedición de normas que limiten la entrada al mercado de productores que no estén debidamente certificados.

6.2.3 Rivalidad de los productores. Si bien el consumo de porcelanatos y pisos puede generar diversidad de oferta entre los productores, se trata de una rivalidad usual en cualquier industria, por lo que este aspecto no incide de manera determinante en el comportamiento de este mercado, dado que no se presentan competidores interesados en que los demás actores del mercado quiebren o desaparezcan del mercado.

6.2.4 Productos sustitutos. Las opciones que tienen los compradores para adquirir los productos de la empresa pueden incluir la utilización de diferentes acabados. Esta diversidad de opciones exige que la empresa deba estar alerta a las tendencias que se presenten en el mercado por parte de la competencia, así como otras ofertas cada vez más interesadas por la protección del medio ambiente, lo que se conoce como compradores responsables (Valverde, Ayala \& Álvarez, 2017).

6.2.5 Poder de los proveedores. En este caso los proveedores son los propietarios de minas de piedra, arenas, metales y demás materiales, quienes pueden llegar a ejercer presión especialmente en el precio. Sin embargo, esa posibilidad se puede reducir en la medida en que se logre desarrollar proveedores que suministren estos productos de manera permanente y, por lo tanto, se genere una dependencia mutua que favorezca las buenas relaciones de largo plazo.

En la tabla 4 se resume el análisis estratégico de acuerdo con las fuerzas del mercado. 


\section{Tabla 4. Posición de las empresas de la competencia en el mercado}

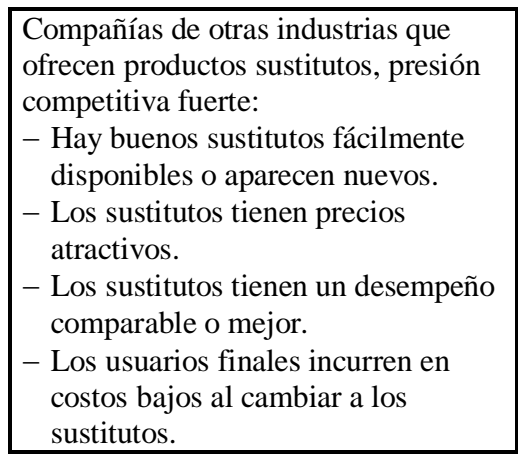

Proveedores. El poder de negociación del proveedor es débil:

- Hay oleada en disponibilidad de suministros.

- El artículo que se provee es un commodity con muchos proveedores.

- Bajos costos de cambiar proveedores.

- Hay buenos sustitutos o aparecen nuevos productos/servicios como suministros.

- Gran fracción de las ventas totales del proveedor.

Nota: Elaboración propia
Rivalidad entre vendedores competidores, es débil:

- La demanda crece con rapidez.

- Bajos costos fijos y de almacenamiento.

- Las ventas se concentran entre unos cuantos grandes vendedores.

- El tamaño, la fuerza, los objetivos, las estrategias y los países de origen de los miembros de la industria son relativamente Homogéneos.
Compradores. El poder de negociación de los compradores es mayor:

- Los costos de cambiar a productos competidores son bajos.

- Los productos de la industria están estandarizados o no están diferenciados.

- Los compradores están bien informados sobre la calidad, precios y costos de los vendedores

- Los compradores son sensibles al precio.
Nuevos participantes potenciales; amenaza de entrada mayor:

- Las barreras a la entrada son bajas.

- Los miembros de la industria no se oponen vigorosamente al ingreso de recién llegados.

- Hay un grupo de interesados en entrar, algunos con capacidad de superar las barreras de ingreso.

- La demanda crece con rapidez y los recién llegados anticipan utilidades atractivas sin provocar una fuerte reacción de las empresas ya presentes.

\section{3 ¿Qué factores promueven el cambio en la industria, y qué efectos tendrán?}

Las transformaciones que se generan en cualquier tipo de industria vienen dadas por la misma esencia, magnitud y potencia que tienen las fuerzas competitivas al interior de esta, las cuales se encuentran ajustadas a las transformaciones. En todas las industrias existe injerencia por parte de 
las nuevas invenciones e inclinaciones que existan dentro del mercado, las cuales transforman sus condiciones. Diversas transformaciones pueden ser tan trascendentales, que necesiten una respuesta estratégica. Ya que las fuerzas competitivas son tan importantes para el alcance de las utilidades que buscan las industrias, se necesita que la parte administrativa esté siempre a la expectativa de los cambios que puedan mostrar injerencia dentro de la fuerza que poseen esas fuerzas competitivas. Con base en la supervisión que realizan los administradores dentro del entorno, buscando descubrir posibles transformaciones de esta índole, se puede lograr prever transformaciones en cuanto al rendimiento que se busca obtener por determinada inversión en la industria, y con base en ello buscar adaptar las tácticas de la empresa.

Las transformaciones que tienen injerencia en las fuerzas competitivas de manera positiva, brindan posibilidades para que las entidades busquen un redescubrimiento y saquen sus mayores beneficios; entre tanto, esas transformaciones que intervienen de manera negativa en contra de esas fuerzas, pueden necesitar una táctica estratégica protectora.

Cuando se presentan condiciones transformadoras, la administración inicia un estudio estratégico del movimiento de la industria, el cual está compuesto por tres fases: i) Establecer los promotores del cambio, ii) Definir si esos promotores, bien sea de manera particular o colectiva, trabajan buscando que la industria sea o más o menos fascinante, y iii) Definir las transformaciones de las tácticas que se requieren para proyectarse de manera previa ante los efectos de las transformaciones.

Con relación a la primera fase, existe diversidad de transformaciones de tipo ambiental que inciden dentro de las industrias de determinadas maneras, dentro de los elementos más destacados y que influyen de una manera más trascendental para replantear la perspectiva de la industria y transformar las condiciones de competencia. Varios de los promotores del cambio, se dan dentro 
del entorno externo de la entidad, pero otros se generan dentro del entorno interno de la industria y su competencia. Existen ciertos promotores de transformaciones que se dan concretamente por una situación específica de la industria, la gran mayoría de promotores de cambio competitivo se condensan en las categorías que se relacionan a continuación.

- Cambios de la tasa de crecimiento de largo plazo de una industria

- Globalización creciente

- Cambios en quienes compran el producto y su forma de usarlo

- Cambio tecnológico

- Surgimiento de nuevas capacidades y aplicaciones de internet

- Innovación en el producto y en el marketing

- Entrada o salida de empresas importantes

- Difusión del conocimiento técnico entre empresas y países

- Mejoras en la eficiencia en mercados adyacentes

- Reducciones de la incertidumbre y del riesgo de negocio

- Influencias regulatorias y cambios de políticas gubernamentales

- Preocupaciones, actitudes y estilos de vida cambiantes de la sociedad.

Para la empresa Porcelanatos y Pisos de Colombia S.A. los factores que más fomentan la transformación dentro de los mencionados anteriormente están los cambios tecnológicos y la innovación en el producto y en el marketing.

Con relación a los cambios tecnológicos éstos generan transformaciones, puesto que en el medio donde se desenvuelve la industria, se cuenta con múltiples avances tecnológicos que les posibilitan cambiar productos que en la actualidad se alcanzan por medio de otros métodos, y que le van a brindar al comprador la fusión entre menos precio mejor desempeño. Igualmente, los 
cambios tecnológicos generan en la empresa la intención de brindar productos con el valor agregado en tecnología, que le va a simbolizar a sus clientes propiedades y provechos que lo distinguen frente a los sistemas de construcción habitual, para lo cual la empresa trabaja permanentemente para conseguir mantener un liderazgo tal basándose en la innovación apoyada en la tecnología, aspecto que al interior de la empresa, debe dársele mayor prioridad y debe enfocarse de manera constante en aquellos atributos que los haga diferentes a sus competidores.

En cuanto a la innovación en el producto y en el marketing, el aspecto más trascendental para la empresa Porcelanatos y Pisos de Colombia S.A., es la entera satisfacción de sus clientes, por lo tanto, se debe saber exactamente cuáles son sus requerimientos, y buscar agotar todas las opciones en busca de satisfacer las necesidades del cliente con respuestas apropiadas, por parte de expertos y que le brinden el mejor trato, buscando que con la labor de atención al cliente se pueda anticipar a satisfacer sus requerimientos y sus expectativas por medio de los productos y servicios con los que cuenta la empresa. Esto se logra instaurando un vínculo de confianza con el cliente, respaldando que con los productos brindados se pueda cumplir con sus requerimientos. Los medios de comunicación que posee la empresa para con el cliente, son también un punto bastante trascendental como táctica de mercadeo y de la responsabilidad por tener un vínculo más cercano con el cliente, respaldando calidad y servicios en los productos bajo el marco de la gestión adelantada de marketing con el cliente. Igualmente, dentro de la empresa se debe estar a la expectativa de los cambios que muestre el mercado, y fundamentados en ellos, producir las mejores estrategias de marketing que le posibiliten no solamente mantener su posición, sino aumentarlo por medio de la generación de programas de marketing enfocados al mejor emplazamiento de la industria.

Teniendo en cuenta lo anterior, a continuación, se detallan con mayor precisión, los dos 
factores que impulsan el cambio y que son de mayor interferencia dentro de la empresa de Porcelanatos y Pisos de Colombia S.A.S.

6.3.1 Vigilancia tecnológica. Dentro de las patentes registradas dentro de los años 2017 y 2018 y relacionadas con la industria de los porcelanatos y pisos, se destacan las que se mencionan a continuación, teniendo en cuenta el impacto que podrían llegar a tener en la industria (FREE patent, 2019).

- Número de publicación: US20140296053 A1. Fecha de publicación: 2 de octubre de 2017. Un compuesto de material de vitrocerámica adecuado para un uso a baja temperatura, que tiene alta resistencia a la humedad y conductividad térmica. El material compuesto de vitrocerámica contiene partículas de nitruro de aluminio como relleno, incluso en un caso en el que el óxido de boro $\left(\mathrm{B}_{2} \mathrm{O}_{3}\right)$ se mezcla como un flujo de una fase de vidrio, ajustando la composición de las materias primas que forman el cristal a una fase de condiciones específicas, para hacer que la fase de cristal que contiene boro se precipite al momento de la cocción del material compuesto de vidrio-cerámica.

- Número de publicación US20140271447 A1; fecha de publicación: 18 septiembre 2017. Una cerámica piezoeléctrica que contiene un compuesto a base $\mathrm{O}_{3}-\mathrm{Pb}(\mathrm{Ti}, \mathrm{Zr})$, lo que le da un alto grado de orientación. Este tipo de patentes muestra que la cerámica puede tener campos de aplicación diferentes a los actuales, lo que podría incidir en su precio como materia prima.

- Vitrocerámica de Cuarzo $\beta$ de aluminosilicatos de litio que no contiene ni óxido de arsénico ni óxido de antimonio; el acabado se logra con óxido de estaño y se incluyen óxido de vanadio, óxido de cromo y un contenido de óxido de hierro (> 950 ppm). Tiene una curva de transmisión controlada, por lo que es apto para producir materiales de vitrocerámica para artículos tales como placas de cocina. 
- Número de publicación US20140206522 A1; fecha de publicación: 24 Jul 2017. Se proporciona una tecnología fácil de administrar que demuestra el efecto de mejora en la conductividad térmica debido a la adición de fase de cristal compuesto de tipo no-óxido en las partículas de relleno, lo que hace que sea posible aumentar suficientemente la conductividad térmica de un material de compuesto de vitrocerámica. En la fase de vidrio propia de un material compuesto de vidrio-cerámica, la cantidad de óxido de aluminio $\left(\mathrm{Al}_{2} \mathrm{O}_{3}\right)$ de los componentes se incrementa bajo una condición en la que existe al menos un componente de óxido de zinc ( $\mathrm{ZnO})$ o un componente de óxido magnesio $(\mathrm{MgO})$ en una cantidad predeterminada. De este modo, se puede suprimir la reacción no deseada entre una fase cristalina del sistema compuesto no-óxido y la fase de vidrio, logrando el efecto de mejora de la conductividad térmica.

- Número de publicación: US20130200750 A1. Fecha de publicación: 8 agosto 2018. Proporciona un método de fabricación de cerámicas de óxido orientadas preferentemente, que tienen un alto grado de orientación cristalina. El método de fabricación incluye la obtención de una suspensión que contiene un cristal de óxido de boro que tiene anisotropía magnética; se aplica un campo magnético al cristal y se obtiene un compacto; éste se somete tratamiento de oxidación para obtener cerámicas de óxido orientadas preferentemente, que incluye un compacto de un cristal de óxido de carbono.

- Número de publicación: WO2013147295 A2; fecha de publicación: 3 octubre de 2018. Piezoeléctrico de cerámica libre de plomo, con mayor factor de calidad mecánico $(\mathrm{QM})$ y de resistencia mecánica. Las cerámicas piezoeléctricas incluyen al menos dos granos de cristal.

- Número de publicación: CN203391091 U; fecha de presentación 26 agosto de 2018. Dispositivo de reciclaje de polvo para la producción de cerámica. El dispositivo toma los excesos de material utilizados en el proceso de producción de cerámica y permite su recuperación y 
reciclado; las materias primas recuperadas se almacenan y clasifican.

Por otro lado, y según la Fundación OPTI (2016), los hogares del futuro contarán con aspectos particulares como: El hogar conectado, digitalizado, la vivienda domótica y el hogar inteligente, conforme a los estudios realizados por agentes del sector que participan en el diseño de las viviendas futuras.

Con relación al hogar conectado, hace alusión a la vivienda que cuenta con conexión constante a internet de banda ancha, donde se puede realizar cualquier tipo de funciones relacionadas con la tecnología. Cuando se habla de la vivienda domótica, es aquella que cuenta con un sistema de mecanismos, como por ejemplo sensores y actuadores que van a posibilitar dirigir distintas funciones como: El alumbrado, la temperatura en la vivienda, todos los dispositivos eléctricos incluidas puertas y ventanas, etc., de acuerdo con la Figura 12 que se observa a continuación.

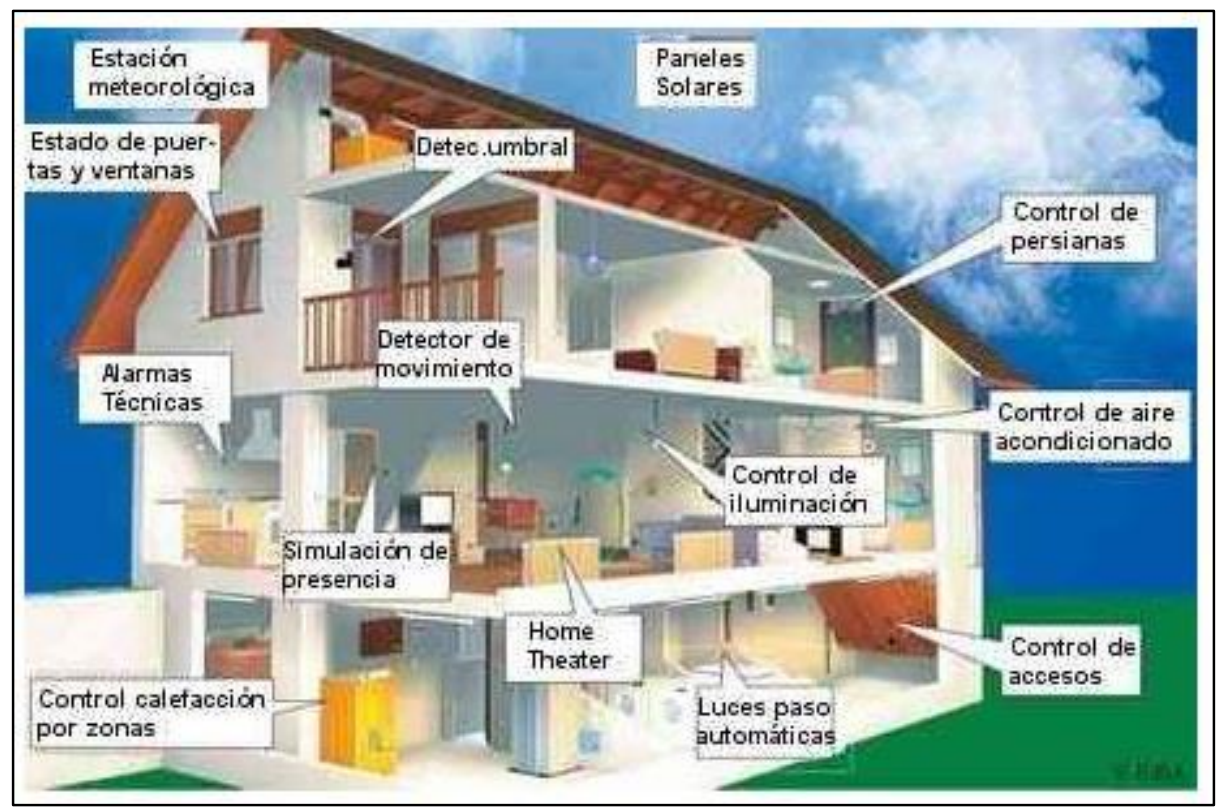

Figura 12. Ejemplo vivienda domótica. Obtenido de Domótica Viva (2015,p.2)

Por su parte el concepto de hogar digitalizado se refiere al uso de computadores, impresoras, dispositivos digitales para captura, almacenamiento, procesamiento y presentación de información 
audiovisual, incluyendo consolas de videojuego, cámaras digitales y de video y música en diferentes formatos, pantallas de televisión cada vez más grandes, teléfonos inalámbricos, etc. Y como consecuencia de la disponibilidad de todos esos recursos, surge el hogar inteligente (Fundación OPTI, 2016), constituido por la denominada inteligencia ambiental, que busca anticiparse al comportamiento del usuario, recopilando información a partir de la cual se adapta a cualquier tipo de situación, necesidad o cambio; estos procesos se harán de la forma más parecida posible a lo que sucedería entre dos personas, lo que exige la incorporación de interfaces inteligentes e intuitivas, integradas con los diferentes objetos cotidianos del hombre.

En la figura 13, se presentan algunos de los servicios que tendrá el hogar digitalizado, a los que habría que agregar por supuesto el Internet de banda ancha y la televisión digital, entre otros.

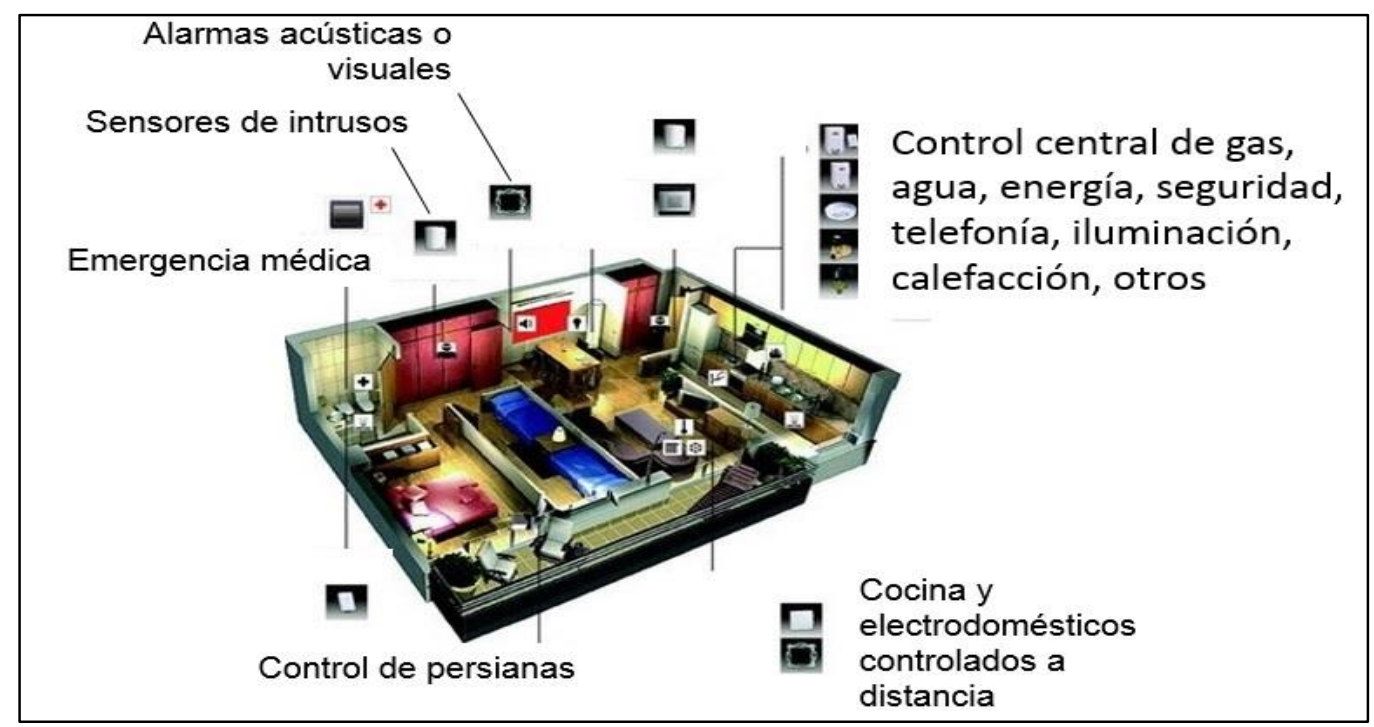

Figura 13. Servicios del hogar digitalizado. Obtenido de Domometrio (2015,p.2)

Además de estos desarrollos que se enfocan especialmente en la vivienda del futuro, existen otras tendencias tecnológicas que modificarán la forma de hacer las cosas en el futuro, tanto en esta industria como en otras. Una de ellas es la impresora en tres dimensiones, que ya es una 
realidad y que ha venido utilizándose para fines cada vez más complejos. Como se puede observar en la figura 14.

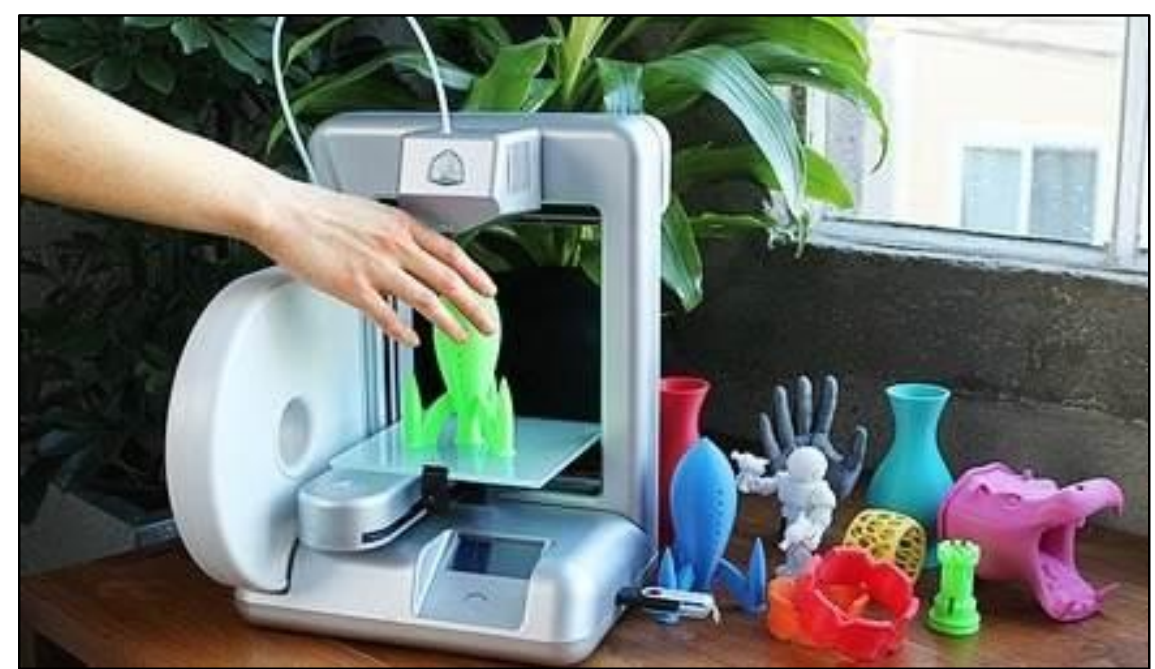

Figura 14. Impresora 3D. Obtenido de Univisión (2015,p.3)

En efecto, "investigadores de un equipo de la universidad de Monash en Melbourne desarrollaron el primer motor de aviación del mundo fabricado con una impresora en 3D, que quieren ahora comercializar" (Univisión, 2015,p.2) (ver figura 15).

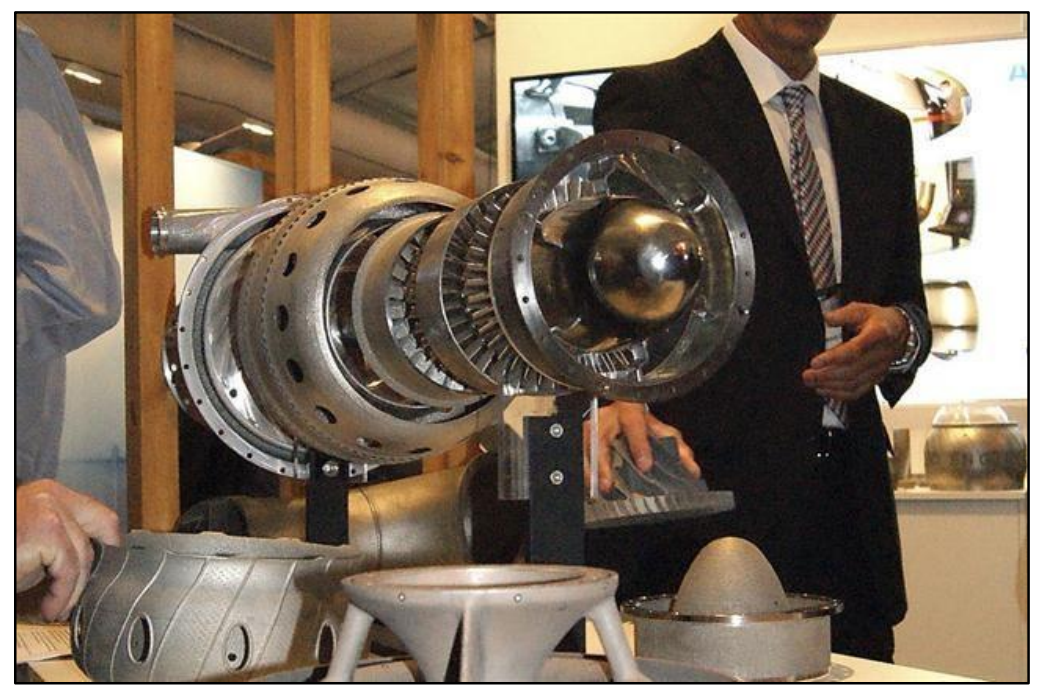

Figura 15. Rotor de turbina de avión desarrollado en impresora 3D. Obtenido de Univisión (2015,p.2) 
Esos avances hacen prever que en un futuro más o menos cercano, tanto las empresas de construcción como los proveedores de esta industria, incluyendo a la empresa Porcelanatos y Pisos, tendrán a su disposición desarrollos que les permitirán sustituir productos que actualmente se obtienen mediante otros métodos, lo que hará que algunos de esos productos simplemente queden obsoletos, tal como sucedió de forma relativamente reciente con productos como los rollos para cámaras fotográficas o carburadores para la inyección de combustibles en motores de combustión interna. Si bien aún falta tiempo para que se logre la optimización y racionalización de costos de esas tecnologías, resulta clara la necesidad de mantener siempre una vigilancia permanente sobre los eventos a través de los cuales se difundirán los productos concretos que tales avances traerán para el mercado en el que tiene presencia la empresa.

Después de esta fase de vigilancia tecnológica, se pueden destacar las siguientes tendencias que pueden tener una gran importancia en el futuro de la industria de las cerámicas a nivel mundial y por supuesto en Colombia:

- El desarrollo de las impresoras 3D aplicadas en la industria de la construcción y sus acabados.

- Pisos que neutralizan las toxinas transportadas por el aire, generando un flujo de aire puro dentro de espacios interiores. Su funcionamiento se activa con la luz natural y artificial, usando un fotocatalizador, una tecnología que implementa dióxido de titanio, que descompone bacterias, virus y moho. Al mismo tiempo, reduce la presencia de potenciales carcinógenos. (Velasco, 2014).

- Pisos con capacidad de detectar el movimiento de las personas y enviar información a una central de seguridad. (Shen, 2012).

- Pisos que cambian de color a gusto del usuario, lo que puede reducir la necesidad de cambiar los materiales para adaptarse a nuevos diseños de los espacios (Graves, Gall, Ludvigsen, 
Lykke-Olesen, 2005).

- Materiales autolimpiantes para la producción de acabados, a partir de óxido de titanio $\mathrm{TiO}_{2}$ depositado sobre sustratos cerámicos. (Paucar, García, García, Hernández, Muñoz, 2013).

- Viviendas y edificios de oficinas o industriales que utilizan paneles solares, y que en momentos de bajo consumo pueden suministrar energía a la red a la cual se conectan.

6.3.1 El internet de las cosas y su impacto cultural. Una de las tendencias que en los últimos años ha venido impactando transversalmente a todas las industrias ha sido el avance de internet y en general de las tecnologías de la información y las comunicaciones. Dada la alta relación que esta tendencia tiene con la industria de la construcción en general y por lo tanto con el sector porcelanatos y pisos, a continuación, se presenta una síntesis de la evolución de estas tecnologías a nivel general y particularmente en Colombia.

Las Naciones Unidas tienen un organismo interno encargado de las Telecomunicaciones a nivel mundial llamado la ITU-T, el que en los últimos años ha impulsado una carrera en la cual fabricantes, operadores y gobiernos, creen una infraestructura que facilite la elaboración, implementación de servicios y aplicaciones de información existentes y futuros dentro y a través de las industrias de las comunicaciones, de tecnología de la información, de electrónica y de provisión de contenido. Esta infraestructura consistirá en mecanismos interactivos, de difusión y otros mecanismos de entrega multimedios acoplados con capacidades para que los individuos puedan compartir, utilizar y gestionar la información, en cualquier momento y en cualquier parte, con seguridad y protección de la privacidad, así como con niveles de costos y calidad aceptables. La GII proporcionará Inter funcionamiento con una multiplicidad de aplicaciones y plataformas diferentes a través de una federación sin fisuras de computadores y capacidades de comunicaciones interconectados que son alimentados por la línea (por ejemplo, pares de cobre, fibras, cables 
coaxiales) y tecnologías inalámbricas (por ejemplo, radiocomunicaciones terrenales fijas/móviles y por satélite o tecnologías con o sin conexión. Los campos de aplicación no deben tener restricciones y son prácticamente ilimitados. Se prevé que las esferas actuales de aplicación comprendan el comercio de la electrónica, la telemedicina, servicios de información urbanos, sistemas de transporte inteligente, teleaprendizaje, bibliotecas y museos electrónicos, itinerancia (continuidad de acceso en el espacio y en el tiempo), etc.

6.3.2 Telefonía celular. En la misma medida en que ha evolucionado Internet, así también se ha observado el avance que ha presentado la voz como método de comunicación, tanto a nivel personal como empresarial, generando su trascendencia a la forma en la que el ser humano se puede comunicar por medio de un dispositivo.

Esta evolución de la tecnología celular o telefonía móvil también va a hacer que cambien la forma de realizar muchas actividades que actualmente demandan tiempo y esfuerzo. Cada vez más, el ser humano podrá efectuar todas sus transacciones utilizando los dispositivos móviles, podrá recibir a través del aparato celular diversidad de ofertas conforme al perfil que posean sus proveedores, al igual, que también el ser humano podrá dominar en mayor medida todos los aparatos eléctricos, dentro de otras oportunidades que están surgiendo en las ferias que realizan las empresas dedicadas al ramo de la parte electrónica.

En Colombia surge el avance en la tecnología de la telefonía celular a partir del año 1994, y fue a partir de la Ley 37 de 1993 que emergió el servicio de telefonía móvil celular (TMC) en el país, dejándolo con cierto atraso frente a otras naciones de la región con relación a este tema. Se estima que dicha ley conformó el medio a través del cual se produjo competencia para las redes de telefonía pública básica conmutada de servicios de voz (TPBC), para las comunicaciones tanto a nivel local e internacional. 
Según Fedesarrollo (2017) este sector ha presentado una cobertura de 98,45 líneas celulares por cada 100 habitantes. A nivel nacional se encuentran inscritos 46,2 millones de personas, de los cuales el 20,2\% corresponde a la Costa Atlántica, el 30,5\% se encuentra en la región oriental, y para la región occidental se encuentran inscritos el 49,3\%. Entre tanto, con relación al internet móvil, no llega a conformar una cifra semejante en cobertura como la telefonía móvil, ya que el desarrollo del mercado de este sector de la economía, se encuentra establecido fundamentalmente en las ciudades, donde se ofrece este servicio, fundamentados en las tecnologías 3G y 4G.

El servicio de internet posee una penetración reducida en el mercado, con un porcentaje a nivel nacional de 3,68 usuarios por cada 100 habitantes, pero se espera que con el paso del tiempo se superen estas cifras, gracias al avance de la tecnología en la expansión proyectada de la información y las telecomunicaciones que posibilitarán utilizar las mejores frecuencias para la telefonía móvil.

El medio de comunicación de mayor utilidad actualmente es el teléfono celular, puesto que permite llegar a más ambientes conforme a sus fundamentales particularidades como el tamaño y la facilidad en el manejo, aspectos que le han permitido ser catalogado como el móvil (Cruz et al, 2008). Según González (2016), la telefonía móvil puede ser descrita como, el método de transmisión a través del cual el usuario cuenta con una terminal, que no es fija, y además no posee cables, y que le posibilita la comunicación en cualquier ubicación geográfica donde exista red, conforma un servicio que permite cobertura en un área, a través de distintas estaciones de planta.

De acuerdo con una investigación realizada por Martínez, la telefonía móvil ha evolucionado a través de lo que se conoce como tres generaciones (Martínez, 2011) ( ver figura 16) 


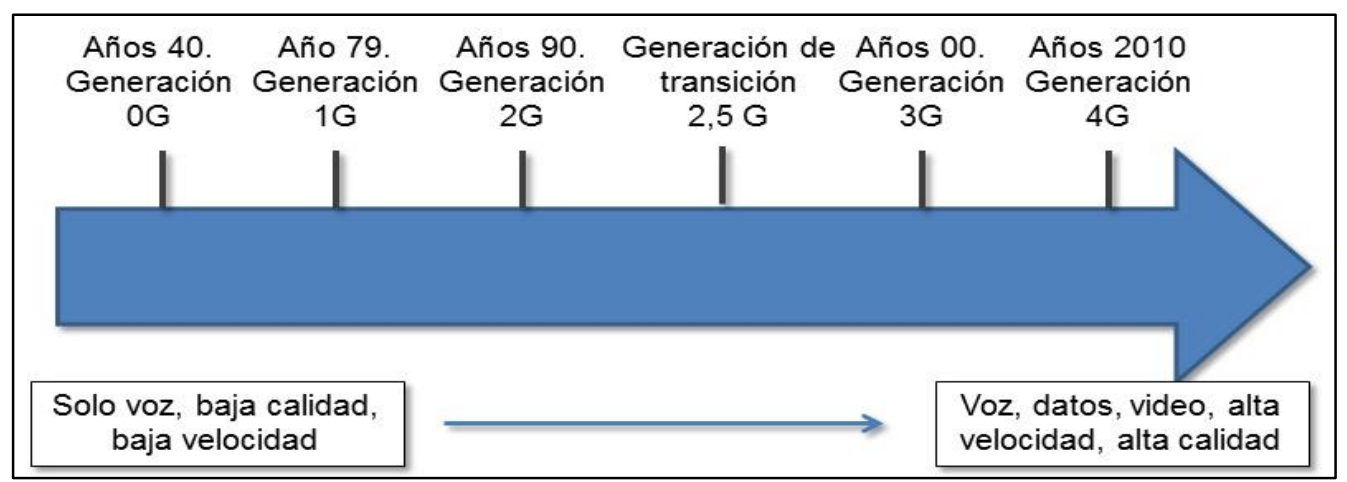

Figura 16. Evolución de la telefonía celular. Adaptado de German (2017,p.11)

En cuanto a la penetración de telefonía móvil, Colombia ha mostrado un crecimiento acelerado en los últimos años, particularmente a partir de la entrada al mercado de un tercer operador en el año 2003.

De acuerdo con Fedesarrollo (2017), se estima que, con la migración a las tecnologías de 3G y 4G, la capacidad instalada de telefonía móvil en los países de América Latina ascendería a 117\% para 2020; así mismo se espera que al menos el $45 \%$ de la población cuente con acceso a los servicios $3 \mathrm{G}$ y $4 \mathrm{G}$; es decir que cuenten con acceso a internet móvil.

Así mismo, se debe tener en cuenta que en la misma proporción como va incrementando la capacidad para adquirirlos y se aminoran los precios a causa de las economías de escala, también podrá existir un incremento en la introducción al mercado de los smartphones y otra clase de equipos, aspecto que generará que se incremente también la demanda por acceso a internet móvil. Para el año 2016 la cifra de smartphones en la región es de alrededor de los 157,4 millones de unidades, e igualmente, 94 millones de aparatos móviles para las corporaciones.

De acuerdo con lo anterior, el avance que ha tenido esta clase de tecnología también se ha dado en Colombia, dejándose seducir por el uso de la telefonía celular en todos sus ámbitos, y permite determinar que este tipo de tecnología se encuentra inmersa tanto en la cultura como en las costumbres de las personas, así como de las empresas. 
Por otro lado, dentro de las tendencias sociales se puede registrar la tendencia tanto a nivel global como nacional de mayor interés por los temas de responsabilidad social empresarial. La Responsabilidad Social Empresarial en una entidad, según Ferrell, Fraedrich \& Ferrell (2000) no se debe confundir con la ética, la cual vincula con los principios y normas bajo los cuales deben basarse los comportamientos en que se llevan a cabo las actividades comerciales, mientras que la RSE corresponde al deber que tiene una entidad de optimizar su efecto positivo, y reducir su impacto negativo sobre los stakeholders. De manera resumida puede sintetizarse el encausamiento dado a la RSE por Archie Caroll citado en Montuschi (2009) quien plantea la generación de una pirámide de preponderancias a tener en cuenta, con relación a la RSE en las empresas conformada por cuatro componentes: Se ubica como primer elemento la responsabilidad legal como pilar esencial para llevar a cabo las actividades en la empresa, es decir, lo concerniente al cabal cumplimiento de las normas y reglamentaciones establecidas por el gobierno. Posteriormente se encuentra el componente de la responsabilidad ética, que le exige a las empresas realizar de la mejor forma su comportamiento hacia los stakeholders.

Bajo el tercer componente, se encuentra ubicada la responsabilidad económica, que corresponde a la base, y que junto con la responsabilidad legal son de estricto cumplimiento en las empresas. La preponderancia que tiene la responsabilidad económica está basada en que para que se puedan producir los siguientes niveles y sea su fundamento en la pirámide, se necesita que la empresa trabaje apropiadamente y de forma eficaz, posibilitando que la empresa se mantenga. Y ya en última posición, se encuentra ubicada la responsabilidad filantrópica que hace alusión a los aportes que realizan las empresas en cuanto a la calidad de vida y bienestar de la sociedad donde se desenvuelven. En la Figura 17, se puede observar el planteamiento de la pirámide efectuado por Carroll, citada en (Montuschi, 2009) 


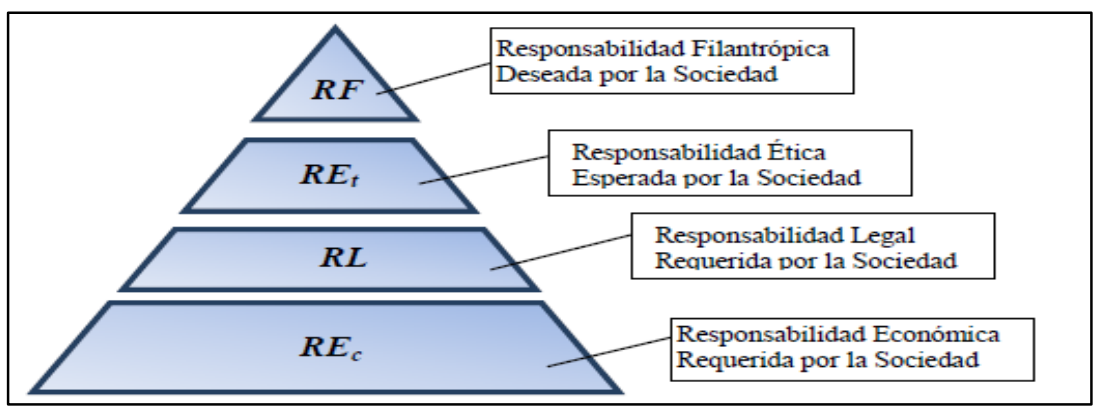

Figura 17. Pirámide de la Responsabilidad Social Empresarial por Archie Carroll. Obtenido de (Montuschi, 2009,p.34)

De otra parte, y con posterioridad a la verificación de los distintos análisis sobre RSE realizados en el Centro Colombiano de Responsabilidad Empresarial, y según Rincón y Díaz (2016), se determinó que la RSE no debe restringirse a las tareas sociales que ejecuta la empresa, sino también acarrea los vínculos que se lleven a cabo con distintos públicos, como son: colaboradores, consumidores, clientes, proveedores, medio ambiente, gobierno y sociedad. De igual forma, estos autores reunieron todas las variables que conforman la RSE, y agruparon las variables y dimensiones que integran la RSE y, basándose en los juicios establecidos por el Centro de Estudio Mexicano de la Filantropía, llevaron a cabo la valoración de las perspectivas sociales que se deben tener en cuenta dentro de una empresa, las cuales se detallan en la Figura 18 a continuación.

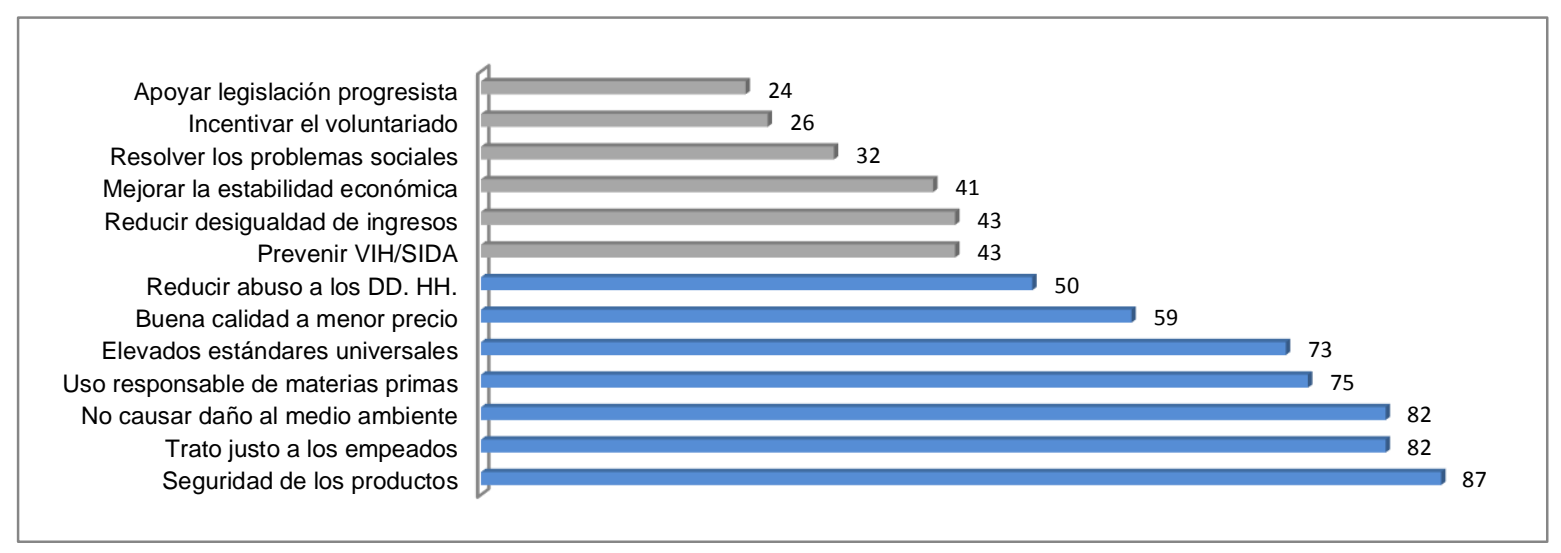

Figura 18. Perspectivas sociales a tener en cuenta en la empresa. Obtenido de Rincón \& Díaz (2016,p.23) 
Como parte de esta tendencia está también el surgimiento del consumidor responsable, es decir, aquella persona que evalúa a la empresa a la que le compra más allá de los productos mismos y mira todos los aspectos involucrados en su gestión, en lo que se denomina un análisis tipo end of pipe, y que incluye las diferentes dimensiones de la responsabilidad social empresarial.

Así mismo ha surgido en los últimos años el concepto de marketing relacional, en sustitución del marketing transaccional. La obsolescencia del concepto de marketing mix ha perdido posición debido a que, en los mercados actuales, más dinámicos y turbulentos, las empresas deben tener una nueva orientación estratégica en las que se orienten a la creación y entrega del valor que los clientes demandan, centrada en el qué hacer por los clientes. (Grönroos,1996). Esta nueva orientación es contraria a las 4P, que se enfocaba una definición del marketing orientada a la producción, que se orientaba en qué hacer a los clientes. Adicionalmente el marketing mix es un concepto más relacionado con los mercados de consumo.Bodonaba y Garrido (2012) proponen una comparación entre el marketing transaccional y el marketing relacional, de acuerdo con la tabla 5 .

Tabla 5. Continuum del intercambio en dos modelos de marketing.

\begin{tabular}{lll}
\hline \multicolumn{1}{c}{ Elementos del intercambio } & \multicolumn{1}{c}{ Marketing Transaccional } & \multicolumn{1}{c}{ Marketing Relacional } \\
\hline Horizonte & Corto plazo & Largo plazo \\
Naturaleza & Intercambio es una función discreta & Intercambio es una función continua \\
Objetivo & Captar clientes & Retener clientes \\
Centro & Ventas individuales & Relación a largo plazo \\
Orientación & Características de los productos & Beneficios de los productos \\
Elasticidad del precio & Consumidores sensibles al precio & Consumidores menos sensibles al \\
Contacto & Bajo & precio \\
Calidad & Endógena & Alto \\
Satisfacción & Centrada en el producto & Exógena \\
Inversión & Pequeña & Centrada en la relación \\
Compromiso & Bajo & Grande \\
Costos de cambio & Bajos & Alto \\
Riesgo percibido & Bajo & Altos \\
Entorno & Estable & Alto \\
Dependencia & Baja dependencia del comprador & Dinámico \\
Énfasis estratégico & Bajo & Alta interdependencia \\
Complejidad de resultados & Baja & Alto \\
\hline
\end{tabular}
Nota: Bordonaba \& Garrido (2012,p.23). 
Como se observa en la tabla 5, el enfoque estratégico del marketing transaccional es bajo, mientras que es alto en el marketing relacional. Es por eso que la implantación exitosa de una estrategia de marketing de relaciones necesita que el negocio sea orientado hacia un negocio de servicio, que la empresa pase de una perspectiva de procesos de gestión al establecimiento de relaciones y redes con los agentes del mercado, lo que implica que a nivel operativo se busquen contacto directo con sus clientes, para lo que se necesita el desarrollo de bases de datos y definir un sistema de servicio que se enfoque en sus necesidades. (Grönroos, 1996)

Además de los anteriores factores, se puede registrar también la tendencia al almacenamiento de la información de las personas y de las empresas "en la nube", es decir, en servidores suministrados por terceros en lugar de hacerlo de manera exclusiva en los discos duros propios de cada empresa (NIST, 2017). Igualmente, el empleo de grandes bases de datos en ambiente big data, capaces de administrar diferentes variables de los clientes como sus patrones de compra, con el fin de poder ofrecerles productos a través de diferentes canales y de manera personalizada (Arango, 2016)

Como se observa, las tendencias destacadas son las generadas por nuevos desarrollos tecnológicos que modificarán algunas técnicas y materiales de la industria, la tecnificación de los hogares, la penetración de la telefonía con internet móvil, el mercadeo relacional, el almacenamiento de información en la nube y el big data. Estas tendencias implican que la empresa Porcelanatos y Pisos de Colombia deba realizar actualizaciones en estos campos, con el fin de mantenerse al nivel de la competencia, debido a que cada una de esas tendencias genera ventajas para las empresas que las acojan como parte de su cultura y su forma de hacer las cosas. 


\section{4 ¿Cuáles son las posiciones que ocupan en el mercado los rivales de la industria?: ¿quién tiene una posición sólida y quién no?}

De acuerdo con el trabajo de Cando, Beltrán, Acosta y García (2018), los competidores de Porcelanatos y Pisos de Colombia S.A.S. son las empresas Prestige, Texturas y Matices y Atmósferas. Prestige se dedica a la importación, distribución e instalación de madera laminada, madera de ingeniería, pisos de vinilo, porcelanatos y revestimientos de pared en madera laminada. Entre sus proveedores están las empresas Krono Original de Alemania; Tarkett, de Suecia, Krono de Suiza y Villagres de Brasil. La empresa cuenta con 16 años de experiencia. (Prestige, 2019)

A su vez, Texturas y Matices, se presenta como una empresa comercializadora de pisos laminados, en madera y de PVC, con sucursales de pisos laminados en Bogotá y oficina y sucursal de pisos laminados de madera y PVC en Medellín. Además, se ha incorporado líneas complementarias, como pisos multipropósito, perfilería común y perfilería especial, con lo que ha incursionado también en el área de decoración. (Texturas y Matices, 2019)

Por su parte, la empresa Atmósferas se dedica a comercializar importados europeos de revestimiento y pavimento, que incluyen pisos porcelánicos, maderas laminadas y vinílicas, y soluciones de ingeniería. La firma dispone de 9 salas de ventas distribuidas en el país: cinco en Bogotá, dos en Medellín, una en Cali, y una en Pereira. Así mismo ha creado franquicias en Bogotá, Ibagué, Villavicencio y Cúcuta que venden sus productos ofreciendo los mismos estándares de las salas propias. Ofrece también servicio de cortes especiales en la planta de corte instalada en sus instalaciones. (Atmósferas, 2019)

La posición de estas empresas en el mercado se muestra en la tabla 6. 


\section{Tabla 6. Posición de las empresas de la competencia en el mercado}

\begin{tabular}{|c|c|c|}
\hline Empresa & $\begin{array}{c}\text { Tipo de estrategias } \\
\text { ejecutadas }\end{array}$ & $\begin{array}{c}\text { Objetivos / Resultados alcanzados con la } \\
\text { ejecución del tipo de estrategia }\end{array}$ \\
\hline Prestige & $\begin{array}{l}\text { Integración hacia } \\
\text { adelante }\end{array}$ & $\begin{array}{l}\text { Lograron consolidarse en la ciudad de Medellín. } \\
\text { Mayores ventas con las constructoras. }\end{array}$ \\
\hline $\begin{array}{l}\text { Texturas y } \\
\text { Matices }\end{array}$ & $\begin{array}{l}\text { Diversificación con } \\
\text { productos }\end{array}$ & $\begin{array}{l}\text { Posición mayoritaria en el mercado de ventas al } \\
\text { detal. }\end{array}$ \\
\hline & relacionados & $\begin{array}{l}\text { Presencia en Bogotá y Medellín, aumento de los } \\
\text { canales de atención. }\end{array}$ \\
\hline \multirow[t]{2}{*}{ Atmósferas } & Diferenciación amplia & $\begin{array}{l}\text { Busca satisfacer las necesidades de sus clientes } \\
\text { brindando una oferta de mercado valorizado en } \\
\text { diferentes líneas de producto que la convierten en } \\
\text { la compañía con el catálogo y portafolio más } \\
\text { integral. }\end{array}$ \\
\hline & & $\begin{array}{l}\text { Portafolio integral de productos y soluciones para } \\
\text { hacer la más completa oferta para todos sus } \\
\text { clientes, en Bogotá, Medellín, Cali y Pereira }\end{array}$ \\
\hline
\end{tabular}

Nota: Obtenido de Cando et al (2018,p.44).

De estas empresas, la que cuenta con una posición más sólida es Atmósferas, si se tiene en cuenta que ofrece la red más amplia de puntos de venta y el interés por ofrecer nuevos servicios. Las otras empresas tienen una solidez moderada, aunque eso no debe interpretarse como debilidad, dado que su permanencia de varios años muestra su conocimiento del mercado y su decisión a continuar compitiendo. Estos aspectos son analizados en el mapa de grupos estratégicos de la figura 19, donde se puede apreciar que la empresa mejor posicionada en cuanto a que abarca una zona más amplia del país, ya que están ubicados en Bogotá, Medellín, Cali y Pereira, y que además cuenta con un portafolio de productos más completo como lo son pisos porcelánicos, maderas vinílicas y soluciones de ingeniería para brindar a todos sus clientes, una más amplia cobertura. 


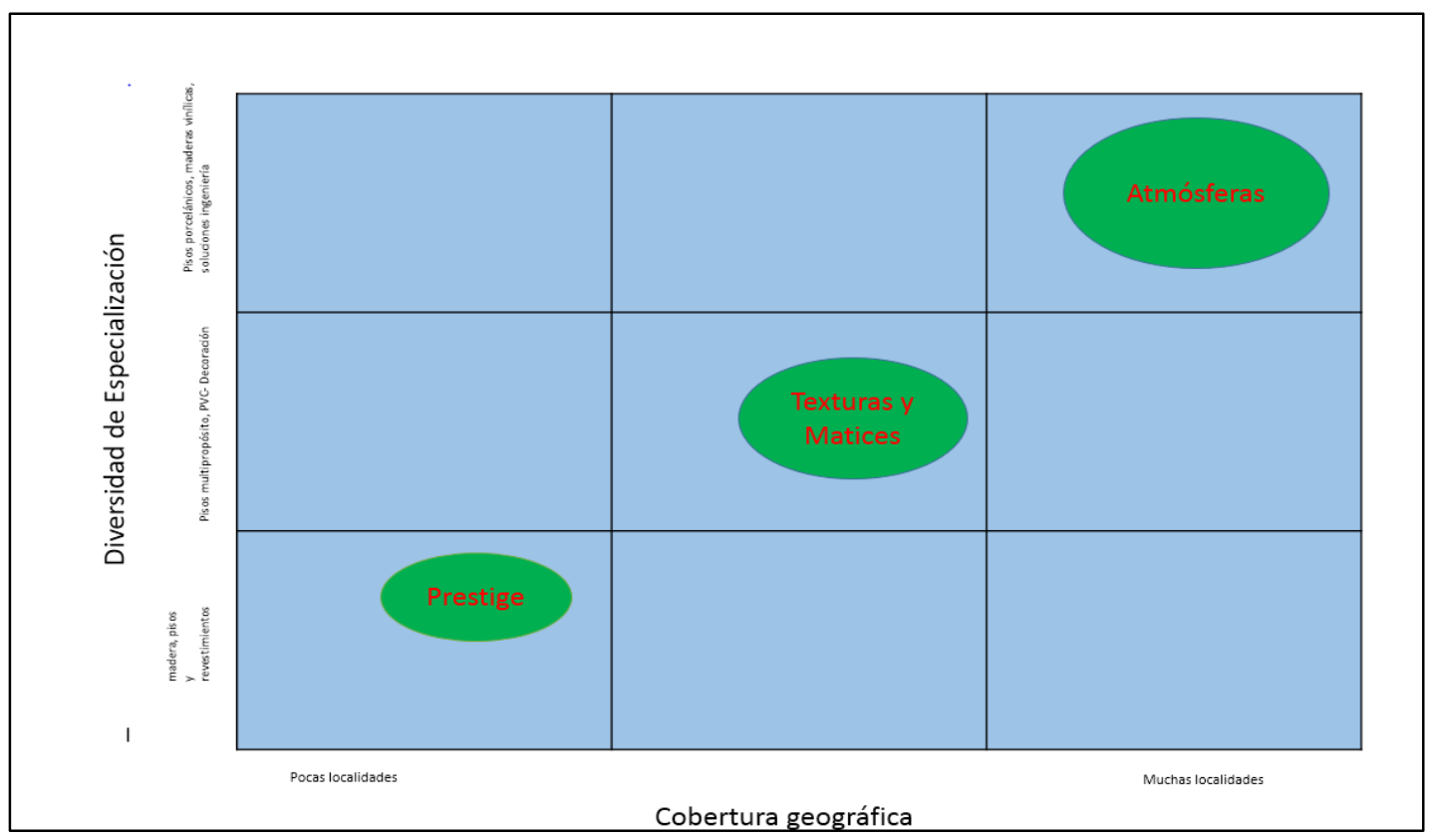

Figura 19. Mapa por grupos estratégicos competidores de Porcelanatos y Pisos. Elaboración propia

\section{5 ¿Qué movimientos estratégicos es probable que realicen los rivales?}

De acuerdo con los puntos analizados hasta el momento en este capítulo, la industria ofrece oportunidades atractivas de crecimiento y existen barreras para la entrada de nuevos competidores; los consumidores tienen una baja fuerza competitiva, se presenta una rivalidad moderada, pueden presentarse productos sustitutos para los porcelanatos y pisos y los proveedores tienen baja influencia en el mercado. También se identificaron factores que pueden promover el cambio en la industria, como son algunas técnicas y materiales empleados en la fabricación de los productos, la tecnificación de los hogares que puede demandar inversiones de parte de los compradores, las cuales pueden reducir la disponibilidad de recursos para la instalación de porcelanatos y pisos, la penetración de la telefonía con internet móvil que facilita la comercialización de los productos por medios digitales, el mercadeo relacional que implica un mayor acercamiento de las empresas con sus clientes mediante sistemas de almacenamiento de información en la nube y el big data. 
En ese escenario, es probable que las empresas rivales tienen las mismas oportunidades de la empresa Porcelanatos y Pisos de Colombia, por lo que puede preverse que algunas de ellas realicen los movimientos estratégicos que se enumeran a continuación:

- Aumento de los puntos de venta para atender la demanda creciente que se espera en los próximos años, de acuerdo con las cifras macroeconómicas de déficit de vivienda, aumento de la población y aumento del PIB per cápita.

- Generación de economías de escala que permitan la reducción de los precios unitarios, en la medida en que se logren negociar mayores volúmenes de compra con los proveedores.

- Integración vertical hacia atrás con el propósito de generar alianzas que permitan reducir los precios.

- Modernización de los procesos productivos para aplicar las novedades tecnológicas identificadas en la vigilancia tecnológica (numeral 0).

- Desarrollo de aplicaciones móviles para que los clientes puedan consultar sus catálogos de productos y realizar compras y/o cotizaciones por medios electrónicos.

- Desarrollo de estrategias para la reducción del impacto ambiental de los procesos de producción y comercialización, con el fin de adaptarse a las normas ambientales cada vez más exigentes.

- Diseño de estrategias de mercadeo basadas en el manejo de big data para una mejor selección de los nichos de mercado, con el apoyo de campañas basadas en redes sociales.

\section{6 ¿Cuáles son los factores clave para el éxito futuro competitivo?}

Teniendo en cuenta el análisis adelantado, se puede señalar que los factores claves para el 
éxito competitivo de la empresa son:

- Permanente actualización en el diseño de los productos, para que los clientes encuentren en la empresa opciones acordes con las tendencias de moda. Este factor implica estar conociendo con frecuencia los lanzamientos en eventos como ferias internacionales y nacionales de productos, equipos y materiales.

- Razonabilidad de los precios, teniendo en cuenta la existencia de competidores que pueden ofrecer productos sustitutos a costos competitivos.

- Localización de los puntos de venta en lugares cercanos a las zonas en donde se producen nuevos desarrollos inmobiliarios.

- Mercadeo especializado y dirigido tanto a empresas constructoras que son grandes compradores, como a clientes individuales que realizan productos de renovación de acabados en inmuebles o construcción de viviendas particulares.

- Tecnificación de los canales de venta, empleando medios electrónicos.

- Difusión de los esfuerzos que hace la empresa para la protección del medio ambiente, tanto en la producción como en la comercialización de sus productos.

Con base en las anteriores seis respuestas, para concluir esta parte se puede responder a la pregunta planteada al comienzo de este capítulo afirmando que la industria de la construcción sí ofrece una perspectiva de utilidades atractivas para una empresa como Porcelanatos y Pisos de Colombia S.A.S. 


\section{Objetivo 2}

Con este objetivo se busca responder a las siguientes preguntas:

1) ¿Qué tan bien funciona la estrategia actual de la empresa?

2) ¿Cuáles son los recursos y capacidades con mayor importancia competitiva de la empresa?

3) ¿Es capaz la empresa de aprovechar las oportunidades que le ofrece el mercado y superar las amenazas externas a su bienestar externo?

4) ¿Los precios y costos de la empresa son competitivos respecto de los rivales clave y tiene una propuesta de valor atractiva para el cliente?

5) ¿Competitivamente la empresa es más fuerte o más débil que sus principales rivales?

6) ¿Qué asuntos y problemas estratégicos merecen la mayor atención por parte de la administración?

Con ese propósito se construyen las matrices correspondientes, de acuerdo con Thompson et al (2012) 
Tabla 7. Matriz FODA Porcelanatos y Pisos de Colombia S.A.S.

\begin{tabular}{|c|c|c|}
\hline Factores externos & $\begin{array}{l}\text { Fortalezas-F } \\
\text { - Bodegas propias para almacenamiento } \\
\text { - Infraestructura de transporte propia } \\
\text { - Bajos costos de almacenamiento } \\
\text { - Disponibilidad de flujo de caja } \\
\text { - Sistema de control de operaciones }\end{array}$ & $\begin{array}{l}\text { Debilidades-D } \\
\text { - Bajo posicionamiento en el } \\
\text { mercado genera déficit de confianza } \\
\text { - Deficiencias en delegación por } \\
\text { fallas de autoridad en ciertos } \\
\text { mandos } \\
\text { - Gestión de marketing débil } \\
\text { - Políticas de bienestar del personal } \\
\text { son débiles } \\
\text { - Vacíos en procesos de formación de } \\
\text { personal }\end{array}$ \\
\hline $\begin{array}{l}\text { Oportunidades-O } \\
\text { - Ofrecer a los clientes diferenciación } \\
\text { en los servicios frente a la } \\
\text { competencia } \\
\text { - Marketing digital basado en redes } \\
\text { sociales } \\
\text { - Crecimiento de la industria de la } \\
\text { construcción (vivienda y comercial) } \\
\text { - Integración vertical hacia atrás }\end{array}$ & $\begin{array}{l}\text { Estrategias - FO } \\
\text { - Creación de stock cuando las } \\
\text { condiciones del mercado lo recomienden } \\
\text { - Marketing resaltando el beneficio del } \\
\text { transporte incluido o a bajo costo } \\
\text { - Atención a proyectos de construcción } \\
\text { que requieran grandes cantidades de } \\
\text { productos } \\
\text { - Marketing basado en redes sociales para } \\
\text { mejorar efectividad de campañas }\end{array}$ & $\begin{array}{l}\text { Estrategias - DO } \\
\text { - Ofrecer garantía ampliada de } \\
\text { productos para compensar déficit de } \\
\text { confianza } \\
\text { - Capacitar a los niveles intermedios } \\
\text { en toma de decisiones y control de } \\
\text { equipos de trabajo } \\
\text { - Creación de políticas de incentivos } \\
\text { por resultados para mejorar } \\
\text { ambiente laboral } \\
\text { - Diseñar programas de carrera de los } \\
\text { empleados con incentivos en } \\
\text { educación }\end{array}$ \\
\hline $\begin{array}{l}\text { Amenazas-A } \\
\text { - Contracción de la demanda interna } \\
\text { por estancamiento del PIB y empleo } \\
\text { - Reducción de consumo de bienes y } \\
\text { servicios no básicos } \\
\text { - Incremento de importaciones de la } \\
\text { competencia } \\
\text { - Efectos negativos de la tasa de } \\
\text { cambios que puedan beneficiar a la } \\
\text { competencia }\end{array}$ & $\begin{array}{l}\text { Estrategias - FA } \\
\text { - Ofrecer condiciones de precio estable } \\
\text { para distribuidores aprovechando } \\
\text { capacidad de almacenamiento y } \\
\text { disponibilidad de flujo de caja } \\
\text { - Ampliar la red de distribución propia } \\
\text { para generar economías de escala } \\
\text { - Diferenciar el canal de grandes } \\
\text { constructores y el de remodelaciones y } \\
\text { proyectos pequeños en hogares }\end{array}$ & $\begin{array}{l}\text { Estrategias - DA } \\
\text { - Fortalecer el nivel académico de } \\
\text { mandos medios mediante programa } \\
\text { de incentivos } \\
\text { - Establecer estrategia de marketing } \\
\text { según perfiles de clientes } \\
\text { - Premiar a los clientes que refieran a } \\
\text { otros compradores }\end{array}$ \\
\hline
\end{tabular}

Nota: elaboración propia

Tabla 8. Matriz de Evaluación de Factores Externos MEFE

\begin{tabular}{|c|c|c|c|}
\hline $\begin{array}{c}\text { Factor externo clave } \\
\text { Oportunidades }\end{array}$ & Ponderación & Calificación & Valor \\
\hline $\begin{array}{l}\text { Ofrecer a los clientes diferenciación en los servicios frente a la } \\
\text { competencia }\end{array}$ & $10 \%$ & 3 & 0.30 \\
\hline Marketing digital basado en redes sociales & $20 \%$ & 4 & 0.80 \\
\hline Crecimiento de la industria de la construcción (vivienda y comercial) & $15 \%$ & 4 & 0.60 \\
\hline Integración vertical hacia atrás & $5 \%$ & 4 & 0.20 \\
\hline Amenazas & Ponderación & Calificación & Valor \\
\hline $\begin{array}{l}\text { Contracción de la demanda interna por estancamiento del PIB y } \\
\text { empleo }\end{array}$ & $10 \%$ & 1 & 0.10 \\
\hline Reducción de consumo de bienes y servicios no básicos & $20 \%$ & 1 & 0.20 \\
\hline Incremento de importaciones de la competencia & $10 \%$ & 2 & 0.20 \\
\hline $\begin{array}{l}\text { Efectos negativos de la tasa de cambios que puedan beneficiar a la } \\
\text { competencia }\end{array}$ & $10 \%$ & 2 & 0.20 \\
\hline Totales & $100 \%$ & & 2.60 \\
\hline
\end{tabular}

Nota: elaboración propia 
Este resultado indica que los factores externos vistos de manera global ubican a la empresa en un nivel de competitividad medio alto.

Tabla 9. Matriz de Evaluación de Factores Internos MEFI

\begin{tabular}{|c|c|c|c|}
\hline $\begin{array}{c}\text { Factor interno clave } \\
\text { Fortalezas }\end{array}$ & Ponderación & Calificación & Valor \\
\hline Bodegas propias para almacenamiento & $20 \%$ & 4 & 0.80 \\
\hline Infraestructura de transporte propia & $10 \%$ & 4 & 0.40 \\
\hline Bajos costos de almacenamiento & $10 \%$ & 3 & 0.30 \\
\hline Disponibilidad de flujo de caja & $8 \%$ & 3 & 0.24 \\
\hline Sistema de control de operaciones & $12 \%$ & 4 & 0.48 \\
\hline Debilidades & Ponderación & Calificación & Valor \\
\hline Bajo posicionamiento en el mercado genera déficit de confianza & $10 \%$ & 1 & 0.10 \\
\hline Deficiencias en delegación por fallas de autoridad en ciertos mandos & $8 \%$ & 2 & 0.16 \\
\hline Gestión de marketing débil & $10 \%$ & 1 & 0.10 \\
\hline Políticas de bienestar del personal son débiles & $7 \%$ & 2 & 0.14 \\
\hline Vacíos en procesos de formación de personal & $5 \%$ & 1 & 0.05 \\
\hline Totales & $100 \%$ & & 2.77 \\
\hline
\end{tabular}

Nota: elaboración propia

Este resultado muestra que el nivel de competitividad que generan los factores internos de la empresa es aún más alto que la generan sus factores externos (2.77 frente a 2.60).

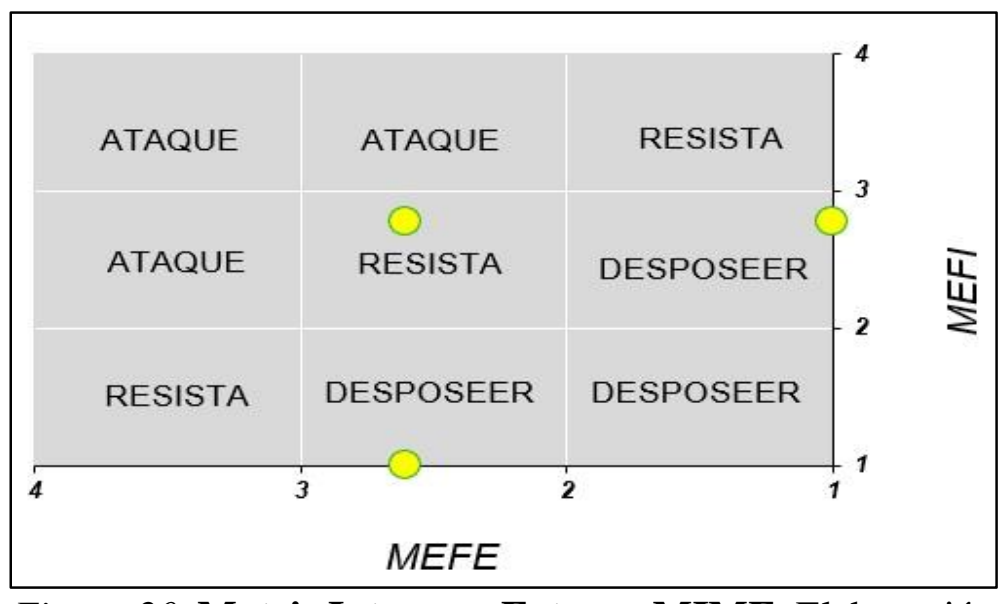

Figura 20. Matriz Interna y Externa MIME. Elaboración propia

Se puede ver en la figura 20 que la empresa se ubica en una posición que le permite resistir a sus competidores. Lo anterior debido a que tanto los factores internos como los externos generan niveles de competitividad de nivel medio alto, como se mostró previamente.

La matriz de posición estratégica y evaluación de acción PEYEA que se muestra en la figura 
21 a continuación, confirma que la empresa está en posibilidad de resistir la competencia e inclusive de ser medianamente agresivos.

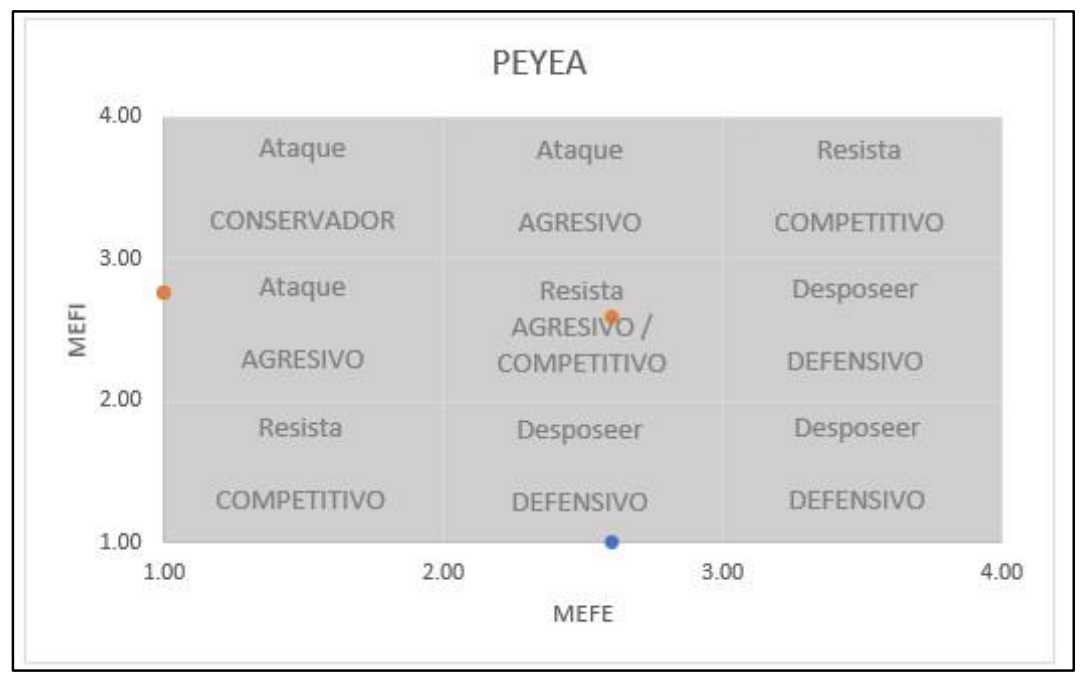

Figura 21. Matriz de Posición Estratégica y Evaluación de Acción - PEYEA. Elaboración propia 
Tabla 10. Matriz de Perfil Competitivo MCP

\begin{tabular}{|c|c|c|c|c|c|c|c|c|c|}
\hline \multirow[t]{2}{*}{$\begin{array}{l}\text { Factores claves de } \\
\text { éxito }\end{array}$} & \multirow[t]{2}{*}{ Ponderación } & \multicolumn{2}{|c|}{$\begin{array}{c}\text { Porcelanatos y Pisos de } \\
\text { Colombia }\end{array}$} & \multicolumn{2}{|c|}{ Prestige } & \multicolumn{2}{|c|}{ Texturas y Matices } & \multicolumn{2}{|c|}{ Atmósferas } \\
\hline & & Calificación & Ponderación & Calificación & Ponderación & Calificación & Ponderación & Calificación & Ponderación \\
\hline $\begin{array}{l}\text { Permanente } \\
\text { actualización en el } \\
\text { diseño de los } \\
\text { productos }\end{array}$ & $30 \%$ & - & 0.9 & (5) & 0.9 & 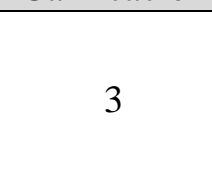 & 0.9 & - & 1.2 \\
\hline $\begin{array}{l}\text { Razonabilidad de } \\
\text { los precios }\end{array}$ & $20 \%$ & 4 & 0.8 & 4 & 0.8 & 4 & 0.8 & 3 & 0.6 \\
\hline $\begin{array}{l}\text { Puntos de venta en } \\
\text { lugares cercanos a } \\
\text { las zonas en donde } \\
\text { se producen nuevos } \\
\text { desarrollos } \\
\text { inmobiliarios. }\end{array}$ & $15 \%$ & 2 & 0.3 & 3 & 0.45 & 3 & 0.45 & 4 & 0.6 \\
\hline $\begin{array}{l}\text { Mercadeo } \\
\text { especializado según } \\
\text { nichos }\end{array}$ & $15 \%$ & 2 & 0.3 & 2 & 0.3 & 3 & 0.45 & 3 & 0.45 \\
\hline $\begin{array}{l}\text { Tecnificación de } \\
\text { los canales de } \\
\text { venta, empleando } \\
\text { medios } \\
\text { electrónicos. }\end{array}$ & $10 \%$ & 2 & 0.2 & 2 & 0.2 & 3 & 0.3 & 2 & 0.2 \\
\hline $\begin{array}{l}\text { Protección del } \\
\text { medio ambiente }\end{array}$ & $10 \%$ & 3 & 0.3 & 3 & 0.3 & 2 & 0.2 & 2 & 0.2 \\
\hline Total & $100 \%$ & & 2.8 & & 2.95 & & 3.1 & & 3.25 \\
\hline
\end{tabular}

Nota: elaboración propia

Al graficar los resultados de la matriz MCP, se obtiene la figura 22 


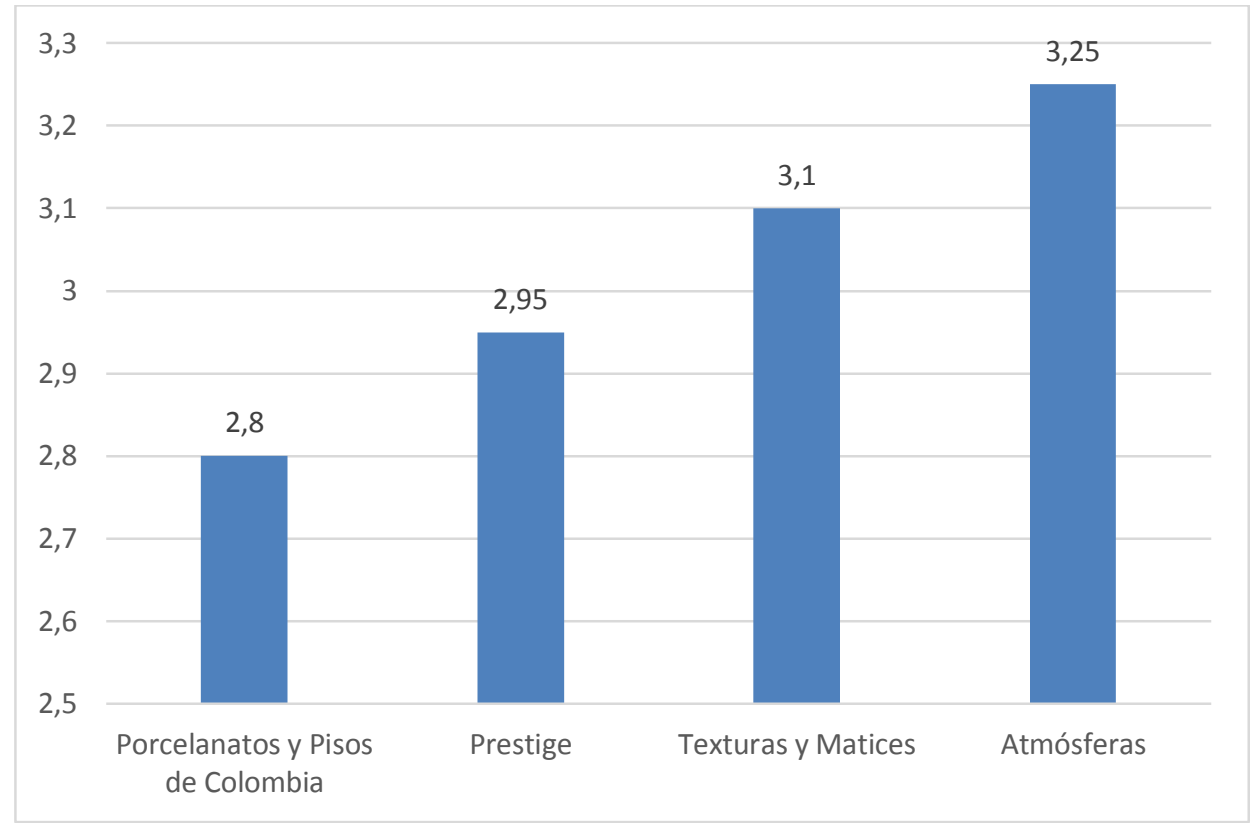

Figura 22. Comparación de perfiles competitivos. Elaboración propia 
Tabla 11. Matriz Cuantitativa de la Planificación Estratégica MCPE

\begin{tabular}{|c|c|c|c|c|c|c|c|c|c|c|c|c|c|c|c|c|c|c|c|c|c|c|c|c|c|c|c|c|c|c|}
\hline \multirow[b]{3}{*}{ Oportunidades } & \multirow[b]{3}{*}{ Ponderación } & \multicolumn{29}{|c|}{ Estrategias } \\
\hline & & \multicolumn{2}{|c|}{1} & \multicolumn{2}{|c|}{2} & \multicolumn{2}{|c|}{3} & \multicolumn{2}{|c|}{4} & \multicolumn{2}{|c|}{5} & \multicolumn{2}{|c|}{6} & \multicolumn{2}{|c|}{7} & \multicolumn{2}{|c|}{8} & \multicolumn{3}{|c|}{9} & \multicolumn{2}{|c|}{10} & \multicolumn{2}{|c|}{11} & \multicolumn{2}{|c|}{12} & \multicolumn{2}{|c|}{13} & \multicolumn{2}{|c|}{14} \\
\hline & & $\mathrm{CA}$ & TCA & CA & TCA & CA & TCA & CA & TCA & $\mathrm{CA}$ & $\mathrm{TCA}$ & $\mathrm{CA}$ & TCA & CA & TCA & $\mathrm{CA}$ & \begin{tabular}{|lc}
$\mathrm{TC}$ \\
\end{tabular} & & & TCA & $\mathrm{CA}$ & \begin{tabular}{|l} 
TCA \\
\end{tabular} & $\mathrm{CA}$ & TCA & $\mathrm{CA}$ & TCA & $\mathrm{CA}$ & TCA & $\mathrm{CA}$ & TCA \\
\hline $\begin{array}{l}\text { Ofrecer a los clientes diferenciación } \\
\text { en los servicios frente a la } \\
\text { competencia }\end{array}$ & $5 \%$ & 4 & 0.20 & 4 & 0.20 & 3 & 0.15 & 3 & 0.15 & 3 & 0.15 & 3 & 0.15 & 4 & 0.20 & 2 & 0. & & & 0.15 & 4 & 0.20 & 3 & 0.15 & 3 & 0.15 & 2 & 0.10 & 2 & 0.10 \\
\hline $\begin{array}{l}\text { Marketing digital basado en redes } \\
\text { sociales }\end{array}$ & $10 \%$ & 3 & 0.30 & 2 & 0.20 & 3 & 0.30 & 4 & 0.40 & 3 & 0.30 & 2 & 0.20 & 4 & 0.40 & 2 & 0.2 & & & 0.30 & 4 & 0.40 & 3 & 0.30 & 3 & 0.30 & 2 & 0.20 & 2 & 0.20 \\
\hline $\begin{array}{l}\text { Crecimiento de la industria de la } \\
\text { construcción (vivienda y comercial) }\end{array}$ & $8 \%$ & 3 & 0.23 & 2 & 0.15 & 3 & 0.23 & 3 & 0.23 & 3 & 0.23 & 3 & 0.23 & 3 & 0.23 & 2 & 0. & & & 0.23 & 3 & 0.23 & 3 & 0.23 & 3 & 0.23 & 3 & 0.23 & 2 & 0.15 \\
\hline Integración vertical hacia atrás & $3 \%$ & 3 & 0.08 & 2 & 0.05 & 3 & 0.08 & 2 & 0.05 & 2 & 0.05 & 3 & 0.08 & 2 & 0.05 & 2 & 0. & & c & 0.08 & 2 & 0.05 & 2 & 0.05 & 3 & 0.08 & 3 & 0.08 & 2 & 0.05 \\
\hline \multicolumn{31}{|l|}{ Amenazas } \\
\hline $\begin{array}{l}\text { Contracción de la demanda interna } \\
\text { por estancamiento del PIB y empleo }\end{array}$ & $5 \%$ & 2 & 0.10 & 2 & 0.10 & 3 & 0.15 & 3 & 0.15 & 3 & 0.15 & 3 & 0.15 & 2 & 0.10 & 2 & 0. & & & 0.15 & 3 & 0.15 & 2 & 0.10 & 3 & 0.15 & 3 & 0.15 & 3 & 0.15 \\
\hline $\begin{array}{l}\text { Reducción de consumo de bienes y } \\
\text { servicios no básicos }\end{array}$ & $10 \%$ & 2 & 0.20 & 3 & 0.30 & 3 & 0.30 & 3 & 0.30 & 3 & 0.30 & 3 & 0.30 & 2 & 0.20 & 2 & 0. & & & 0.30 & 3 & 0.30 & 3 & 0.30 & 3 & 0.30 & 3 & 0.30 & 2 & 0.20 \\
\hline $\begin{array}{l}\text { Incremento de importaciones de la } \\
\text { competencia }\end{array}$ & $5 \%$ & 2 & 0.10 & 3 & 0.15 & 3 & 0.15 & 3 & 0.15 & 3 & 0.15 & 3 & 0.15 & 3 & 0.15 & 2 & 0. & & & 0.15 & 2 & 0.10 & 3 & 0.15 & 3 & 0.15 & 3 & 0.15 & 3 & 0.15 \\
\hline $\begin{array}{l}\text { Efectos negativos de la tasa de } \\
\text { cambios que puedan beneficiar a la } \\
\text { competencia }\end{array}$ & $5 \%$ & 4 & 0.20 & 2 & 0.10 & 3 & 0.15 & 3 & 0.15 & 3 & 0.15 & 3 & 0.15 & 2 & 0.10 & 2 & 0. & & & 0.15 & 2 & 0.10 & 3 & 0.15 & 3 & 0.15 & 3 & 0.15 & 2 & 0.10 \\
\hline \multicolumn{31}{|l|}{ Fortalezas } \\
\hline $\begin{array}{l}\text { Bodegas propias para } \\
\text { almacenamiento }\end{array}$ & $10 \%$ & 4 & 0.40 & 3 & 0.30 & 4 & 0.40 & 3 & 0.30 & 3 & 0.30 & 3 & 0.30 & 4 & 0.4 & 2 & 0. & & & 0.30 & 3 & 0.30 & 2 & 0.20 & 3 & 0.30 & 2 & 0.20 & 2 & 0.20 \\
\hline Infraestructura de transporte propia & $5 \%$ & 3 & 0.15 & 4 & 0.20 & 4 & 0.20 & 3 & 0.15 & 3 & 0.15 & 3 & 0.15 & 4 & 0.2 & 2 & 0. & & & 0.15 & 3 & 0.15 & 2 & 0.10 & 3 & 0.15 & 2 & 0.10 & 2 & 0.10 \\
\hline Bajos costos de almacenamiento & $5 \%$ & 4 & 0.20 & 4 & 0.20 & 4 & 0.20 & 3 & 0.15 & 3 & 0.15 & 4 & 0.20 & 4 & 0.21 & 2 & 0. & & c & 0.15 & 3 & 0.15 & 2 & 0.10 & 3 & 0.15 & 2 & 0.10 & 2 & 0.10 \\
\hline Disponibilidad de flujo de caja & $4 \%$ & 4 & 0.16 & 4 & 0.16 & 4 & 0.16 & 3 & 0.12 & 4 & 0.16 & 4 & 0.16 & 4 & 0.1 & 2 & 0. & & c & 0.12 & 3 & 0.12 & 3 & 0.12 & 3 & 0.12 & 3 & 0.12 & 2 & 0.08 \\
\hline Sistema de control de operaciones & $6 \%$ & 3 & 0.18 & 4 & 0.24 & 4 & 0.24 & 3 & 0.18 & 3 & 0.18 & 3 & 0.18 & 3 & 0.18 & 2 & 0. & & c & 0.18 & 3 & 0.18 & 2 & 0.12 & 3 & 0.18 & 2 & 0.12 & 2 & 0.12 \\
\hline \multicolumn{31}{|l|}{ Debilidades } \\
\hline $\begin{array}{l}\text { Bajo posicionamiento en el mercado } \\
\text { genera déficit de confianza }\end{array}$ & $5 \%$ & 3 & 0.15 & 3 & 0.15 & 4 & 0.20 & 2 & 0.10 & 3 & 0.15 & 3 & 0.15 & 3 & 0.1 & 2 & & & 3 & 0.15 & 3 & 0.15 & 4 & 0.20 & 3 & 0.15 & 3 & 0.15 & 3 & 0.15 \\
\hline $\begin{array}{l}\text { Deficiencias en delegación por fallas } \\
\text { de autoridad en ciertos mandos }\end{array}$ & $4 \%$ & 1 & 0.04 & 1 & 0.04 & 1 & 0.04 & 1 & 0.04 & 1 & 0.04 & 1 & 0.04 & 1 & 0.0 & 4 & 0. & & 3 & 0.12 & 1 & 0.04 & 1 & 0.04 & 3 & 0.12 & 4 & 0.16 & 3 & 0.12 \\
\hline Gestión de marketing débil & $5 \%$ & 2 & 0.10 & 1 & 0.05 & 3 & 0.15 & 4 & 0.20 & 3 & 0.15 & 2 & 0.10 & 2 & 0.11 & 4 & 0. & & 3 & 0.15 & 3 & 0.15 & 4 & 0.20 & 3 & 0.15 & 4 & 0.20 & 3 & 0.15 \\
\hline $\begin{array}{l}\text { Políticas de bienestar del personal son } \\
\text { débiles }\end{array}$ & $4 \%$ & 1 & 0.04 & 1 & 0.04 & 1 & 0.04 & 1 & 0.04 & 1 & 0.04 & 1 & 0.04 & 1 & 0.0 & 4 & 0. & & 3 & 0.11 & 1 & 0.04 & 1 & 0.04 & 3 & 0.11 & 4 & 0.14 & 3 & 0.11 \\
\hline $\begin{array}{l}\text { Vacíos en procesos de formación de } \\
\text { personal }\end{array}$ & $3 \%$ & 1 & 0.03 & 1 & 0.03 & 1 & 0.03 & 1 & 0.03 & 1 & 0.03 & 1 & 0.03 & 1 & 0.0 & 4 & 0. & & 3 & 0.08 & 1 & 0.03 & 1 & 0.03 & 3 & 0.08 & 4 & 0.10 & 3 & 0.08 \\
\hline Totales & $100 \%$ & & 2.84 & & 2.65 & & 3.15 & & 2.88 & & 2.82 & & 2.74 & & 2.92 & & 2. & & & 3.00 & & 2.83 & & 2.57 & & 3.00 & & 2.74 & & 2.30 \\
\hline
\end{tabular}

Nota: elaboración propia 
En esta matriz, las estrategias fueron identificadas mediante un número consecutivo de 1 a 14. En la

tabla 14 , se resumen los resultados de la matriz MCPE.

Tabla 12. Puntuación de las estrategias, de acuerdo con la Matriz Cuantitativa de la Planificación Estratégica MCPE

\begin{tabular}{|l|c|c|}
\hline \multicolumn{1}{|c|}{ Estrategias } & Número & Puntaje \\
\hline Estrategias - FO & & \\
\hline Creación de stock cuando las condiciones del mercado lo recomienden & 1 & 2.84 \\
\hline Marketing resaltando el beneficio del transporte incluido o a bajo costo & 2 & 2.65 \\
\hline Atención a proyectos de construcción que requieran grandes cantidades de productos & 3 & 3.15 \\
\hline Marketing basado en redes sociales para mejorar efectividad de campañas & 4 & 2.88 \\
\hline Estrategias - FA & & \\
\hline $\begin{array}{l}\text { Ofrecer condiciones de precio estable para distribuidores aprovechando capacidad de } \\
\text { almacenamiento y disponibilidad de flujo de caja }\end{array}$ & 5 & 2.82 \\
\hline Ampliar la red de distribución propia para generar economías de escala & 6 & 2.74 \\
\hline $\begin{array}{l}\text { Diferenciar el canal de grandes constructores y el de remodelaciones y proyectos pequeños } \\
\text { en hogares }\end{array}$ & 7 & 2.92 \\
\hline Estrategias - DA & & \\
\hline Fortalecer el nivel académico de mandos medios mediante programa de incentivos & 8 & 2.30 \\
\hline Establecer estrategia de marketing según perfiles de clientes & 9 & 3.00 \\
\hline Premiar a los clientes que refieran a otros compradores & 10 & 2.83 \\
\hline Estrategias - DO & & \\
\hline Ofrecer garantía ampliada de productos para compensar déficit de confianza & 11 & 2.57 \\
\hline Capacitar a los niveles intermedios en toma de decisiones y control de equipos de trabajo & 12 & 3.00 \\
\hline Creación de políticas de incentivos por resultados para mejorar ambiente laboral & 13 & 2.74 \\
\hline Diseñar programas de carrera de los empleados con incentivos en educación & 14 & 2.30 \\
\hline
\end{tabular}

Nota: elaboración propia

Por último, con el fin de priorizar las estrategias, en la Tabla 15 se presentan todas, en orden

descendente de puntaje generado en la matriz MCPE.

Tabla 13. Prioridad de las estrategias según la matriz MCPE

\begin{tabular}{|l|c|}
\hline \multicolumn{1}{|c|}{ Estrategias } & Puntaje \\
\hline Atención a proyectos de construcción que requieran grandes cantidades de productos & 3.15 \\
\hline Establecer estrategia de marketing según perfiles de clientes & 3.00 \\
\hline Capacitar a los niveles intermedios en toma de decisiones y control de equipos de trabajo & 3.00 \\
\hline Diferenciar el canal de grandes constructores y el de remodelaciones y proyectos pequeños en hogares & 2.92 \\
\hline Marketing basado en redes sociales para mejorar efectividad de campañas & 2.88 \\
\hline Creación de stock cuando las condiciones del mercado lo recomienden & 2.84 \\
\hline Premiar a los clientes que refieran a otros compradores & 2.83 \\
\hline $\begin{array}{l}\text { Ofrecer condiciones de precio estable para distribuidores aprovechando capacidad de almacenamiento y } \\
\text { disponibilidad de flujo de caja }\end{array}$ & 2.82 \\
\hline Ampliar la red de distribución propia para generar economías de escala & 2.74 \\
\hline Creación de políticas de incentivos por resultados para mejorar ambiente laboral & 2.74 \\
\hline Marketing resaltando el beneficio del transporte incluido o a bajo costo & 2.65 \\
\hline Ofrecer garantía ampliada de productos para compensar déficit de confianza & 2.57 \\
\hline Fortalecer el nivel académico de mandos medios mediante programa de incentivos & 2.30 \\
\hline Diseñar programas de carrera de los empleados con incentivos en educación & 2.30 \\
\hline
\end{tabular}

Nota: elaboración propia 
Puede apreciarse que las estrategias que mostraron mayor prioridad fueron la atención a proyectos de construcción que requieran grandes cantidades de productos, el establecimiento de estrategias de marketing según el perfil de los clientes, la capacitación de niveles intermedios de la organización en toma de decisiones y control de equipos de trabajo. Las dos primeras estrategias corresponden a un enfoque especializado de la empresa. Esta tabla 14 es la respuesta a la pregunta central de este segundo objetivo, es decir que son, en ese orden, los asuntos y problemas estratégicos merecen la mayor atención por parte de la administración. 


\section{Objetivo 3}

El tercer objetivo del trabajo consiste en definir alternativas estratégicas para la construcción de planes de acción que propicien el desarrollo competitivo sostenible de Porcelanatos y Pisos de Colombia S.A.S.

Las estrategias competitivas genéricas que puede poseer una industria, y que plantean Thompson et al, (2012), tienen que ver con las determinaciones de un planteamiento hecho por la administración para poder competir con éxito, los preceptos concretos que permitan satisfacer y agradar a los clientes, las acciones que adopten para contrarrestar a sus rivales, las posiciones que se tomen frente a las condiciones predispuestas en el mercado, la inventiva de ideas y proyectos que les permita robustecer su ubicación dentro del mercado y el tipo concreto de ventaja competitiva que busca alcanzar.

Al momento de establecer el tipo de estrategia competitiva a utilizar, intervienen dos factores primordiales para conseguir instaurar dicha estrategia. Según lo planteado por Thompson et al (2012), y teniendo en cuenta las características de la empresa Porcelanatos y Pisos de Colombia S.A.S., se utilizarán estrategias dirigidas (o de nicho de mercado) de diferenciación, ya que se busca analizar específicamente una reducida parte de compradores y buscar dominar a la competencia, brindando un producto que complazca los gustos concretos y requerimientos de quienes integran ese nicho, y que esos productos sean superiores a los que ofrece la competencia.

En la industria Porcelanatos y Pisos de Colombia S.A.S., las dos principales estrategias que requieren buscar unos planes de acción para el desarrollo competitivo son: prestar la atención a 
proyectos de construcción que requieran grandes cantidades de productos y el establecimiento de estrategias de marketing según el perfil de los clientes; para lo cual, dado que se van a utilizar estrategias dirigidas, se necesita dar aplicabilidad a las estrategias dirigidas de bajos costos, ya que estas están enfocadas a respaldar la ventaja competitiva, porque busca brindar al nicho de mercado escogido, un costo y un precio menores que los que pueden ofrecer los competidores. La estrategia dirigida de bajos costos, tiene que ver con el grupo de compradores que la compañía busca atraer, que es un pequeño grupo de compradores que realizan grandes volúmenes de compras.

Con relación a la estrategia de diferenciación dirigida, se busca respaldar una ventaja competitiva con aquel producto que sirva para satisfacer los deseos y predilecciones de un grupo reducido y concreto de compradores, el cual busca características singulares en el producto o capacidades de la industria de sobresalir sobre sus competidores en el mismo nicho de mercado. Uno de los atributos que tiene el hecho de enfocar los esfuerzos competitivos a un solo nicho de mercado, es que está enfocado a empresas pequeñas y medianas como en este caso para la empresa de Porcelanatos y Pisos de Colombia S.A.S.

La utilización beneficiosa de una estrategia dirigida de diferenciación, obedece a la presencia de un grupo de compradores que busquen características distintivas del producto, y de la capacidad que tiene la empresa de diferenciarse de sus competidores dentro del mismo nicho de mercado, el segmento objetivo se puede dar por su singularidad geográfica, por los atributos especiales de la mercancía que sean atractivos únicamente para el nicho de mercado, siendo Porcelanatos y Pisos de Colombia S.A.S una empresa pequeña que busca respaldar una ventaja competitiva con un producto creado para atraer las preferencias y requerimientos particulares de un grupo reducido y bien definido de compradores como lo son los clientes de Porcelanatos y Pisos de Colombia S.A.S. Esta estrategia se concentra en un pequeño segmento de compradores y se busca vencer a los 
competidores al brindar un producto que satisfaga los específicos gustos y requerimientos de los miembros en ese nicho, mejor que los que brinda la competencia. Al aplicar esta estrategia dirigida de diferenciación, fundamentalmente a la empresa Porcelanatos y Pisos de Colombia S.A.S., por ser una empresa pequeña tiene la ventaja de brindar productos personalizados, de forma creativa, innovadora y con mayor proximidad a sus clientes.

Con el fin de definir las bases sobre las cuales se cimentan los motivos por los cuales se implementa la estrategia competitiva en la empresa Porcelanatos y Pisos S.A.S., pudiendo beneficiarse de las ventajas que brinda seguir este tipo de estrategia, y que le permite competir de mejor forma dentro del mercado.

El nicho al cual están enfocados los productos de Porcelanatos y Pisos de Colombia S.A.S. es suficientemente amplio, provechoso y posibilita un enorme potencial de desarrollo.

Las empresas que están repuntando el sector de los porcelanatos, no estiman a Porcelanatos y Pisos de Colombia S.A.S. como una intimidación para lograr sus triunfos dentro del mercado, y por tal motivo, no tienen en cuenta las estrategias utilizadas por ellos para conseguir cierta cantidad de adeptos de su público meta.

Se considera bastante complicado hallar un entorno donde algún competidor use todas sus capacidades para saciar todos los requerimientos concretos del consumidor que simboliza su nicho de mercado, e igualmente, que puedan complacer todas las perspectivas de sus clientes más óptimos.

En la industria de los porcelanatos, existe una gran multiplicidad de público meta, posibilitando que una táctica se pueda poner en marcha a un nicho de mercado concreto y fundamentado en las capacidades con las que cuenta la empresa. Así mismo, cuando existe diversidad de nichos, también existirá un más elevado entorno de desenvolvimiento para aquellas 
entidades que cuentan con diferenciación dirigida, eludiendo de esta forma competencias entre estas empresas.

Es menos fuerte el abarrotamiento en el mercado de un mismo producto, cuando la competencia que se presente frente a un mismo segmento de mercado es también reducida.

Esta clase de empresas que aplican una estrategia dirigida, cuentan con una cantidad de clientes fieles a ellas, y a los que pueden dirigirse buscando limitar el aumento de factibles competidores que desean adueñarse del nicho de mercado que tiene la empresa como suyo.

La estrategia implantada por Porcelanatos y Pisos S.A.S. está enfocada a la diferenciación de sus productos buscando respaldar un producto que se creó concretamente para captar las predilecciones singulares de un segmento en el mercado, y que desea conseguir condiciones singulares del producto que quiere adquirir. Así mismo, la empresa Porcelanatos y Pisos de Colombia S.A.S., busca alcanzar la capacidad de producción, de atención al cliente y la distinción frente a sus competidores, que lo posicione como el único en su género.

Esta clase de estrategia está enfocada a compradores con particularidades singulares que busquen adquirir un producto con características singulares, que es aquello que desea conseguir Porcelanatos y Pisos de Colombia S.A.S. Todos estos aspectos encierran atributos con los que cuentan los productos que posee Porcelanatos y Pisos S.A.S., debido a que, en la variedad de mercados, existe un grupo de compradores que están determinados a cancelar más, por productos con una mejor calidad, lo que le genera a Porcelanatos y Pisos de Colombia S.A.S. una enorme ventaja competitiva, aspecto que puede generar grandes beneficios, buscando alcanzar ser los líderes en ese mercado.

Una ventaja competitiva que puede asegurar la empresa de Porcelanatos y Pisos de Colombia S.A.S., viene dada porque las empresas que están repuntando en este sector de los porcelanatos, 
no la estiman como riesgosa para su propio éxito, de tal forma que no existe una rivalidad directa contra determinados competidores más fuertes del sector, a causa de la experiencia que tienen los fundadores de Porcelanatos y Pisos de Colombia S.A.S. en dicha industria, que posibilitó identificar aquellos procesos o productos que no son tan relevantes en la industria, direccionando su atención a obtener utilidades sobre este aspecto.

Por lo tanto, Porcelanatos y Pisos de Colombia S.A.S. ofrece un proceso bastante distinto de los que poseen sus competidores más grandes, con el fin de no utilizar procesos que pueden no ser tan provechosos para la empresa.

La empresa direcciona toda su atención hacia una ventaja competitiva concreta, ya que es dificultoso que sus rivales le presenten atención a muchas de sus capacidades para poder cumplir con las necesidades específicas de los clientes que conforman el nicho de mercado meta, y que, a su vez, puedan cumplir con las perspectivas de sus clientes potenciales.

La industria del porcelanato posee diversos nichos, por lo tanto, Porcelanatos y Pisos de Colombia S.A.S. busca complementar con otros productos que conforman también la industria de la construcción, y que son esenciales al momento de la utilización de los productos principales ofrecidos por la compañía, buscando que se realicen también estrategias dirigidas que se apliquen a un nicho atractivo del mercado que esté acorde a las fortalezas de recursos y capacidades de la empresa. Cuando se presenta diversidad en los segmentos, existe mayor amplitud para que la empresa no compita ente sí al entrar en competencia por los mismos compradores. Bajo estas circunstancias, no van a existir muchos competidores que busquen prepararse dentro del mismo objetivo, minimizando el peligro de saturarlo.

La estrategia competitiva que utiliza Porcelanatos y Pisos de Colombia S.A.S. es la estrategia dirigida por diferenciación, bajo la cual cuenta con un cúmulo de clientes fieles, que se sienten 
satisfechos de sus requerimientos, clientes a los cuales puede dirigirse para apaciguar de forma temporal a los competidores que buscan ingresar en la industria, e igualmente, que buscan plagiar tanto sus procesos como sus productos. Esta clase de tácticas son bastante atrayentes, ya que consiguen que una entidad pueda ingresar en un nicho de mercado y atraiga a clientes de empresas que usan esta clase de estrategia.

Utilizar esta estrategia conlleva riesgos, como por ejemplo la factibilidad de que quienes son su competencia consigan la manera de equiparar capacidades de concentración de la entidad, así como de sus productos o elementos que fueron creados para captar a compradores de estos mercados, o que puedan generar habilidades que neutralicen las potencias que posee la empresa con estrategia dirigida.

También está el peligro de las permanentes transformaciones en los gustos y necesidades que tiene el nicho con el paso del tiempo, referente a las características del producto por los que se inclinan casi todos los compradores. O también el peligro de que el nicho de mercado consiga un gancho sugestivo que atraiga más competidores, lo que haría que se aumentara la competencia y se fraccionaran las utilidades. Por lo tanto, Porcelanatos y Pisos de Colombia S.A.S. busca prever los riesgos que se pueden presentar implementado estrategias que reduzcan estos efectos negativos y que puedan generar la salida de la compañía del mercado, como se observa en la ¡Error! No se encuentra el origen de la referencia. 23 a continuación. 


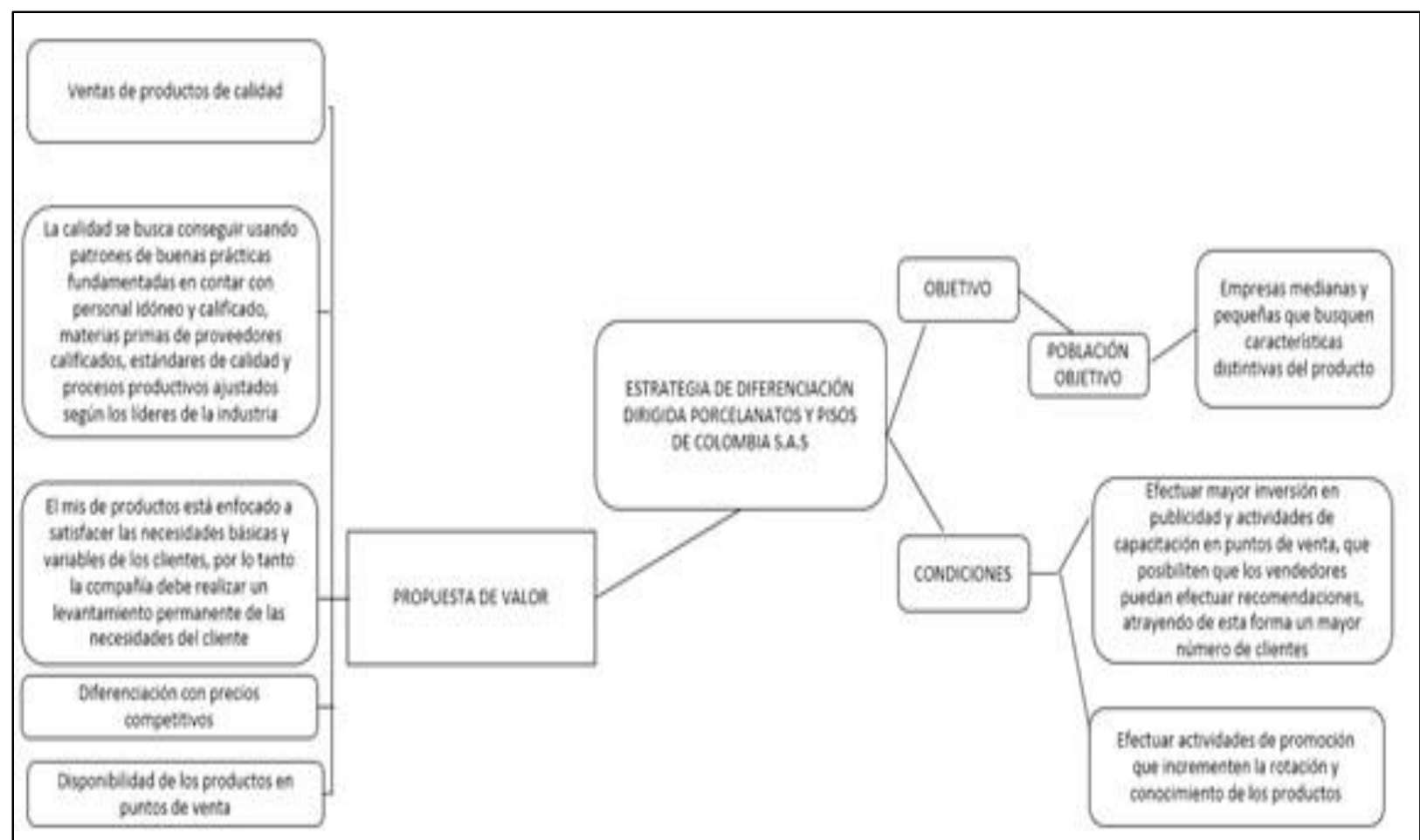

Figura 23. Estrategia de Diferenciación dirigida Porcelanatos y Pisos de Colombia S.A.S. Elaboración propia

Para poder definir las estrategias de marketing de acuerdo con el perfil de los clientes o poder prestar atención a los proyectos de construcción que requieran grandes cantidades de productos, se deben basar de igual manera, en tácticas que agrupen, conforme a lo señalado por David (2013); inicialmente la integración hacia atrás, ya que se requiere que los vendedores minoristas busquen surtirse del porcelanato y los pisos con los que cuenta la empresa Porcelanatos y Pisos de Colombia S.A.S. Con ello se busca incrementar el control que la empresa tiene sobre ellos, por lo cual dentro de los objetivos de marketing que debe proyectar la empresa, debe poner en marcha una estrategia de mayor penetración en el mercado para aumentar la participación de mercado de los productos y servicios por medio de una acentuación en los esfuerzos de marketing.

Una de las alternativas en estrategias que puede utilizar la empresa para mejorar sus esfuerzos en el marketing, es desarrollar el producto, buscando con ello incrementar su nivel de ventas. Para 
poner en marcha este plan de marketing, la empresa podría adquirir la diferenciación con sus competidores a través de la realización de asesorías personalizadas. De esta manera se puede agregar a sus servicios una diversificación que esté relacionada con lo que actualmente está trabajando, que son los pisos y porcelanatos de alta calidad, adicionándole servicios nuevos, pero que tienen que ver con la actividad en la cual se está desempeñando.

De esta manera la empresa no solo puede posicionarse como comercializadora de pisos y porcelanatos, sino que también puede ser una empresa de asesoría en diseños de ambientes, dependiendo de lo que requiera el cliente. Para el desarrollo de esta estrategia se requiere, que dentro del personal de la empresa existan diseñadores de interiores que conozcan el manejo de las obras de construcción o remodelación, con el fin de que pueda presentarle al cliente las posibilidades de diseños que requiere su ambiente, servicio de asesoría que será de primera calidad y especializada, realizada por profesionales que estén en capacidad de guiar al cliente en la escogencia de los productos óptimos para el ambiente deseado.

Otra acción que la empresa requiere es la de realizar publicidad masiva a través de las redes sociales, incorporarse dentro de las ferias de decoración que se presenten en la ciudad, la información de los productos en trípticos para ser entregados a los maestros de obras, arquitectos, ingenieros y demás personas del ramo.

También otros planes de marketing que se pueden implementar al interior de la empresa y que le generarán mayor posicionamiento a ésta, serán aquellos de promoción, la cual se debe efectuar a través del internet, a través de una página web propia que sea promovida a través de estrategias de segmentación a través de redes sociales como Facebook e Instagram que son las alternativas que tienen mayor aceptación por parte del público, y que le permitirán a la empresa racionalizar su inversión publicitaria y enfocarse en los segmentos de clientes que le interesan. 


\subsection{Plan de Comunicación}

8.1.1 Presencia en la web. Dentro de las estrategias de marketing que puede emplear Porcelanatos y Pisos de Colombia S.A.S., es elaborar un plan de comunicación que abarque inicialmente, el hecho de que la empresa debe crear una página web, por medio de la cual puedan los usuarios hallar toda la información requerida, y que le va a permitir tomar la decisión de compra. Dentro de esta página web debe estar todo el material que se utiliza en los folletos publicitarios que maneja la empresa, incluyendo también en dicha página, todas las imágenes de los productos, los lugares en donde hayan sido utilizados, alternativas de diseños, fotografías, así como de los canales de distribución, formas de pagos y de los servicios ofrecidos para el asesoramiento personalizado de los pequeños proyectos de construcción y remodelación.

Este sitio web, también debe contar con la opción de poder adquirir a través de la página los productos, es decir que en este sitio web se puedan llevar a cabo las transacciones de compra, contando con las opciones de los diversos medios de pago, teniendo en cuenta el objetivo previsto de mejorar el nivel de ventas. Esta característica implica que el sitio web debe realizar convenios con empresas del sector financiero, como bancos y operadores de tarjetas de crédito, para que el visitante pueda encontrar un enlace que le permita realizar el pago en línea de manera segura.

8.1.2 Otros medios BTL. ${ }^{2}$ Ya cuando la empresa de Porcelanatos y Pisos de Colombia S.A.S., cuente con el sitio web para uso de sus clientes, debe buscarse la manera de que los clientes potenciales hagan uso de este sitio web. Para ello, se incluirán banners en Facebook, puesto que a través de este medio se puede realizar la selección del público que puede acceder a cada anuncio,

\footnotetext{
${ }^{2}$ Hace referencia a los medios alternativos y especialmente a los electrónicos. Incluye publicidad novedosa por su formato, concepto, tecnología o combinación de espacio, modo y tiempo. Normalmente no incluye pauta en televisión, radio o prensa impresa. (Vega, Montiel, Rodríguez \& López, 2017)
} 
teniendo en cuenta las necesidades específicas de cada cliente. En cuanto a la cancelación por este servicio, se llevará a cabo en la página del anunciante, respaldados por los ingresos que realice el cliente al sitio web de la empresa. El costo por este servicio se verá reflejado en las visitas realizadas por los clientes, y en la eficacia de este servicio como mecanismo para realizar una venta. El contenido de los banners que se incluyan en el sitio Facebook permitirá asegurar que las personas que visiten la web de la empresa lo hagan porque están interesados en los productos y servicios de la empresa. En la página web de Porcelanatos y Pisos de Colombia S.A.S. se adicionarán videos, donde los usuarios puedan visualizar las características del servicio que se brinda.

8.1.3 Medios ATL. ${ }^{3}$ De igual manera, el plan de comunicación de la empresa debe abarcar los demás medios habituales, buscando generalizar su divulgación a través de estos medios, con el fin de que todos los usuarios ingresen y visiten el sitio web. Dentro de los medios que más uso se le dará para el plan de comunicación, será a través de revistas y secciones de periódicos en las áreas dedicadas a la construcción y remodelación.

La revista especializada en construcción de mayor circulación en el país es la revista Metrocuadrado, del Grupo Editorial El Tiempo, esta es la mejor opción para pautar a nivel nacional.

8.1.4 Otros elementos de la campaña. De igual forma, el plan de comunicación implementado por la empresa Porcelanatos y Pisos de Colombia S.A.S., debe incluir publicidad realizada en el exterior. Todos los elementos que se utilicen como imagen de la compañía, debe ser igual para todo el material utilizado dentro del plan de comunicación, por ende, la imagen de la empresa, debe estar bajo la misma presentación en todos los medios de publicidad usados, ya

\footnotetext{
${ }^{3}$ Hace referencia a los medios tradicionales de mercadeo, como prensa, radio, volantes, entre otros. (Salas,, 2018)
} 
sea en la página web, los medios ATL, la publicidad realizada en el exterior, y demás material usado.

\subsection{Zonificación Comercial}

Teniendo en cuenta que la ciudad de Bogotá es muy extensa, se recomienda que la gestión comercial se atienda de manera zonificada, de manera que los asesores se especialicen y se responsabilicen de la efectividad de esa gestión en determinados sectores. Comparada con otras ciudades, el tamaño de la capital del país por número de viviendas y por cantidad de habitantes y de proyectos de construcción equivale a varias ciudades intermedias del país, por lo que se debe buscar la máxima cobertura antes de pensar en atender sedes en otras ciudades, dado que de esta manera se racionalizan los costos de transporte y se facilita el control de la gestión, sin tener que recurrir a oficinas y costos fijos adicionales.

La asignación de zonas para la gestión comercial debe hacerse teniendo en cuenta tanto la extensión de cada zona, como el número de proyectos que se estén adelantando en cada zona. Lo anterior teniendo en cuenta que existen zonas de la ciudad en donde la construcción de proyectos nuevos de vivienda es la principal fuente de ventas para Porcelanatos y Pisos de Colombia, mientras que en otros sectores más antiguos la tendencia puede ser la de remodelaciones en viviendas construidas hace varios años; estas diferencias implican diferentes enfoques de la gestión comercial, diferentes potenciales de ventas, diferentes tipos de productos, necesidades diferentes en cuanto al asesoramiento personalizado, etc.

Dado que la empresa no cuenta con experiencia en esta estrategia, se recomienda que se vayan llevando estadísticas que puedan servir en el futuro cercano para la determinación de presupuestos 
por sectores, por tipo de clientes, etc., de manera que se pueda evaluar de manera más sustentada la efectividad de la gestión comercial de cada canal y de cada asesor comercial.

Esta estrategia de zonificación puede estar acompañada de estrategias de comunicación ATL, es decir, volantes, revistas especializadas y comunicación directa con los gerentes de proyectos de construcción y con pequeños constructores independientes para que reciban información de los productos y servicios de la empresa y para que sean invitados a ingresar al sitio web.

\subsection{Mejoramiento del servicio al cliente}

A diferencia de un producto defectuoso dentro de un lote de producción, el servicio tiene la característica de que se entrega en el mismo momento en que se produce, de manera que la mayoría de las acciones que se emprenden para mejorar el servicio en una empresa se deben hacer antes de que el cliente llegue para ser atendido. Porcelanatos y Pisos de Colombia debe aplicar una serie de indicadores de gestión, incluyendo un indicador del nivel de satisfacción de los clientes. Se pueden

y se deben establecer y evaluar permanentemente indicadores que contribuyan a que mejore el indicador que mide la satisfacción global de los clientes.

Dentro de los indicadores que se pueden adicionar y que inciden en la satisfacción de los clientes, existen unos que se relacionan con la satisfacción que sienten respecto del producto como tal, o sea los porcelanatos y los pisos que adquieren, así como existen otros que se relacionan específicamente con el servicio que reciben de la compañía. Dentro de estos últimos se encuentran:

- Tiempo de espera para recibir atención telefónica.

- Tiempo de espera para recibir atención personal (colas en el área de atención).

- Precisión de la información recibida.

- Rapidez en la resolución de inquietudes. 
- Trato recibido de los funcionarios.

- Calidad y comodidad de las instalaciones de servicio al cliente.

- Claridad sobre los procedimientos a seguir durante el proceso de compra.

- Calidad de la asesoría personalizada en el diseño de los espacios a remodelar.

Algunos de estos indicadores se pueden medir directamente por la empresa, como en el caso de los tiempos de espera; estos indicadores se deben medir de manera permanente, diaria, y debe haber alguien que dentro de sus responsabilidades tenga la evaluación del número de personas que están esperando a ser atendidas; también es importante evaluar el impacto de los cambios de procedimientos de la compañía en los tiempos de atención de los clientes.

Existen otros aspectos que no se pueden cambiar fácilmente o de manera permanente, como las instalaciones en las que se atiende a los clientes. En estos casos, debe procurarse que al momento de hacer diseños de estas áreas intervengan todas las personas de la empresa que tienen relación con estos procesos y muy especialmente quienes atienden directamente al cliente, pues son ellos quienes observan a diario lo que los clientes hacen mientras esperan ser atendidos y escuchan de manera directa sus comentarios sobre estos aspectos.

Por último, existen otros que solo los sabe el cliente, que son todos aquellos de carácter subjetivo, relativos a lo que ellos aprecian o perciben; en este caso deben emplearse instrumentos permanentes de medición, que pueden incluir encuestas impresas para diligenciamiento de cada cliente que visita las instalaciones de la empresa, como encuestas telefónicas que tienen el mismo objetivo.

Las mediciones deben procesarse de manera periódica, siendo la evaluación mensual la más recomendada; para cada una de esas mediciones debe establecerse un estándar; por ejemplo, un teléfono no debe repicar más de 2 veces antes de ser contestado o un cliente no debe esperar más de 10 minutos antes de ser atendido. En otras variables lo que debe medirse en la evolución mes a 
mes; por ejemplo, si en promedio en el mes de mayo los clientes en un $92 \%$ manifestaron que recibieron un trato adecuado, la meta para el mes siguiente debe ser del 92,5 o 93\% y así con todas las demás.

Los resultados de estas mediciones deben ser conocidos por todas las personas que de manera directa o indirecta inciden en su logro. En algunas organizaciones, dentro del contrato laboral se establecen salarios variables para reconocer bonificaciones económicas condicionadas al logro de estos objetivos.

\subsection{Diversidad de Portafolios}

Teniendo en cuenta que se busca diversificar los productos con los que cuenta la empresa de Porcelanatos y Pisos de Colombia S.A.S., se recomienda el énfasis en diseños enfocados a los baños y cocinas, con diversidad de colores y tamaños, e igualmente un portafolio de diseños dirigidos a los niños, de acuerdo con sus gustos actualizados.

También es importante conocer el presupuesto que cada cliente desea invertir en su proyecto de remodelación y construcción y específicamente en los productos de la empresa; con ese propósito, se le puede preguntar al cliente si tiene establecido ese presupuesto, o cuál es el uso que le piensa dar al espacio que desea remodelar. La experiencia indica que es diferente la inversión que se hace en un inmueble que va a ser habitado por el propietario directamente, que si se trata de un inmueble para arrendar (Alvis \& Ochoa, 2016), por lo que el uso del inmueble debe tenerse en cuenta al momento de diseñar los espacios, los materiales, la calidad de los acabados, y en general todos los aspectos relacionados con los productos y servicios que brinda la empresa. 


\subsection{Sistema de indicadores que definen la medición del cumplimiento de las metas}

Con el propósito de que la empresa cuente con un punto de referencia que permita evaluar el nivel de cumplimiento de cada proyecto y estrategia, en la tabla 14 se presenta a manera de ejemplo, el objetivo mensual a alcanzar por cada uno de esos indicadores, así:

- Cumplimiento de la utilidad neta: el propósito es lograr que el nivel de utilidad neta de la empresa se mantenga en el nivel en que estuvo el año anterior.

- Cumplimiento del cronograma de creación del departamento comercial zonificado: se busca que el departamento comercial esté completo (100\%) en el mes 12, por lo cual debe tener un crecimiento del $10 \%$ cada mes a partir del mes 2 .

- Cumplimiento presupuesto de ingresos: Si bien el presupuesto de ventas será creciente mes a mes, el indicador correspondiente es que se cumpla cada mes el $100 \%$ del presupuesto correspondiente.

- Cumplimiento presupuesto de inversiones en tecnología: se busca que el presupuesto de inversiones en tecnología se complete (100\%) en el mes 12; teniendo en cuenta el período de tiempo definido para su ejecución, se toma un avance mensual de $20 \%$ y el primer mes se deja como de planeación de la meta.

- Reducción de los tiempos de producción: se estima que se logre una reducción total de $25 \%$ en el último, lo que equivale a $5 \%$ mensual.

- Reducción de los costos de producción: se establece como meta una reducción de costos en el $25 \%$, o sea una reducción mensual de $5 \%$. 
Tabla 14. Objetivos a cumplir por cada indicador

\begin{tabular}{|c|c|c|c|c|c|c|c|c|c|c|c|c|c|c|}
\hline \multirow[b]{2}{*}{ Meta } & \multirow[b]{2}{*}{ Descripción } & \multirow[b]{2}{*}{ Indicador } & \multicolumn{12}{|c|}{ Objetivo / Mes } \\
\hline & & & 1 & 2 & 3 & 4 & 5 & 6 & 7 & 8 & 9 & 10 & 11 & 12 \\
\hline 1 & $\begin{array}{l}\text { Establecer un } \\
\text { presupuesto } \\
\text { anual y } \\
\text { quinquenal de } \\
\text { ingresos y gastos }\end{array}$ & $\begin{array}{l}\text { Cumplimiento de la } \\
\text { utilidad neta }\end{array}$ & & & & & & & XX & & & & & \\
\hline \multirow[t]{2}{*}{2} & \multirow{2}{*}{$\begin{array}{l}\text { Crear un área de } \\
\text { gestión } \\
\text { comercial que } \\
\text { garantice la } \\
\text { continuidad de la } \\
\text { demanda de } \\
\text { productos y } \\
\text { servicios de la } \\
\text { empresa }\end{array}$} & $\begin{array}{l}\text { Cumplimiento del } \\
\text { cronograma de } \\
\text { creación del } \\
\text { departamento } \\
\text { comercial } \\
\text { zonificado }\end{array}$ & & & $\begin{array}{l}10 \\
\%\end{array}$ & $\begin{array}{l}20 \\
\%\end{array}$ & $\begin{array}{l}30 \\
\%\end{array}$ & $\begin{array}{l}40 \\
\%\end{array}$ & $\begin{array}{l}50 \\
\%\end{array}$ & $\begin{array}{l}60 \\
\%\end{array}$ & $70 \%$ & $80 \%$ & $90 \%$ & $\begin{array}{c}100 \\
\%\end{array}$ \\
\hline & & $\begin{array}{l}\text { Cumplimiento } \\
\text { presupuesto de } \\
\text { ingresos }\end{array}$ & \multicolumn{12}{|c|}{$100 \%$} \\
\hline \multirow{3}{*}{3} & \multirow{3}{*}{$\begin{array}{l}\text { Adquirir } \\
\text { tecnología que } \\
\text { permita la } \\
\text { optimización de } \\
\text { los procesos } \\
\text { productivos }\end{array}$} & $\begin{array}{l}\text { Cumplimiento } \\
\text { presupuesto de } \\
\text { inversiones en } \\
\text { tecnología }\end{array}$ & & & & & & & & $\begin{array}{l}20 \\
\%\end{array}$ & $40 \%$ & $60 \%$ & $80 \%$ & $\begin{array}{c}100 \\
\%\end{array}$ \\
\hline & & $\begin{array}{l}\text { Reducción de los } \\
\text { tiempos de } \\
\text { producción }\end{array}$ & \multicolumn{7}{|c|}{ Nivel actual } & $\begin{array}{l}+ \\
5 \%\end{array}$ & $\begin{array}{l}+10 \\
\%\end{array}$ & $\begin{array}{l}+15 \\
\%\end{array}$ & $\begin{array}{l}+20 \\
\%\end{array}$ & $\begin{array}{l}+25 \\
\%\end{array}$ \\
\hline & & $\begin{array}{l}\text { Reducción de los } \\
\text { costos de } \\
\text { producción }\end{array}$ & \multicolumn{7}{|c|}{ Nivel actual } & $5 \%$ & $-10 \%$ & $15 \%$ & $20 \%$ & - \\
\hline \multirow{2}{*}{4} & \multirow{2}{*}{$\begin{array}{l}\text { Diseño y } \\
\text { ejecución de la } \\
\text { estrategia de } \\
\text { comunicación }\end{array}$} & $\begin{array}{l}\text { Estrategia con } \\
\text { medios BTL }\end{array}$ & & Plani & ficaci & & \multicolumn{8}{|c|}{$100 \%$} \\
\hline & & $\begin{array}{l}\text { Estrategia con } \\
\text { medios ATL }\end{array}$ & \multicolumn{7}{|c|}{$\begin{array}{l}\text { Selección del personal y diseño de } \\
\text { la estrategia }\end{array}$} & $\begin{array}{l}10 \\
\%\end{array}$ & $10 \%$ & $10 \%$ & $10 \%$ & $10 \%$ \\
\hline & \multirow{2}{*}{$\begin{array}{l}\text { Crear un sistema } \\
\text { de compensación } \\
\text { del personal } \\
\text { según los } \\
\text { resultados } \\
\text { individuales y } \\
\text { grupales }\end{array}$} & $\begin{array}{l}\text { Diseño del plan de } \\
\text { compensación }\end{array}$ & \multicolumn{12}{|c|}{$100 \%$} \\
\hline 5 & & $\begin{array}{l}\text { Puesta en marcha } \\
\text { del sistema de } \\
\text { compensación } \\
\text { variable según } \\
\text { resultados }\end{array}$ & & & & & \multicolumn{8}{|c|}{$100 \%$} \\
\hline
\end{tabular}

Nota: elaboración propia.

- Para el diseño y ejecución de la estrategia de comunicación se establece una fase de planificación, seguida de la fase de implantación. Igual sucede con la creación del sistema de compensación variable según resultados

De igual manera, en la tabla 15 a continuación, se presenta el formato que se le hará llegar a la parte directiva de la empresa Porcelanatos y Pisos de Colombia S.A.S., con el fin de que se 
sirvan plasmar allí sus opiniones y recomendaciones.

Tabla 15. Formato de socialización para los directivos Porcelanatos y Pisos de Colombia S.A.S.

\begin{tabular}{cccc}
\hline \multicolumn{4}{c}{ Socialización del Plan de acción } \\
Fecha
\end{tabular}

Nota: elaboración propia. 


\section{Conclusiones y Recomendaciones}

\subsection{Conclusiones}

Frente a los objetivos planteados se puede concluir, en primer lugar, que el contexto competitivo en el que se desempeña la empresa Porcelanatos y Pisos de Colombia S.A.S. se caracteriza por la presencia de varias empresas que están en capacidad de captar porcentajes significativos de mercado, lo que obliga a la empresa a definir nichos específicos en los que pueda aprovechar sus ventajas de manera más clara.

La organización cuenta con ventajas que le permiten también generar algunas tendencias de manera independiente de la competencia, lo cual es una característica que le permite lograr la preferencia de los clientes.

Así mismo se concluye que existen diferentes acciones que en conjunto permiten lograr los objetivos estratégicos, con el fin de asegurar la sostenibilidad de la empresa en el corto y mediano plazo. Debido a la incertidumbre que existe en el mercado de la construcción en general, es difícil asegurar la sostenibilidad a largo plazo.

\subsection{Recomendaciones}

De acuerdo con el estudio realizado, se recomienda que la empresa emprenda las siguientes acciones concretas: 
- Crear stock cuando las condiciones del mercado lo recomienden.

- Resaltar en las estrategias de marketing el beneficio del transporte incluido o a bajo costo.

- Crear un canal de atención a proyectos de construcción que requieran grandes cantidades de productos.

- Fortalecer el marketing basado en redes sociales para mejorar efectividad de las campañas.

- Ofrecer condiciones de precio estable para distribuidores aprovechando capacidad de almacenamiento y disponibilidad de flujo de caja.

- Ampliar la red de distribución propia para generar economías de escala.

- Diferenciar los canales de grandes constructores y el de remodelaciones y proyectos pequeños en hogares.

- Ofrecer garantía ampliada de productos para compensar déficit de confianza.

- Capacitar a los niveles intermedios en toma de decisiones y control de equipos de trabajo.

- Crear políticas de incentivos por resultados para mejorar ambiente laboral.

- Diseñar programas de carrera de los empleados con incentivos en educación.

- Fortalecer el nivel académico de mandos medios mediante programa de incentivos.

- Establecer una estrategia de marketing basada en perfiles de clientes.

- Premiar a los clientes que refieran a otros compradores. 


\section{Referencias Bibliográficas}

Alvis, Y \& Ochoa, B. (2016). Propuesta plan de marketing para la Empresa Conti Construcción \& Ingeniería SAS CI. Bogotá: Universidad Piloto de Colombia.

Arango, L. (2016). El Big Data. Pereira: Norma editores.

Asobancaria. (2018). Tipología de la vivienda para los hogares del siglo XXI. Semana Económica 2018, 8(12), 1-12.

Astigarraga, E. (2016). "Prospectiva estratégica: orígenes, conceptos clave e introducción a su práctica". Revista Centroamericana de Administración Pública, 33(42), 13-29.

Atmósferas. (2019). Quiénes somos. Obtenido de https://www.attmosferas.com/quienes-somos/

Banco de la República. (2000). Nota Editorial Enero. Bogotá: Banco de la República.

Banco de la República. (2005). Estadísticas monetarias. Indice de precios al consumidor. Bogotá: Banco de la República.

Banco de la República. (2014). Informe de Estabilidad Financiera. Inclusión Financiera. Bogotá: Banco de la República.

Barrios, D. (2009). Diseño Organizacional bajo un Enfoque Sistémico para Unidades Empresariales Agroindustriales. Bogotá: Universidad Nacional de Colombia.

Bonal, X \& Verger, A. (2017). "Economía política de la educación en tiempos de austeridad: mecanismos de gestión de la crisis en la política educativa catalan". Cuadernos de Relaciones Laborales, 8(11), 17-26.

Bordonaba, M \& Garrido, A. (2012). Marketing de relaciones, ¿un paradigma? Zaragoza: 
Universidad de Zaragoza.

Camacol. (2010). Cámara Colombiana de la Construcción. Informes sectoriales. Recuperado el 20 de julio de 2014, de ww.camacol.co/sites/default/files/secciones_informes

Camacol. (2017). Cámara Colombiana de la Construcción. Tendencias de la construcción: Economía y Coyuntura Sectorial 11a. Ed. Bogotá: Departamento de Estudios Económicos y Técnicos.

Cando, J ; Beltrán, J ; Acosta, C \& García, M. (2018). Caso de estudio de la empresa porcelanattos y pisos de colombia. Bogotá: Universidad Santo Tomás.

Chasdi, R \& Ronis, S. (2017). "Visionario: A Series of Unfortunate Events". The International Journal of Intelligence, Security, and Public Affairs, 11 (23), 69-73.

Cruz, M ; Espinoza, A ; González, G ; Cortes, C ; Cruz, M.; Espinoza, A.; González, G. (2008). "COMEN" Comprensión del mensaje. Urianguto, México: Instituto Tecnológico Superior del Sur de Guanajuato.

DANE. (2005). Departamento Administrativo Nacional de Estadística. Censo 2005. Proyecciones demográficas 2005 - 2020. Bogotá: DANE.

DANE. (2012). Departamento Administrativo Nacional de estadística. Encuesta Anual Manufacturera. Bogotá.

DANE. (2014). Departamento Administrativo Nacional de Estadistica. Estimaciones 1993-2005 y proyecciones 2005-2020 de viviendas nacional y departamental por área. Bogotá: DANE.

David, F. (2013). Conceptos de administración estratégica. Ciudad de México: Pearson.

Domometrio. (2015). La Cumbre mundial del hogar digital impulsa la infraestructura IP. Obtenido de http://www.domonetio.com/content/la-cumbre-mundial-del-hogar-digital- 
impulsa-la-infraestructura-ip

Domótica Viva. (2015). Casa domótica. Obtenido de http://www.domoticaviva.com/demo.htm

Drucker, P. (1996). Su visión sobre: La administración, La organización basada en la información, la ecnomía, La sociedad. México: Norma.

Enter. (2015). La impresora $3 D$ que construye casas en un día. Obtenido de http://www.enter.co/cultura-digital/ciencia/investigadores-desarrollan-una-casa-impresaque-se-construye-en-un-dia/

Fedesarrollo. (2017). Promoción de la competencia en la telefonía móvil en Colombia. Bogotá: Fedesarrollo.

Ferrell, O ; Fraedrich, J ; Ferrell, L. (2000). Business ethics. Ethical decision making and cases. Boston: Mifflin Co.

FREE patent. (2019). FreshPatents.com New Patents and Technology. Glass-ceramics composite material. Obtenido de http://www.freshpatents.com/-dt20141002ptan20140296053.php

Fundación OPTI. (2016). Estudio de Prospectiva sobre el Hogarl Digital. Madrid: Agencia de Innovación y Desarrollo de Andalucía IDEA y Fundación OPTI.

Galindo, L \& García, J. (2017). "Fundamentos de administración". Vida Científica, 7 (21), 4-14.

German, L. (2017). Blog de tareas de la materia de informática y computación. Recuperado el 6 de junio de 2015, de http://lauraninamoxitha.blogspot.com/2011/05/g1-la-primerageneracion-de-telefonia.html

Gómez, B. (2010). Estado de la Situación del Derecho a la Educación en Colombia. Recuperado el 3 de $\quad$ Noviembre de 2012, http://www.derechoalaeducacion.com/admin/docs/1280164230Contexto\%20de $\% 201 \mathrm{la} \% 2$ 0Educacion\% 
González, A. (2016). La telefonía móvil: el impacto social (Primera ed.). Madrid, España: Universidad Politécnica de Madrid.

Graves, M; Gall, P ; Ludvigsen, M ; Lykke-Olesen, A. (2005). Floor interaction HCI reaching new ground. Extended Abstracts on Human Factors in Computing Systems, 11(23), 12-29.

Grönroos, C. (1996). Relationship Marketing: strategic and tactical implication. Management Decissions, 34(3), 9(21), 5-14.

Hernández, H ; Cardona, D \& Del Rio, J. (2017). "Direccionamiento Estratégico: Proyección de la Innovación Tecnológica y Gestión Administrativa en las Pequeñas Empresas". Información tecnológica, 7 (12), 15-22.

Hernández, R ; Fernández, C.; Baptista, P. (2010). Metodología de la investigación. México:: McGraw-Hill.

Kotler, P \& Murray, M. (1975). Third Sector Management--The Role of Marketing. Public Administration Review, 35(5), 8(23), 467- 472.

Legiscomex. (2019). Importacines de pisos laminados 2017-2018. Bogotá.

Lemaire, J. (2017). Stratégies d'internationalisation. Paris: Dunod.

Martínez, E. (2011). La evolución de la telefonía móvil. La guerra de los celulares. Red, 2001, 8(11), 1-6.

MEN. (2010). Ministerio de Educación Nacional. Plan Sectorial de Educación 2010-2014. Bogotá: MEN.

Ministerio de Vivienda, Ciudad y Territorio. (2017). Informe de rendición de cuentas. Bogotá: Oficina Asesora de Planeación.

Montenegro, A \& Rivas, R. (2018). Colombia: desafíos y oportunidades. Bogotá: Cesantías y Pensiones Protección. 
Montuschi, L. (2009). Consideraciones respecto de la ética en los negocios: La resonsabilidad social empresarial. Buenos Aires: Universidad del CEMA.

Mora, E ; Vera,M ; Melgarejo, Z \& Molina. (2015). "Planificación estratégica y niveles de competitividad de las Mipymes del sector comercio en Bogotá". Estudios Gerenciales, 83(72), 79-87.

Munuera, A \& Rodríguez,A. (2007). Estrategias de Marketing. Madrid: ESIC.

Naciones Unidas. (2013). Objetivos de Desarrollo del Milenio. Informe de 2013. Washington: Naciones Unidas.

Nicholson, W. (2014). Teoría macroeconómica. Principios básicos y aplicaciones. Madrid: Siglo XXI.

Nikulin, C \& Becker, G. (2015). "Una metodología Sistémica y creativa para la gestión estratégica: Caso de Estudio Región de Atacama-Chile". Journal of technology management \& innovation, 8(11), 127-144.

NIST. (2017). Cloud Computing: una definición formal (y la más ampliamente aceptada). Recuperado el 2015 de 31 de mayo, de http://tissat.wordpress.com/2012/02/20/cloudcomputing-una-definicion-formal-y-la-mas-ampliamente-acept

Ogliastri, E. (1996). Manual de Planeación Estratégica. Teoría, aplicaciones y casos. Bogotá: Tercer Mundo y Uniandes.

Paucar, C ; García, C ; García, C ; Hernández, S ; Muñoz, A. (2013). Propiedades autolimpiantes de nanopartículas de dióxido de titanio sobre sustratos vítreos. Medellín: Universidad Nacional de Colombia. Sede Medellín.

Pavón, M. (2015). "Diagnóstico estratégico para el desarrollo agropecuario y forestal de la Empresa Agropecuaria". Industria Agrícola, 9(11), 7-13. 
Porter, M. (2004). Competitive Strategy: Techniques for analyzing industries and competitors. New York: Free Press.

Porter, M. (2004). Estrategia competitiva: técnicas para analizar industrias y competidores. New York: Free Press.

Porter, M. (2009). Ser Competitivo. Nuevas Aportaciones Y Conclusiones. Capitulo 7 "Cúmulos y competencia: nuevos objetivos para empresas, Estados e instituciones. Bilbao, España: Editorial Deusto.

Prestige. (2019). La Empresa. Obtenido de https://pisosprestige.com/

Pulido, L. (2011). Aportes de la sistémica a la construcción de una identidad epistemológica de la administración de organizaciones. Econógrafos, 13(22), 2 - 8.

Rincón, L \& Díaz, L. (2016). Diagnóstico y creación de un modelo de gestión basado en responsabilidad social empresarial aplicado la empresa Marval S.A. (Tesis de Maestría ed.). Bogotá: Universidad del Rosario.

Rodríguez, C \& Garzón, C. (2009). Modelo de análisis para los grupos económicos colombianos. Bogotá: Criterio Libre.

Salas, E. (2018). ATL Como Acción de Construcción de Marca a Largo Plazo. INNOVA Research Journal, 8( 12), 204-215.

Shen, Y. (2012). Distributed Sensing Floor for an Intelligent Environment. Browse Journals \& Magazines, 8(21),11-29.

Superintendencia Financiera de Colombia. (2013). Evolución de las tarifas de los servicios financieros. Bogotá: Superfinanciera.

Texturas y Matices. (2019). La entidad. Obtenido de https://www.texturasymatices.com/

Thompson, A ; Gamble, J ; Peteraf, M ; Strickland, A. (2012). Administración estratégica. Teoría 
y $\operatorname{casos}\left(18^{\circ}\right.$ ed.). Mésico, D. F.: McGrawHill.

Treacy, M \& Wiersema, F. (1995). La disciplina de los líderes del mercado. New York: Granica. Univisión. (2015). Fabricaron el primer motor de avión con una impresora 3D. Obtenido de http://noticias.univision.com/article/2257740/2015-02-27/tecnologia/noticias/fabricaronel-primer-motor-de-avion-con-una-impresora-3d

Valverde, A; Ayala, D \& Álvarez, A. (2017). Una aproximación al sistema voluntario de certificación de edificios denominado "Bogotá Construcción Sostenible". Arquitectura y Urbanismo, 21(33), 71-86.

Vega, A ; Montiel, O; Rodríguez, C \& López, M. (2017). La publicidad BTL como estrategia para fomentar la consolidación de las Pymes. Caderno Profissional de Marketing-UNIMEP, $9(21), 36-52$.

Velasco, J. (2014). Diseño interior de la agencia de estrategia digital "La Motora". Cuenca, España: Universidad de Cuenca. 